\title{
Making science come alive Student-generated stop-motion animations in science education
}

Daniel Orraryd
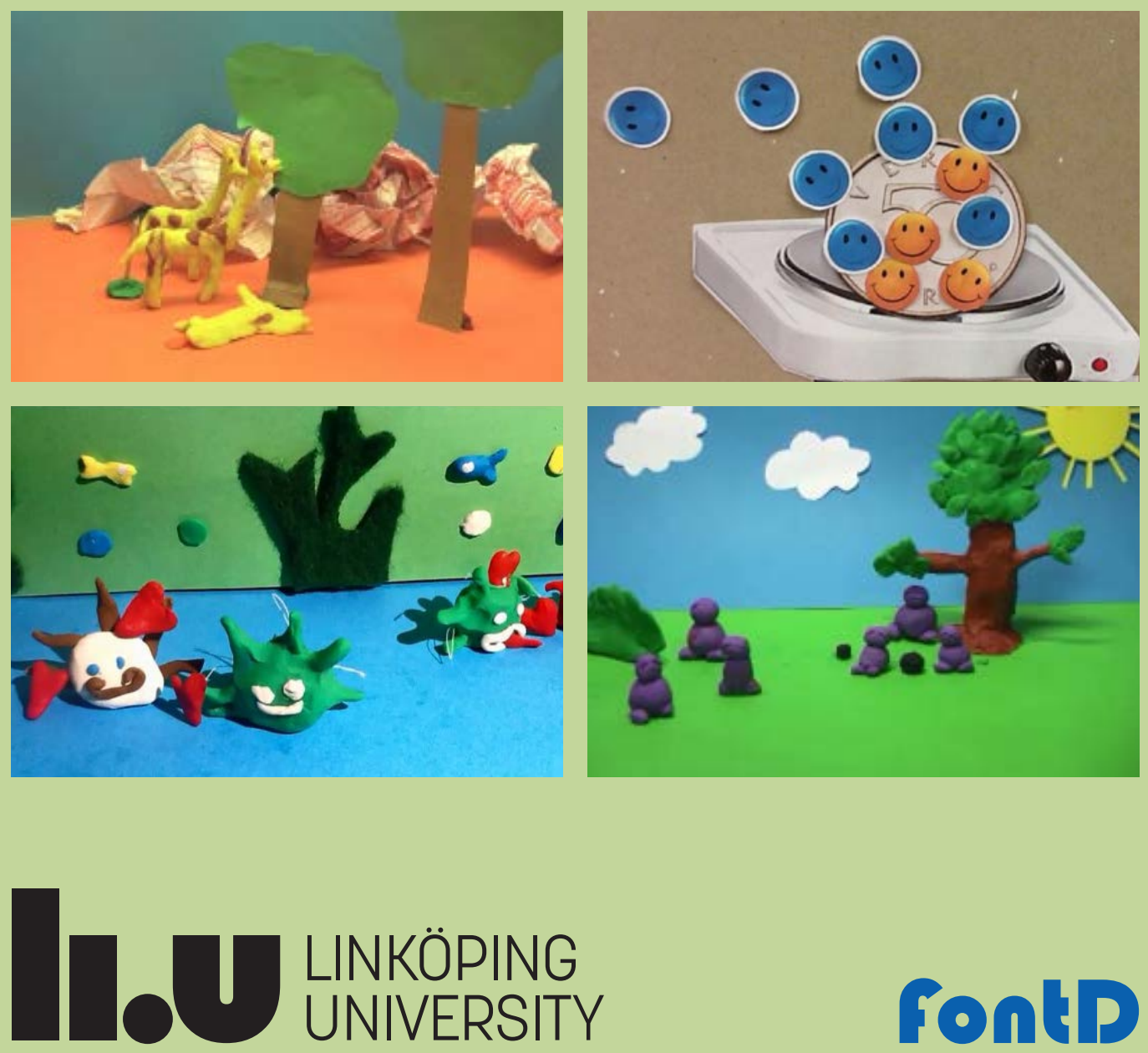

Linköping Studies in Science and Technology Education •

No. 110

\title{
Making science come alive \\ Student-generated stop-motion animations in science education
}

\author{
Daniel Orraryd
}

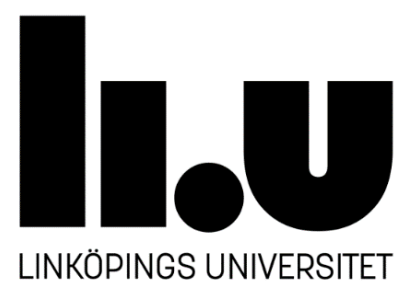

Department of Behavioural Sciences and Learning

Faculty of Educational Sciences

Norrköping 2021 
Linköping Studies in Science and Technology Education • No. 110

Distributed by:

Department of Behavioural Sciences and Learning

Linköping University

SE-60174 Norrköping

(c) EY-No This work is licensed under a Creative Commons AttributionNonCommercial 4.0 International License.

https://creativecommons.org/licenses/by-nc/4.0/

\section{Daniel Orraryd}

Making science come alive

-Student-generated stop-motion animations in science education

\section{Edition 1:1}

ISBN 978-91-7929-700-8

ISSN 1652-5051

CDaniel Orraryd

Department of Behavioural Sciences and Learning, 2021

Printed by: LiU-tryck, Linköping 2021 


\section{Abstract}

The availability of digital technology in classrooms does not only increase the possibility for teachers to present content in new visual and dynamic ways. This technology also offers students the opportunity to become cocreators of content in science classrooms. The dissertation explores, mainly through qualitative methods, the potential of student generated stop-motion animations in science education research and practice. This exploration is motivated by the challenges learners experience when they are introduced to abstract dynamic science concepts spanning several organisational levels in space and time. In addition, it emphasises the importance of multiple representations for communicating and reasoning about such concepts. This novel approach is used, in combination with a conceptual characterisation of students' written explanations, to expand the knowledge about students' conceptions of evolution by natural selection. The potential of a stop-motion approach to stimulate meaning making of evolution biology and redox-chemistry classrooms is also explored. The thesis consists of four studies and a comprehensive summary with an extended analysis and discussion of the results.

In relation to students' written explanations about the mechanisms of evolution, the student generated stop-motion animations express the same pattern concerning key-concepts connected to evolution by natural selection. However, the analysis of misconceptions in the student-generated animations resulted in interesting differences from written explanations. The globally reported misconception of essentialism (the idea that all individuals of a species share a common essence, and that this essence is what is changed in evolution) was represented in only a low proportion of the animations. On the other hand, another misconception was expressed more often in the stop-motion animation than in written explanations, namely evolution as an event. These findings support the view that students' expression of different misconceptions is influenced by the context and representational form.

The work reveals that generating stop-motion animations to explain scientific concepts is an engaging approach that stimulates students to explore their understanding in a creative and personal manner. The analysis of the videorecorded animation process showed that one important realisation expressed in the student dialogue was that a representation is symbolic and cannot be a picture of reality, as it then would lose some of its explanatory value. The design of the task, the forms of feed-back during the work process, as well as the nature of the science content are important to consider before the approach of stop-motion animations is used in the classroom. Otherwise, the potential for meaningful learning may be lost and the activity becomes at best a lesson in creating an animation, albeit a fun and creative one.

Keywords: (Stop-motion animation, Student generated representations, Evolution, Alternative conceptions, Redox chemistry) 


\section{Sammanfattning}

Tillgång till digitala verktyg i klassrummen gör det i dag möjligt för elever att aktivt skapa multimedia representationer med naturvetenskapligt innehåll. En tillgänglig och flexibel metod för att skapa animationer är stop-motion. Den här avhandlingen utforskar potentialen med att introducera stop motionanimationer i naturvetenskaplig undervisning huvudsakligen med hjälp av kvalitativa metoder. Utforskandet motiveras av de svårigheter många elever upplever med att lära och förstå abstrakta och dynamiska naturvetenskapliga begrepp som sträcker sig över flera organisationsnivåer i tid och rum. Den innovativa ansatsen som används är elevskapade stop-motion animationer. Avhandlingen bygger vidare på kunskapen om elevers föreställningar om evolution genom naturligt urval och utforskar potentialen av att nyttja stopmotion animationer för att stimulera meningsskapande i klassrum där evolutionsbiologi och redox-kemi står i centrum.

Avhandlingens första studie jämför hur studenter förklarar evolutionära mekanismer i olika kontexter. Här kan man tydligt se att beskrivningarna till stor del beror av om frågan gäller bakterier eller djur, eller uppkomst av en ny egenskap eller förlust av en egenskap. Detta gäller även vanliga missförstånd. I nästa studie jämför vi elevers skrivna förklaringar av evolutionära mekanismer med, hur dessa uttrycks i elevernas stop-motion animationer. Båda uttrycksformerna ger samma mönster av de nyckelbegrepp som utgör evolution genom naturligt urval. Uttrycket av vanliga missförstånd skiljde sig dock åt på intressanta sätt mellan animationerna och de skrivna förklaringarna. Den ofta rapporterade alternativa uppfattningen att samtliga individer i en population har en gemensam essens som måste förändras om populationen ska förändras, uttrycktes enbart i enstaka fall i elevernas animationer. Å andra sidan uttrycktes den alternativa förståelsen att evolutionen sker snabbt och som en avslutad händelse mer frekvent i stop-motion animationerna än i skrivna förklaringar. Dessa fynd stödjer ståndpunkten att elevers uttryck av olika alternativa förklaringsmodeller påverkas av uttrycksformen, på liknande sätt som visades gälla för kontexten i den första studien.

Dessutom visar de båda nästa studierna att arbetet med att skapa stop motionanimationer för att förklara naturvetenskapliga begrepp utgör en engagerande aktivitet som stimulerar elever att utforska sin förståelse på ett kreativt och personligt sätt. Analysen av videoinspelningar från processen då elever skapar animationer visade att de diskuterar de visuella representationernas symboliska natur och hur de inte kan vara en bild av 'verkligheten' eftersom de då skulle förlora en del av sitt förklaringsvärde.

Men, animationsuppgiftens utformning, den återkoppling som ges samt det naturvetenskapliga innehållets natur är viktiga faktorer att överväga innan stop motion-animationer används i klassrummet. Om inte, så riskerar potentialen för meningsfullt lärande att gå förlorad och det hela blir som mest en övning $\mathrm{i}$ att göra en animation, om än en rolig och kreativ sådan. 


\section{Preface}

The final stages of writing this dissertation have been set in the middle of the COVID-19 pandemic. Considering the work that teams of researchers around the world are doing to produce vaccines in record time, or the life and death situation for hospital personnel, the work with this $\mathrm{PhD}$ project seems rather small and insignificant. For me personally, however, it has meant a tremendous amount.

Much can happen during a $\mathrm{PhD}$ project, and in my case many things have happened. It has been an exciting and transforming journey, frustrating at times, disappointment of papers being rejected, joyful when a paper is accepted. A stroke followed by a long rehabilitation, and to top it off a pandemic. What an adventure!

I have always been curious, wanting to understand how things work. However, I have never really had the patience to be hooked on one thing. There was always something new to catch my attention and curiosity before I became an expert. In hindsight, it almost looks like a strategy in my life, learn a little about a lot. And in a way it is in the areas between disciplines that the new and interesting knowledge emerges. Like when chemistry meets biology, and the area of biochemistry emerges and revolutionise our understanding about life. Partly this was the reason that made me interested in the interdisciplinary field of science education.

This type of curiosity is reflected in the work I have done as a PhD student. I have followed my curiosity, disregarding established borders between disciplines, trying to identify common problems and solutions that can be useful in many areas. I have tried to learn as much as possible during this $\mathrm{PhD}$ education. Taking the chance of trying different perspectives, methods, and learning something about a lot. The challenges with this approach became apparent in preparation of this thesis. With each study using different perspectives, and aims and focuses, the task has been to establish a coherent cover story (Kappa in Swedish) that can show that the studies constitute a larger whole. In this endeavour, I have come to realise that I got hooked by the idea of student-generated representations as way to engage students in authentic scientific reasoning. That is why I spent so many years on studies that have contributed to an exploration of how student-generated stop-motion animations can contribute to student learning in science education. Furthermore, the perspective of threshold concepts that overarch different science disciplines (and school subjects) made it possible to find commonalities across different topics, in this case evolution and redox chemistry. In the cover story I combine findings from all studies and relate them to an extended literature review underlying my crosscutting perspective.

My hope is that my work has contributed with yet another piece in the puzzle of students' understanding of abstract science concepts and the potentials and drawbacks of student-generated representations in science education and 
practice. I personally have learned a lot from this adventure. It is, however, a paradox of education that the more you learn the more you realise that there are still more things that you do not understand, and less things that you can know for certain. After this adventure I am certain of less than I have ever before. However, I am still eager to learn more, it is I now my life as researcher begins.

\section{Acknowledgements}

Research can perhaps be done in isolation, but that is not a strategy for me. This work would not have been completed without the support, and cooperation of many important people.

Thanks to my supervisors Lena Tibell and Jesper Haglund for all the support and sparring that made it possible to complete this work. Lena, for believing in me and taking me under your wings. And thank you for letting me try my own wings during these years, wherever my curiosity led me, and most importantly for being there and picking me up when I crashed. Thank you Jesper for an ever so insightful and honest feedback during these years. You have been a valued guide into the academic world and a role model with your great knowledge and inspiring attitude to science education.

I have also been blessed with fantastic co-workers on inspiring research projects. Wise, thoughtful, empathetic, humble, and supportive, are words to describe Astrid, thank you for everything. Hope that this is just the beginning of a long cooperation. Special thanks to Andreas Göransson for fruitful cooperation in research but perhaps more importantly for all the conversations about evolution, life, education, and much more. Without your enthusiasm I would have given up.

The work I have done has also been much improved by all comments and questioning critique I have got from the research groups I have been associated with. Thank you, all members of the VCL group, Konrad Schönborn, Jörgen Stenlund, Gustav Bohlin, Caroline Engskär, Gunnar Höst, Nalle Jonsson, Henry Fröklin, Martha Koc-Januchta. The EvoVis team from Kiel, Ute Harms and Daniela Fiedler. All colleagues at TekNaD and LEN that in seminars, conferences, and at 'fika' have made this work stimulating and interesting.

I am grateful to Niklas Gericke who read and helped me find a direction at my $60 \%$ seminar. The same goes for Maria Petersson who together with Linnéa Stenliden, and Jonte Bernard, helped me find a structure when the dissertation still was amoeba-like at the $90 \%$ seminar.

One vital person for making this work possible is Anna Ericson. I cannot thank you enough for all support, not just with all practical things, but for being someone to rely on through the years.

Johanna Andersson, my roommate since day one. The best kind of friend, keeping things in perspective, always caring and supportive, sharing your insights, worries, hardships, joys, and happiness in the PhD-student life and in 
the real life as well. We have shared a large part of the journey from being an experienced teacher to becoming a novice research student and the long road back to feeling competent again. As if that was not enough, you showed me the first paper on stop-motion animations I read, so it is safe to say that without you, this thesis would not have been written.

I would never have embarked on this adventure without a few people I would like to mention and thank. Carl-Johan Rundgren, for introducing me to science education. Lasse Björklund, for teaching me all about how to get as much as possible out of conferences. Måns Ahlin, Christian Tidebrink, and Andreas Larsson, for giving me the opportunity to explore how to create animations together with students. Alma Jahic Petterson, for bringing chocolate when I needed it the most.

I would also like to take the opportunity to thank the students and teachers who contributed to this work, without you it literally would not have been possible. An extra thank you to Bengt Bengtson for giving me a place to write undisturbed during the final work with compiling this thesis. Furthermore, big thanks are due to John Blackwell for invaluable language reviews and productive suggestions. Furthermore, Malin Kankare, my work therapist, who gave me the tools for slowly returning to, and being able to complete this PhD-work after the stroke. One of the everyday heroes who make the impossible happen.

Lastly, I would not have endured without the loving support of my family: Johanna Kajsa, Svante and Stina, you are what matters most in my life. I love you all more than words can express.

Norrköping January 2021 


\section{Table of Contents}

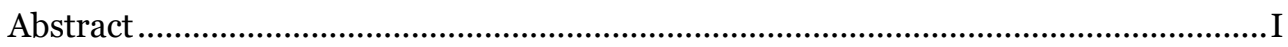

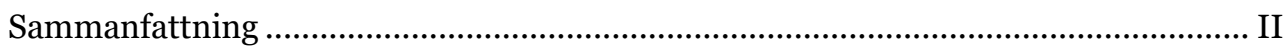

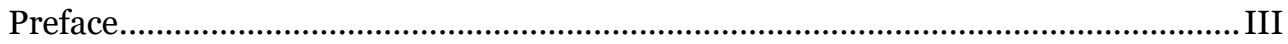

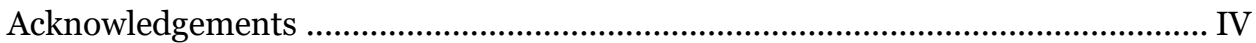

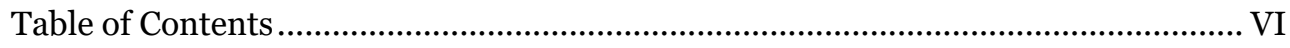

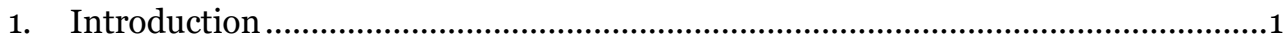

1.1 Reasoning and communicating in science education ...................................... 3

1.2 Creating content instead of only consuming …………................................. 3

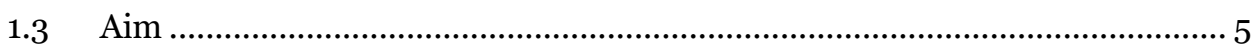

2. Theoretical background ................................................................................... 7

2.1 Models and representations in science education ............................................... 7

2.2 What are visual representations for? .............................................................. 9

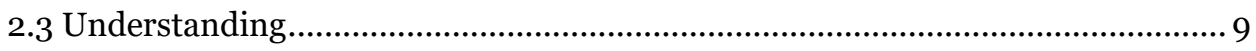

2.3.1 Conceptual change .................................................................................. 10

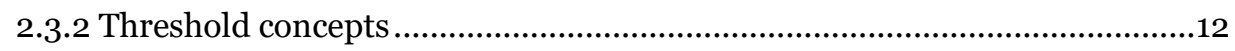

2.3.3 Misconceptions in science education .............................................................13

3. Learning with representations in science education................................................15

3.1 Reasoning with representations ........................................................................15

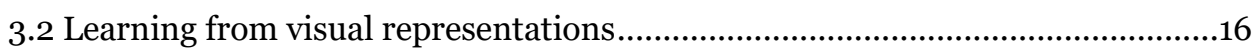

3.3 Multiple representations ................................................................................17

3.4 Student-generated representations .............................................................. 18

3.5 Student-generated stop-motion animations ..................................................... 20

3.5.1 Learning from SMAs ...................................................................................21

4. Biology education, explaining evolutionary change................................................. 23

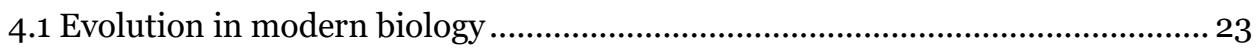

4.1.1 The modern synthesis................................................................................ 24

4.2 Teaching and learning evolution ..................................................................... 25

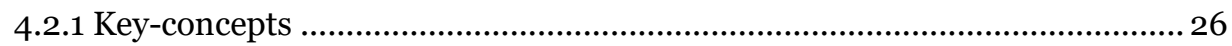

4.2.2 Threshold concepts and evolution education ……......................................... 27

4.2.3 Randomness and probability................................................................ 28

4.2.4 Different scales ......................................................................................... 29

4.2.5 Spatial scale and organisational levels ......................................................... 30

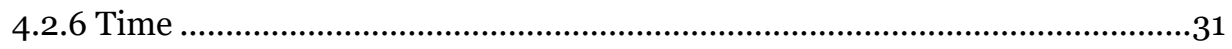

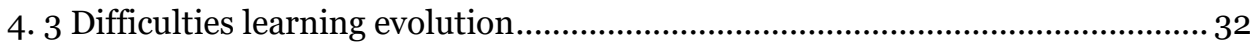

4.3.1 Acceptance of evolution .......................................................................... 33

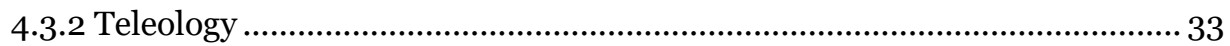




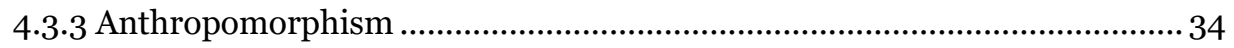

4.3.4 Essentialism ............................................................................................ 35

4.4 Representing the model of evolution by natural selection .................................. 36

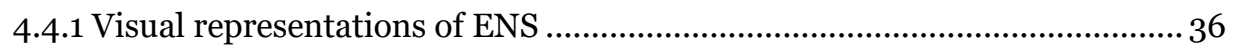

4.5 Multiple representations in evolution education ................................................ 38

4.6 Student generated representations of evolution ……......................................... 39

5. Chemistry education .......................................................................................

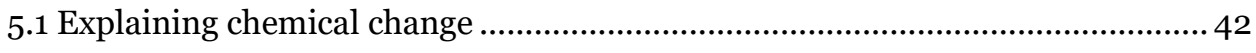

5.2 Teaching and learning chemical reactions ...................................................... 42

5.2.1 Essentialism...................................................................................... 43

5.2.2 Teleology ……….................................................................................. 44

5.2.3 Mechanistic causality (Anthropomorphism) ................................................. 44

5.3 The chemistry triplet .................................................................................... 44

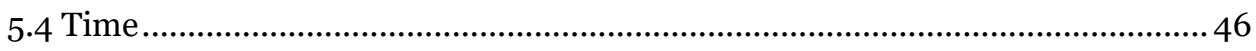

5.5 Understanding symbolic representations of chemical reactions ........................ 46

5.6 Student generated representations in chemistry............................................... 47

5.6.1 Student-generated animations in chemistry education .................................4 48

5.6.2 Generating stop-motion animations: a collaborative task............................ 49

6. Crosscutting perspective across evolution and chemistry .......................................51

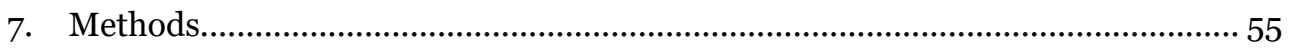

7.1 Methodological approach, design-based research ............................................. 55

7.2 Overview of data collection and manuscripts ................................................... 57

7.3 Rationale behind and descriptions of the data collection rounds ....................... 57

7.3.1 Data collection round 1.............................................................................. 58

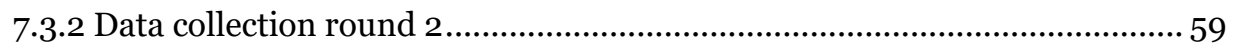

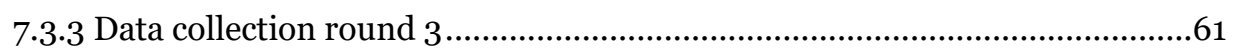

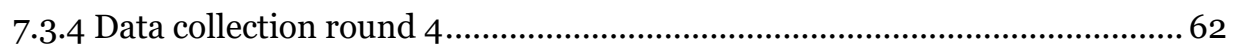

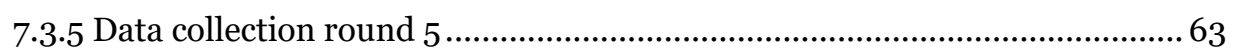

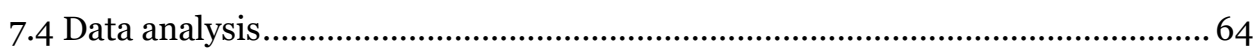

7.4.1 Content analysis of written explanations and animations ............................. 64

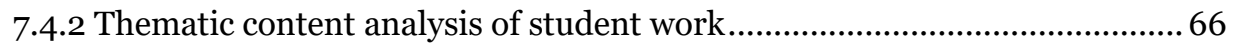

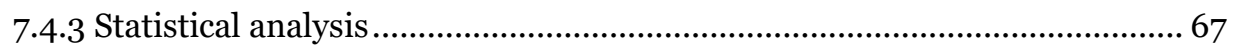

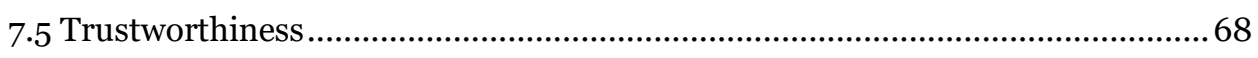

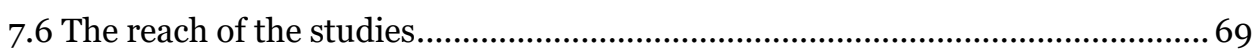

7.7 Ethical considerations ................................................................................... 70

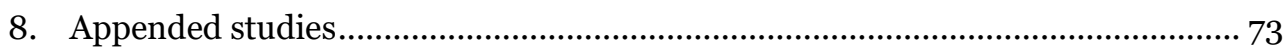

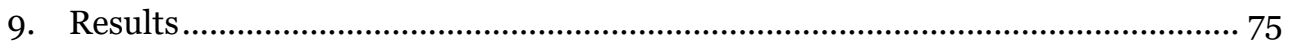


9.1 Student-generated stop-motion animations for probing understanding ............77

9.1.1 Evolution content in animations ...........................................................77

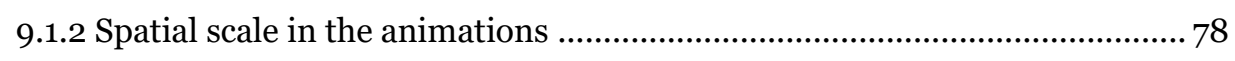

9.1.3 Representing time in the animations..................................................... 80

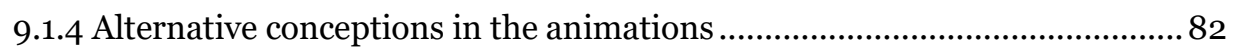

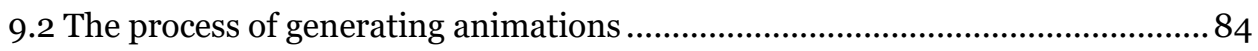

9.2.1 Students discussing organisational levels ................................................ 84

9.2.2 Students discussing time in the animations............................................. 88

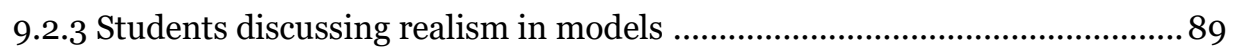

9.2.4 The storyboard: a target for teacher feedback ........................................91

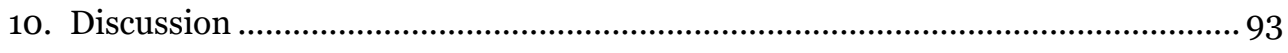

10.1 Student-generated SMAs for probing students' understanding ......................93

10.1.1. What do students' animations reveal about their understanding?............93

10.1.2 Alternative conceptions in a new light? .................................................94

10.1.3 The role of prior knowledge. .................................................................. 96

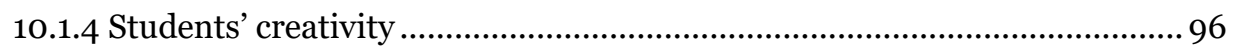

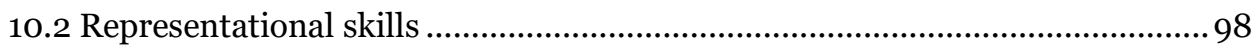

10.2.1 Representing organisational levels ...................................................... 99

10.2.2 Representing time .......................................................................... 100

10.3 The process of generating stop-motion animations ...................................101

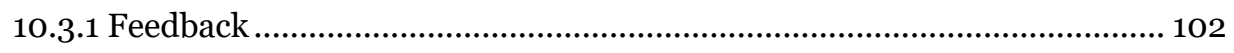

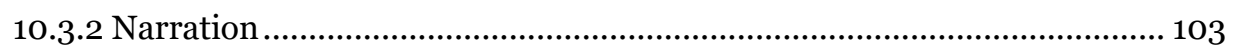

10.3.3 Choosing a reasonable task ................................................................. 103

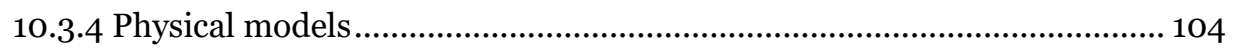

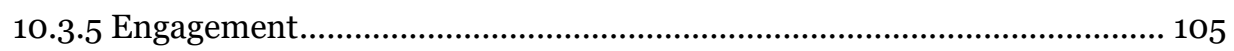

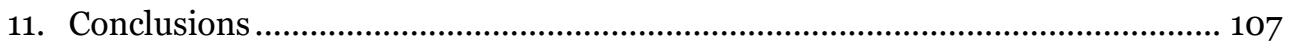

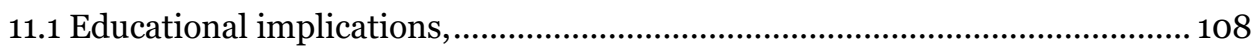

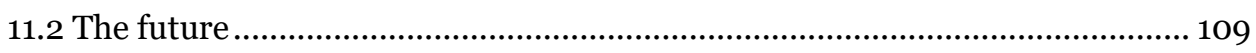

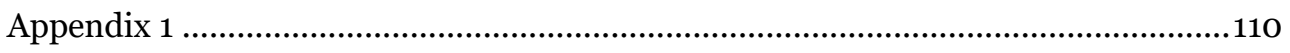

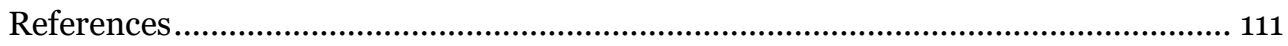




\section{Introduction}

We are biological creatures and as such the result of our evolutionary history. However, as the latest link in an evolutionary chain, we do not normally experience evolution in our everyday lives in any direct way. The year 2020 has perhaps been a reminder that our culture does not make us immune to the mechanisms of evolution. When a new pathogen evolves and spreads causing a pandemic, it surprises some, but it is far from a unique event in the history of humankind or any other organism. The emergence of new viruses is a natural and inevitable phenomenon in the light of evolution now a new disease is spreading among humans and causing death, and social and economic disruption.

Historically, outbursts of sickness would have been explained by bad spirits or as a punishment from the gods. Through scientific work by many scholars, dedicated to exploring the world and how to improve life for mankind, we now know that disease is caused by microscopic pathogens like bacteria and viruses. A virus is difficult to understand for several reasons. For a start, it is so small (between the size of a chemical particle and a living cell) that we cannot see it. Although it is not a living being according to most definitions, it is still subject to natural selection and evolution. Viruses comprise an example of content in the science curricula that seems particularly difficult to learn. However, it is clearly important to understand their emergence and evolution, partly because (as we have all recently seen) a new virus can suddenly spread among humans, causing widespread death and socio-economic disruption. Similarly, understanding chemical reactions is difficult but essential as they govern the creation and changes of all substances, living and non-living, natural and artificial. A good understanding of evolution and microbiology make the rise of new pathogens and their continuous mutations into new strands less enigmatic. All the misinformation and mysticism about the nature of viruses and how they spread and evolve that circulate in various media during this pandemic show the relevance of the topic of this thesis, making the invisible and abstract, tangible and sensible.

"Science is more baffling than magic" as stated by Perkins and Grotzer (2000, p. 3) at the start of a text on why science education is challenging for many learners. They reason that when a magician reveals how an unbelievable act is done, the audience understand the secret trick and remember it. But when a science teacher explains a baffling phenomenon, a substantial portion of students refuse to accept the explanation because it appears too counterintuitive. Further, most of the students will have forgotten the explanation the next week. For example, although we know that a bullet fired from a gun held horizontally will hit the ground at the same time as a bullet that is dropped simultaneously from the same height as the gun, this can be hard to accept and align with our lived experience. Thus, Perkins and Grotzer's statement seems to be true, but this raises an important question: Why are some concepts so hard to digest? 
In response to this question, concepts that generally appear to cause science educators and learners the most trouble, seem to share some common characteristics. Many concern phenomena beyond our natural perceptual range (Niebert \& Gropengiesser, 2015) and, processes with a complex causal structure (Chi, Roscoe, Slotta, Roy, \& Chase, 2012). Furthermore, the most troublesome seem to involve chance and randomness, which makes them counter-intuitive as associated processes seem to be directed towards set goals (Garvin-Doxas \& Klymkowsky, 2008). Two examples of concepts with these characteristics are discussed in this thesis, although they apparently operate at different scales in time and space: chemical reactions between atoms, and evolution by natural selection (ENS), which potentially pose similar challenges for learners.

Scientists have various strategies for handling concepts that are outside the human perceptual range, an important one is inventing representations that render the concepts tangible (Kozma, Chin, Russell, \& Marx, 2000). Such representations can be drawings, equations, diagrams, physical models, simulations, written text or spoken words. When it comes to representing abstract concepts in text or spoken words, the use of analogies is a common strategy in science education (Haglund, 2013). Textbooks and experts use analogies to explain things like 'an atom strives to achieve a full outer shell', or 'the organism developed an ability to survive'. However, this is a potential source for misunderstandings: How should the student know that anthropomorphic expressions like these are metaphorical and should not be taken literally?

When language falls short and explaining an abstract and complex process correctly would require many lengthy words, pedagogues often use a range of graphical representations to help learners 'see' the invisible and grasp the concepts. Textbooks and digital teaching resources are today laden with representations (Phillips, Norris, \& Macnab, 2010). Using digital technology, $3 \mathrm{D}$ images, and animations adds new possibilities in addition to e.g., static 2D images. For instance, the dynamic aspects of processes such as chemical reactions at an atomic level or population level changes in evolution, can be captured in a dynamic visualisation like an animation or simulation (Tversky, Morrison, \& Betrancourt, 2002). However, as no representation fully can capture a concept and is based on disciplinary conventions of how to use various symbols (like arrows, pluses etc.), this leaves the learner in a position of interpreting the representations presented by the teacher. This is specially challenging for representations of abstract concepts that we cannot experience directly (Catley, Novick, \& Shade, 2010; Taber, 2009). Less often, students (especially in later educational stages, when the difficult concepts are usually introduced) are encouraged to generate such graphical representations themselves to develop and communicate their understanding to peers and teachers.

Meanwhile, the concepts of focus in this thesis keep causing trouble throughout the educational system and additional repetition or adding to the learners' 
existing knowledge does not seem to help them to overcome reported difficulties (Sinatra, Brem, \& Evans, 2008). Thus, new strategies need to be explored.

\subsection{Reasoning and communicating in science education}

An international study of high school students' conceptions of science, found that many students regard science as autocratic, immutable, and as a collection of facts that students are expected to memorise and not question (Lyons, 2006). Accordingly, analysis of science textbooks has shown that concepts are often introduced as facts without bothering about how scientists established them, thus depriving students of opportunities to develop understanding of how science works and practice scientific reasoning (Lawson, Alkhoury, Benford, Clark, \& Falconer, 2000). Moreover, school science has been heavily skewed towards the products of science. This indicates a need to strengthen emphasis the process of science rather than merely transmitting the products. This is reflected in curricular goals for science. For example, the Swedish National Agency for Education's statements of goals for biology, chemistry, and physics declare that:

Teaching should give students the opportunity to discuss and present analyses and conclusions. They should also be given the opportunity to use computerised equipment for collecting, simulating, calculating, processing and presenting data. (Skolverket, 2013)

Hence, learning science should be about more than remembering and understanding concepts. The students should also obtain some ability to use theories and communicate in a scientific way. However, more often than not a limited representation of scientific practice is conveyed in a typical science classroom (Lyons, 2006), and scientific literacy including ideas about the nature of science is seldom integrated in the day-to-day practice. As most curricula are stuffed with content to cover, literacy aspects of learning science are often assumed to be taught implicitly. To move beyond this rote learning of facts, the epistemic practices of scientists should be mirrored in the classroom practices. If education can show that science is more than a collection of facts, I believe it may attract more students to participate in the curious and creative collective venture that science is in practice.

\subsection{Creating content instead of only consuming}

Reviews of science education research often highlight the benefits of active learning over lectures and that fundamental reasoning difficulties may limit learning (e.g. Nelson, 2012). Creating representations is an important part of scientific practice (Law \& Lynch, 1990). While scientists and science educators use graphical representations to handle complex issues and make clear connections that would be hard to communicate using only words or numbers, students only rarely are given the opportunity to communicate using multimedia. If pictorial representations are useful for scientists to make invisible, complex processes tangible, and such representations are becoming 
increasingly ubiquitous elements of science education (Phillips et al., 2010), methods that also allow students to express their understanding in multimedia format have clear apparent value (Nielsen, Georgiou, Jones, \& Turney, 2020). Recent research indicates that having students creating representations can support scientific reasoning (Ainsworth, Prain, \& Tytler, 2011) and increase students' engagement (Bruna, 2013; Jakobson \& Wickman, 2008). One way in which an approach based on student generated representations might activate learners is by emphasising the creative side of science (Ainsworth et al., 2011; Gilbert \& Treagust, 2009a; Wickman, 2006). One example of student generated representations is stop-motion animations (SMAs) (Hoban \& Nielsen, 2010).

Apart from their potential as an approach to teaching science concepts, it has been suggested that SMAs may be useful for probing students' understanding, but this possibility has received little attention to date (Farrokhnia, Meulenbroeks, \& van Joolingen, 2020). Studies of this could aid teachers to combine assessment and learning (R. White \& Gunstone, 1992) and seeking assessment methods to complement summative measures of students' performances in written tasks.

In summary, findings from science education research on aspects that promote learning, overlap with teaching approaches involving students co-operatively creating animations in terms of:

$\checkmark$ Being student-centred, active, and cooperative.

$\checkmark$ Being engaging, showing the creative and aesthetic elements of science.

$\checkmark$ Involving various visual representations for visualising abstract concepts.

Based on this it is motivated to explore a teaching approach like studentgenerated SMAs further. Further, there is support for such approaches in the curriculum. In the 21st century skills framework (Kereluik, Mishra, Fahnoe, \& Terry, 2013), reasoning and representational skills prioritised more than memorizing facts (which was prioritised in $20^{\text {th }}$ century schools). This also resonates with how students should be graded in Swedish schools. The level of reasoning is a major criterion for high grades in all subjects. This calls for teaching approaches that give students opportunities to practice reasoning and enable teachers to assess and help the students develop associated skills (Laverty et al., 2016).

Furthermore, in the goals for biology, chemistry and physics in Swedish upper secondary school, the Swedish National Agency clearly indicates not only to that reasoning skills are important but also that students' creativity should be encouraged.

Teaching should take advantage of current research and students' experiences, curiosity and creativity.

(Skolverket, 2013) 
In theory student generated animations looks like the perfect teaching approach. However, in reality, implementing it in a science of course implies a shift in classroom roles, as students become cocreators of content rather than passive recipients of information (Ferry, Hoban, \& Macdonald, 2009; Papert \& Harel, 1991). Furthermore, it is not clear if the approach is applicable to all types of science concepts (particularly troublesome concepts such as those associated with ENS and chemical reactions), the type of support that is needed and how tasks should be designed. This provided two lines of investigation: exploration of the utility of students generating SMAs to develop understanding and ways of probing students' understanding during that development.

Like any new approach to science teaching, it was important to assess its utility for addressing challenging topics, such as evolution and chemical reactions. Various approaches have been applied and tested for this purpose, a prevailing one is to focus on key-concepts, but problems of misconceptions seem to remain. My doctoral work, which this thesis is based upon, was part of a broader project designed to identify new ways to help students grasp such troublesome concepts by addressing threshold concepts. In an early phase of my PhD project, I came to recognise that students expressed different aspects of evolution, depending on the way we probed their understanding. The idea of asking students to generate a multimedia explanation rather than the usual task of producing a written explanation took form and SMA was deemed particularly interesting. Thereafter I focused on ways that generating SMAs may enable students to represent complex, dynamic phenomena that are at least partly outside our perceptual range. The aims of the research and questions that guided it are presented in the following section.

\subsection{Aim}

The general aim of my research was to assess the utility and pedagogical features of a new form of instruction: student-generation of SMAs in science education. More specific aims were to explore its potential to stimulate and probe understanding in classrooms, and reasoning about abstract dynamic science concepts with examples from biology and chemistry. The two main lines of investigation were probing students conceptual understanding using this approach of and the opportunities to reason it affords on students' conceptual understanding and sense-making in science. Thus, I have monitored obstacles and possibilities that students face when asked to generate a SMA illustrating a complex and dynamic phenomenon, with special regard to different scales in space and time. The results may assist teachers who are inspired to introduce student-generated SMAs into science classes.

The research was guided by the following questions:

1) In what ways does stop-motion animation facilitate or hinder students to represent their conceptual understanding of complex natural phenomena, in particular evolution and chemical reactions? 
2) In what ways does the process of generating a stop-motion animation to explain a scientific phenomenon afford the students to reason about evolution and chemical reactions? 


\section{Theoretical background}

This section is structured as follows. First, the models and representations used in science and their applications are briefly outlined, then reasoning and communication in science and the nature of explanations in science education are considered. The section ends with presentation of background information regarding understanding, conceptual change, threshold concepts and misconceptions in science education.

\subsection{Models and representations in science education}

In highly simplified terms, scientists collect data from the world out there through observation and experiments. The data are interpreted through the lens of theories and used to refine previous models or support new models that explain the collected data (Fig. 1). An important aspect is that a theoretical model is a simplification of the considered phenomena. Theories are based on models, and models can be used to test theories. There are several conflicting views regarding the difference between models and theories (Bailer-Jones, 2002). However, here it suffices to conclude that models play key roles in the practice of science as tools for generating and disseminating knowledge. Models are used in all sciences for making predictions, designing experiments, and solving problems, therefore use of models helps to make science education authentic (Hallström \& Schönborn, 2019). This is also emphasised in the curriculum:

Development occurs in interaction between theory and experiment, where hypotheses, theories and models are tested, reassessed and revised. Teaching should thus cover the development, limitations and areas of applicability of theories and models. (Skolverket, 2013)

One way of communicating models is to generate visual representations of them. In cognitive psychology literature a distinction is made between external representations, which can be perceived by others, and internal representations, i.e., representations of a concept or model in a person's mind. Similarly, visualisation may refer to an internal process of visualisation of a model in the 'mind's eye', or the process of making an internal understanding visual to others through creation of an external representation. In addition, a visualisation may refer to an external representation as manifested in an auditory, visual, and/or tactile format that enables others to perceive it via their senses. For example, the Bohr model of the atom is often communicated externally as a picture of a nucleus and electron shells. This last meaning is applied here. Roth and PozzerArdenghi (2013) use the term pictorial representation to mean all representations beside written or spoken words. I use representations to mean all external representations, regardless of mode, and visual representations to mean external representations beside written and spoken language.

Tsui and Treagust (2013) have ordered modes of representation as follows, from abstract (top) to concrete/realistic (bottom): 


\section{Spoken and written language \\ Mathematical \\ Graphs/Tables \\ Maps/Diagrams \\ Natural Drawings \\ Photos/Animations \\ Worldly objects/ Actions}

This continuum of abstraction has also been categorised as a spectrum from descriptive to depictive representations (e.g. diagrams and animations) (Schnotz, 2002). Descriptive representations are by necessity symbolic as the letters in a word bear no resemblance to the object they represent, whereas the second type can be more analogous to, and often depict, the referents, what they are meant to represent. Due to such differences, some aspects of a topic may be easily represented in one mode but troublesome in the other. For instance, a depictive representation has the potential to convey simultaneous events directly while the linear format of the descriptive representation constrains that possibility (Lowe, Boucheix, \& Fillisch, 2017). Many representations used in science education have elements from both ends of this scale.

In short, both representations and models have a role in knowledge production and can be represented in different modes in dissemination of knowledge.

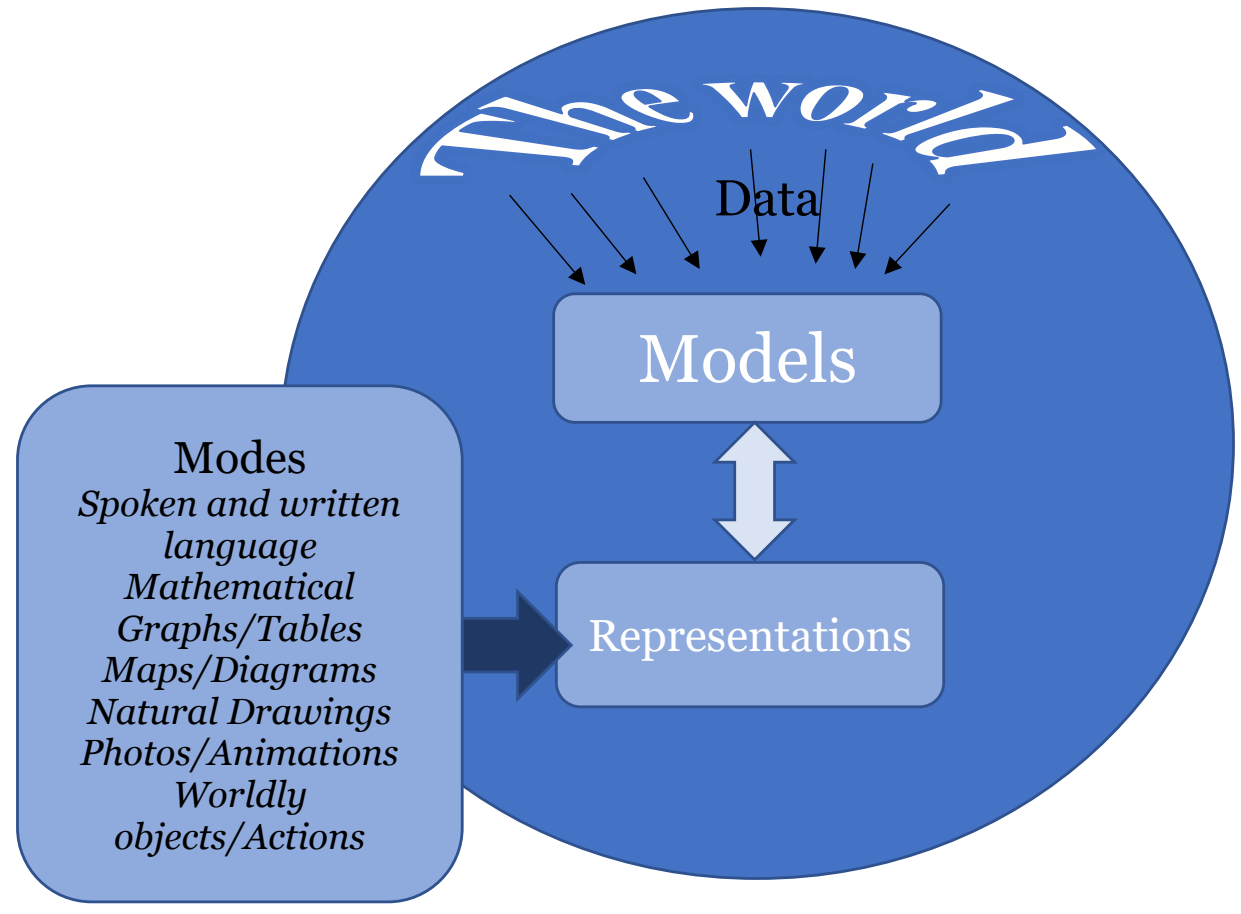




\subsection{What are visual representations for?}

As noted above, scientists have developed various types of representations to communicate with each other. Representations in science are "signs that enable users to explore, imagine, create, contest, critique, clarify and communicate meanings generated by practices in this domain" (Prain, 2019, p. 154). Some argue that these representations are even necessary for the development of novel discoveries (Ainsworth et al., 2011; Harrison \& Treagust, 200ob). One reason for making representations is that the world is too complex to be easily understood as it is (Gilbert, 2010). Thus, converting large amounts of abstract data into graphical format that can be studied by scientists is a ubiquitous part of the epistemology of science. There is a need to widen the public conception of scientific methods and their limitations, inter alia, raise awareness that science is as much about communicating one's findings as spending time in the lab, or in the world observing. The important point in this context is that using different representations is ubiquitous in this practice (Tytler, Prain, \& Hubber, 2018). As people train to become specialists in specific fields they, often implicitly, learn to communicate using specific disciplinary representations in a disciplinary discourse together with the special tools and activities that define their respective disciplines (Airey \& Linder, 2009). For an authentic science education, students must be allowed not only to memorise models but use them for creating explanations of various phenomena.

\subsection{Understanding}

Learners may enter a science classroom with various ideas about the scientific process and its products that depend on the cultural environment. The process and products are often referred to as the nature of science. In philosophy the ways of knowing, understanding, accepting, and believing are referred to as epistemology (M. Smith, 2010a). Aspects of knowing and understanding were addressed in the research underlying this thesis, but not acceptance and belief.

There are many views of what constitutes knowledge and understanding. It may not even be possible to formulate a definition that is universally accepted, partly because learning and understanding are so multifaceted. For instance, the learning process can be influenced by the content, student's age and aptitude, type of learning activities and intended outcome. There is also a difference in learning a skill, like putting up wallpaper, and learning a more abstract concept like the theory of relativity (diSessa, 2009). In science education some concepts are static, like sodium is a metal, but others like chemical reactions and ESN, are dynamic processes (Chi, 2008). I use the term concepts in the broad sense it has been used in science education (rather than the narrower ways the concept has been defined in psychology).

Another relevant factor is the grain size of concepts. According to (Chi, 2008) this may range from individual beliefs (factual statements like hydrogen has an atomic mass of one), through mental models (collections of beliefs organized in the mind) to categories (types of concept, e.g., things or processes). 
By understanding I mean something more than rote memorisation of words, phrases, or facts. Such surface learning can best be done through mnemonic techniques and repetition. Meaningful understanding of science includes not only factual but also procedural, schematic, and strategic knowledge. Thus, learner clearly should know rules and algorithms as well as why, how, when and where to apply the knowledge (Nieswandt \& Bellomo, 2009). Other scholars include criteria like connectedness, sense-making, application, and justification in definitions of knowing (M. Smith \& Siegel, 2004). Like Nieswandt and Bellomo (2009) and M. Smith and Siegel (2004), I believe that understanding is about knowing how to use and apply concepts in an appropriate way for a particular context. This kind of knowledge requires another level of deep learning. As an example of superficial learning, I have met many learners who proudly remember that the chemical equation for photosynthesis is often written as follows:

$$
6 \mathrm{CO}_{2}+12 \mathrm{H}_{2} \mathrm{O}->\mathrm{C}_{6} \mathrm{H}_{12} \mathrm{O}_{6}+6 \mathrm{O}_{2}
$$

This 'knowledge' has little use without understanding that the equation summarises a complex web of energy-requiring chemical transformations through which most plants and algae, as well as various bacteria, absorb carbon dioxide from the air and 'fix' the carbon it contains in carbohydrates.

\subsubsection{Conceptual change}

A theory about learning that has been influential in science education is constructivism. A central idea of constructivism is that new ideas emerge from old ones. Thus, from a constructivist perspective, student's conceptions require attention in order to adjust teaching accordingly so that taught content can be efficiently assimilated with what the learners already know (Ausubel, 1968). In simplified terms, learning a new concept may occur by adding new information if the learner has no pre-knowledge of it, filling gaps if the learner has partial understanding prior to instruction, and conceptual change, if the learner already has ideas that conflict with the concept being taught (Chi, 2008). Accordingly, research on students' conceptions often rests on the assumption that the general role of teaching is to change people's erroneous ideas about something into other forms that are hopefully more in line with the main scientific ideas (Posner, Strike, Hewson, \& Gertzog, 1982). It follows that there are scientific conceptions and alternative or misconceptions, and that learning entails a shift from naïve, folk, conceptions to scientific conceptions. Most science education research in the last decades of the $20^{\text {th }}$ century (which mostly focused on physics education and to some extent biology education) was rooted in conceptual change theory (diSessa, 2009). Although it has lost its dominance, this theory has been established as a powerful framework that has facilitated advances in science education (Duit \& Treagust, 2003), not least with the identification of several areas of science that pose difficulties for learners. 
This research field has subsequently divided into two branches, viewing students' knowledge as either coherent frameworks or collections of smaller fragments (Özdemir \& Clark, 2007). According to the coherent framework view (Vosniadou, 1994), learners have consistent conceptions of different phenomena at a particular point in time, and conceptual change is therefore primarily a matter of shifting from one conception to another that is more in line with the established scientific view (Fig. 2).
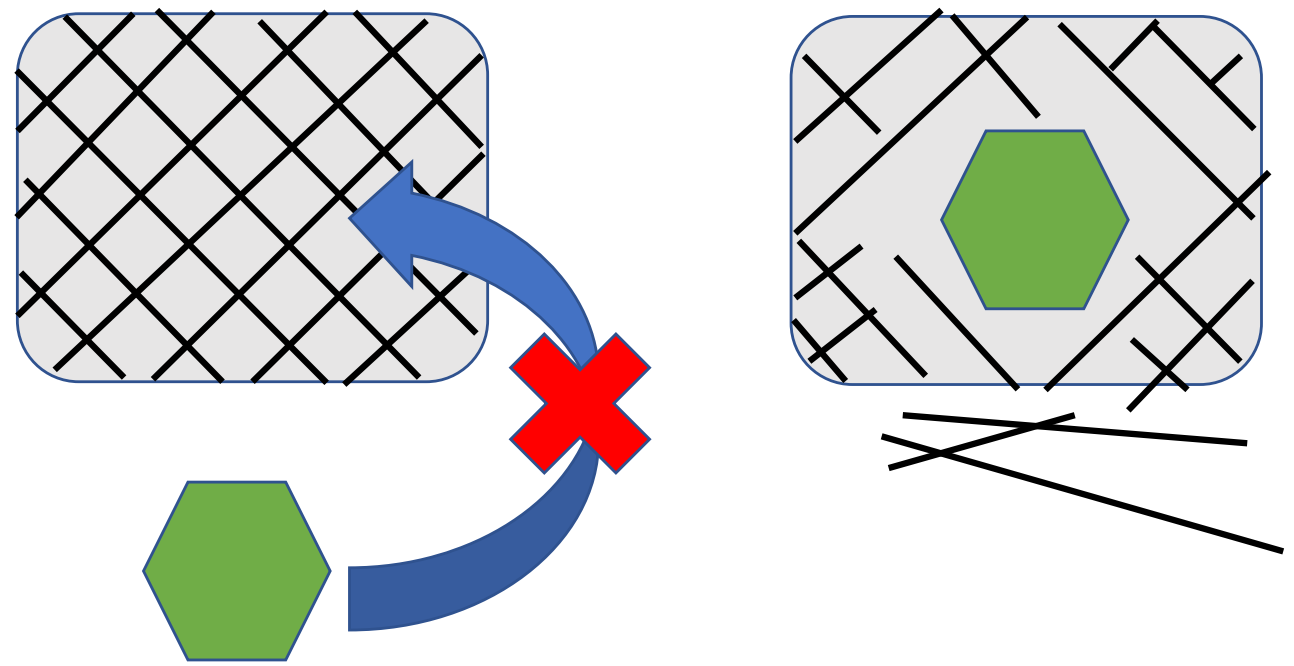

Figure 2, The knowledge framework model: Left panel: Inclusion of new knowledge (green hexagon) is hindered by the current conceptual frameworks (black grid) in the mind (grey rectangle). Right panel: If the erroneous framework is taken apart the new knowledge can replace old knowledge.

This view is influenced by philosophy of science and Kuhnian theories of how science progresses by shifts between paradigms, rather than incremental development. Such a shift is said to occur when enough incommensurable data contradicting a current paradigm have accumulated. This is mirrored in the idea that cognitive conflict (Posner et al., 1982) is necessary for inducing shifts. from erroneous pre-conceptions to scientific ones.

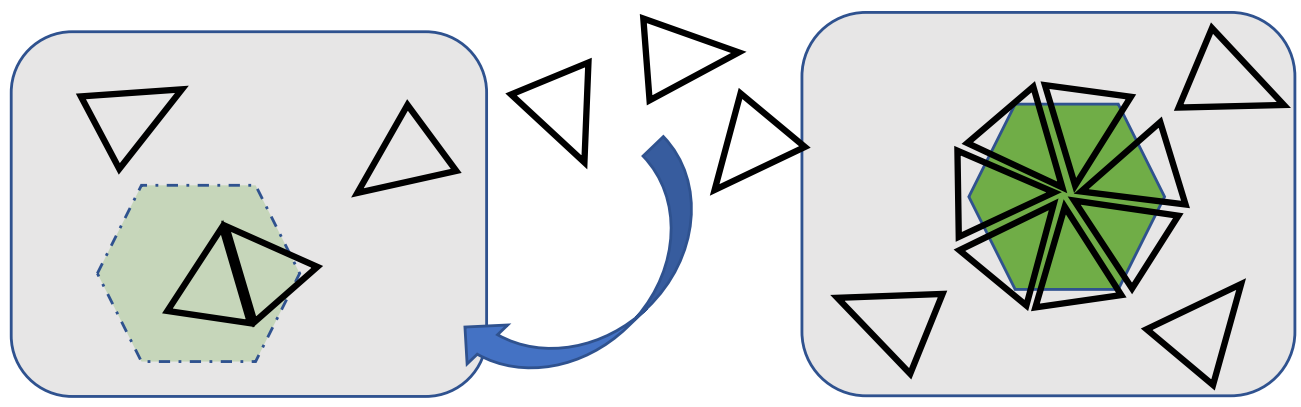

Figure 3, The knowledge in pieces model. Left panel: new knowledge (green hexagon) cannot be completely conceptualised because the mind (grey rectangle) does not contain the necessary knowledge fragments (triangles). However, when more resources are added (right panel), the learner can integrate and use the new knowledge. 
Other researchers argue that research findings on students' conceptualisations of science concepts can be better explained with a model of context-dependent, flexible coordination of resources (diSessa, 1993). This can be called the fragmentary knowledge, or knowledge in pieces model (Fig. 3).

There is ongoing debate regarding the relative validity of these views. Further theory development and empirical work is required before knowledge coherence versus fragmentation issue can be settled (diSessa, 2009). Meanwhile, Leonard, Kalinowski, and Andrews (2014) conclude that evidence that either model is more correct would have little practical effect on advice for planning effective education. This conclusion can be questioned, because logic suggests that different educational strategies are required if a learner's ideas are big slabs of misunderstanding that must be removed or pieces that are flexibly formulated, depending on social (and other) contexts. However, it is appropriate to recognize that these are subtle distinctions regarding the nature and extent of systematic learners' conceptions within a constructivist framework (diSessa, 2009).

\subsubsection{Threshold concepts}

Threshold concepts comprise a special type of concepts (Meyer \& Land, 2003) that are important elements of multiple scientific (and other) topics, and must be grasped before those topics can be properly understood (Ross et al., 2010). Examples of proposed threshold concepts are organisational scale, dimensions of time, and chance in the forms of randomness and probability (Tibell \& Harms, 2017). The process of acquiring threshold concepts is parallel to conceptual change framework presented earlier. "(T)he idea of "threshold concept" emphasizes the importance of embarking students on journeys that transform their ways of thinking in highly productive manners within a domain." (Talanquer, 2015, p. 3) This transformation may take time or be sudden but entail "ontological and cognitive shifts that are also often accompanied by the students' use of more advanced language" (Tibell \& Harms, 2017, p. 958).

With such formulations, the threshold concept idea is close to the notion of why some misconceptions are robust suggested by Chi (2005): that difficulties in learning a scientific concept may not be due to a conflicting belief or mental model. Instead, the tenacity of a misconception may be due to the learner making a categorical error and putting the concept in the wrong ontological category, for example regarding process and interactions as material, so heat may be understood as a kind of fluid, or chemical bonds as material links. This can also be regarded as the learner getting stuck on a threshold and unable to move beyond it, despite additional instruction, until (s)he realizes how to make the ontological shift. Such shifts do not come easy (Land, Meyer, \& Baillie, 2010), some students remain standing with one leg on each side of a threshold, as shown by their reasoning moving back and forth, and using the threshold concept inconsistently. This has been described as getting stuck in a liminal state (Land, Meyer, \& Flanagan, 2016), which as described within the threshold 
concepts framework would correspond more with the flexible resource model of diSessa than the coherent framework model of Vosniadou.

Moreover, due to the fundamental nature of these suggested thresholds, they should be introduced early in a student's science education as they are portals to understanding many concepts. If they are not traversed at secondary level, fundamental thresholds may not be covered later at university level because of assumptions that they have already been learnt (Kinchin, 2010).

\subsubsection{Misconceptions in science education}

When a model, framework or other kind of internal representation is incorrect vis-a-vi a canonical scientific model, and consistently used to produce incorrect explanations of various phenomena it can be classified as a misconception. "The pattern and consistency of the generated explanations allow us to capture the structure of the flawed mental model." (Chi, 2008, p. 68) Previous research has revealed some persistent misconceptions that have proven hard for students to abandon despite more instruction. Researchers may not agree about how these conceptions are constituted in the minds of learners, but they manifest in conceptual inventories and interviews.

Several alternatives to the word misconception are used in the field of science education, e.g., alternative concepts, alternative frameworks, naïve ideas, naïve explanations, and intuitive conceptions. Some claim that the term misconception has fallen out of style and is (or at least should) no longer be used (Maskiewicz \& Lineback, 2013). In response, Leonard et al. (2014) show that the claim that misconceptions is rarely used in science education is false. They found an array of studies focusing on misconceptions in a search for the term in a research database, but they argue that the meaning of the term misconception has shifted during the decades of its use. Many who use it do not explicitly state what they mean by it (Gouvea, 2018), but most commonly it is assumed to simply refer to "noncanonical ideas students express in science" (Leonard et al., 2014, p. 180) without the previous association with students' knowledge structures. In cases where this description of the term's use is correct, abandoning the use of misconception as proposed by Maskiewicz and Lineback (2013) would be more virtue signalling than a profound progression in practice or theory. I agree with Leonard and colleagues in that we might as well use the term misconceptions, as this comes naturally and intuitively. However, it would be helpful if researchers more clearly described the theoretical view of knowledge and learning they have adopted when studying conceptions (Gouvea, 2018).

In this thesis, and the attached papers, I use the terms misconceptions and alternative conceptions interchangeably, meaning explanations that differ from those commonly considered the best available scientific explanations. 


\section{Learning with representations in science education}

A picture is worth 10,000 words, according to the old proverb. Larkin and Simon (1987) attempted to answer why this may be true from a cognitive perspective. Through studying how two types of representations could be used to solve science problems, they concluded that information in a diagram (visual representation) is indexed by location, which allows grouping of related information that supports perceptual inferences. Grouping information then facilitates searching for elements needed for problem-solving inference. In contrast, the same information presented in writing (sententially) is sequential making searching for information more demanding. Thus, a visual representation has the potential to represent information that is only implicit in a sentential representation. This can to some extent explain why visual representations are indispensable in science to support reasoning about complex phenomena (Gilbert \& Treagust, 2009b; Mathewson, 2005; Phillips et al., 2010; Treagust \& Tsui, 2013).

\subsection{Reasoning with representations}

As already mentioned, there is an assumption that learners read visual representations as easily as they read text. As with verbal language, an inability to communicate with visual language will result in erroneous interpretations of visual representations (Pintó \& Ametller, 2002). Thus, the notion of visual literacy has been introduced as an important part of learning science.

In science education visual representations are being increasingly used to communicate ideas (Lowe et al., 2017; Phillips et al., 2010). However, studies report that traditional science education does not help students to develop the graphing competences used by professional scientists (Roth \& Bowen, 1999) If we are to educate learners who are capable of reading and processing visual scientific information, visual literacy must be treated as a vital component of effective learning and teaching of science. A consensus in the literature is that if visual literacy is neglected, students will have difficulties, especially when interpretation of inscriptions representing abstract scientific concepts is required.

There are several suggestions for what to call a skillset needed to read, interpret, and generate representations. A few examples from the literature are representational competence (Kozma \& Russell, 2005), visual literacy (Lowe, 2000), metarepresentational competence (diSessa, 2004), and metavisual capability (Gilbert, 2005). However, despite the different names the listed skills generally have high similarities. The goal in developing the skills is to enable learners to interpret and understand the specialised visualisations in science by becoming aware of specific conventions of representations (such as arrows), their purpose, and general functions (Ainsworth et al., 2011). This is essential for participation in practices where representations are used to explain phenomena, support claims, solve problems, and/or make predictions. The required skills include abilities to: 
- Critically evaluate representations' usability,

- Understand the purpose of representations,

- Explain representations,

- Invent and design new representations,

- Interpret novel representations without problem.

Here I use the term representational skills to denote this core set of competences associated with representational work in science.

\subsection{Learning from visual representations}

Learning from representations has been studied based on various characters in their format, e.g., colour, dimensionality (2D or $3 \mathrm{D})$, abstraction, relevance, static or dynamic nature, and interactivity. While visual representations have great potential for communicating complex information, research has revealed that learners struggle with decoding representations of abstract phenomena like weather maps (Lowe, 1996), evolutionary trees (Catley et al., 2010), and chemical reaction equations (Taber, 2009). Although the visual channel into the brain is wide it is not infinite (Sweller, 2005). Furthermore, many studies show that the learner's pre-knowledge of a topic strongly influences what information is perceived in a visual representation. Material features of representations and social contexts they are used in strongly influence representations' ability to stimulate meaning-making, but individuals' background knowledge and experience with particular representations also affect the sense and use that the individuals can make of them (Kozma, 2003).

A limitation of static representations of processes is that they must represent dynamic features of the processes symbolically. Therefore, the possibilities of using dynamic representations i.e., animations and simulations, have been met with enthusiasm in the science education community. In a meta study of research comparing learning with static and dynamic representations, Höffler and Leutner (2007) showed that dynamic representations are generally superior to static counterparts. However, one should not assume that there are automatic benefits of working with animations when trying to understand a dynamic process. For example, in a study where students were asked to sort pictures of a kangaroo jumping in the correct order, those who studied the kangaroo's locomotion using an animation were outperformed by those who studied representations that broke down the jump into a series of still images (Lowe, Schnotz, \& Rasch, 2011).

The longstanding debate about whether animations are superior learning instruments (Lowe et al., 2011; Tversky et al., 2002) has not been resolved, partly perhaps because learning is complex, and subjective. Peoples' experiences of a representation differ, and what works for one individual does not necessarily work for another. Moreover, all representation involves some form of interpretation, which has major consequences for science education. The animation a teacher chooses to illustrate movement of atoms in a solution may not resonate with the students' experience or pre-knowledge. The information 
about the random movement of the particles the teacher clearly saw may be completely imperceptible to the students. Instead, they may perceive a trivial aspect of the animation, like a colour change of some particles to be the main take-home message (López \& Pintó, 2017). General claims are not relevant: outcomes depend on the students, content, context and learning objectives (Lowe et al., 2011). However, one way to reach various preferences and obtain opportunities to discuss limitations of particular representations is to use multiple representations in teaching.

\subsection{Multiple representations}

Specific information can best be portrayed in one representation, but several representations can display a variety of information. Research has shown that in many cases learning from both visual representations and text is more effective than traditional instruction based solely on text (Mayer, 2003) Multiple representations presented simultaneously can support learning by being complementary, constraining, and constructing deeper understanding (Ainsworth, 2006). This may be particularly important for complex concepts where complementing and constraining multiple representations can illuminate different aspects of the concepts (Ainsworth, 2006; Mayer, 2005).

However, the abilities of experts and beginners to make these complementing and constraining connections between multiple representations strongly differ. If introduced to a new innovative representation of haemoglobin the expert may appreciate additional aspects that it conveys, while the novice learner may have trouble realising that it represents a familiar substance. Thus, to use multiple representations fruitfully in teaching tool the teachers must guide the learners to make appropriate connections between each representation (Ainsworth, 2006). For instance, Hubscher-Younger and Narayanan (2008) found that when groups of students had access to multiple representations for solving a problem they chose one at an early stage and stuck it, even when the problem required use of information presented in other representations. This evidence of a process the cited authors called premature convergence shows that combining information from multiple representations may be difficult. This further underlines the difficulties students experience when trying to interpret expert-generated representations of abstract invisible concepts (Catley et al., 2010; Taber, 2009).

For such reasons we may never produce perfect representations for others, but an alternative to expert-generated representations is to engage and guide learners in generation of their own representation (Ainsworth et al., 2011; Haglund, 2013; Tytler et al., 2018). Collaborative generation of visual representations may provide opportunities to discuss and reason about crucial aspects for making sense of the considered concept. At the same time, there may be opportunities for increasing the visual literacy, including representational competence (Ainsworth et al., 2011). Furthermore, an important aspect of visual representations is the aesthetic dimension. Scientists are not only driven by instrumental criteria such as how well representations or models describe, 
predict and explain a phenomenon. The aesthetic experience of beautiful representations and awe-inspiring solutions to problems is also part of the scientific experience (Bruna, 2013; Wickman, 2006).

\subsection{Student-generated representations}

There is a growing interest for students generating their own representations in science education (Ainsworth et al., 2011; Chang, Quintana, \& Krajcik, 2010; Haglund, 2013; Hoban \& Nielsen, 2011; Prain \& Tytler, 2012) For example, through work with middle school children Prain and Tytler (2012) concluded that generating representations, in various media, is a process of personal and social knowledge construction. It is also claimed that encouraging students to show their understanding of scientific concepts through drawing is a learning strategy that promotes students' communication, reasoning, representational skills and engagement (Ainsworth et al., 2011). Furthermore, it has been shown that students who generate their own material remember the targeted information significantly better than students who use materials generated by others. This has been called the generation effect (Foos, Mora, \& Tkacz, 1994). For anyone who has tried to explain something to someone else, this effect is relatable. A learning framework based on constructivism, but involving substantial generation of representations called, constructionism has also been proposed (Papert, 1994; Papert \& Harel, 1991). This postulate, inter alia, that that learning is most effective when the learner is offered the opportunity to construct a concrete and meaningful product.

When students are asked to generate new representations, rather than just redraw textbook diagrams, they are required to actively make decisions about what is important, and how relations between different components of the topic should be represented (Van Meter \& Garner, 2005), enabling more comprehensive learning. To generate drawings learners must integrate new and previously learnt representations with the generated representation and thus create a more flexible conception of the focal concept than studying isolated representations could afford. This sentiment is shared by Hoban and Nielsen (2011), who studied effects of inviting teacher students to generate multimedia representations of scientific concepts and found that generation of SMAs developed their conceptions (Hoban \& Nielsen, 2013; Macdonald \& Hoban, 2009). Similarly, in a study where students were asked to make drawings while working with an animation showing atomic interactions during hydrogen combustion, Zhang and Linn (2011) showed that generating drawings helped students to interpret complex visualisations and integrate information. This relates to the observation that learner-generated drawing as a learning strategy does not primarily affect factual recollection but higher-order tasks such as knowledge transfer and problem-solving (e.g. Van Meter \& Garner, 2005).

In contrast, Marbach-Ad, Rotbain, and Stavy (2008) found that learning about molecular genetics from an animation was more effective than learning the same content through generating illustrations. The dynamic media helped the $11^{\text {th }}$ and $12^{\text {th }}$ grade students to reason about molecular processes. In the same vein, 
Chang et al. (2010) found that watching teacher-generated animations promoted students' learning about the particulate nature of matter more than students generating their own animations. This could be explained by the observation that when generating their own representations students often revert to externalising 'accepted' or standardised representations, and often revert to memory rather than to their own observations (diSessa, 2004). However, when the researchers (Chang et al., 2010) included peer evaluation in the students' design process they displayed higher learning gains. This is consistent with the conclusion by Van Meter and Garner (2005) that instructional support is critical (see also Tytler et al., 2018).

Student-generated representations can also be useful tools for investigating learners' conceptions of science concepts. For example, student-generated diagrams have been used as supporting materials in interviews probing university students' conceptions about antibody binding (Schönborn \& Anderson, 2009). Other studies have focused on representations to explore conceptions of learners, especially young children who have not yet learned to write yet (J. Andersson, Löfgren, \& Tibell, 2020; Reiss et al., 2002) and older students (Church, Gravel, \& Rogers, 2007; Nielsen et al., 2020; Zhang \& Linn, 2011). However, adopting an approach focusing on students' generated multiple representations entails embracing assessment as an ongoing part of learning (Tytler et al., 2018).

Use of student-generated representations is justified by research rooted in cognitive science, conceptual change theory, social semiotics and socio cultural perspectives (Tytler et al., 2018). This is a sign of the potential relevance of the approach beyond each research field, e.g., in classroom practice. This also explain to some degree the eclectic approach to theory in this thesis. According to a cognitivist perspective on student-generated representations, playing with both material and symbolic tools in speculative option-testing can produce new insights, enabling reviewable outcomes, while sociocultural accounts of science learning facilitate explanations of the importance of intentions and first-hand experiences for meaningful sign-making (Prain, 2019, p. 153). Thus, the most appropriate and fruitful theoretical lens depends on the focal aspect of interest.

In accordance with findings that learning from a representation can be affected by the mode of the representation, the mode a learner can use to represent a concept will influence the result. Representing a dynamic process in a drawing using pen and paper has different constraints from, for example, generating a verbal explanation or an animation.

As shown in this background section, there are theoretical motives for using student-generated representations to engage students in scientific practices, and numerous studies on the use of drawings and diverse computer environments to generate mathematical and graphic representations of phenomena. As most studied digital environments are more or less limited to a specific content or restricted set of representations, which may for example prevent students from representing collisions between particles (Yaseen \& 
Aubusson, 2020), they have the drawback of being tied to one content. If there is an aspiration to use this approach for more than one topic, the students need to learn to handle different visualization software. An alternative would be to use some form of open format of generating multimedia representations. One such technique is stop-motion animation (SMA).

\subsection{Student-generated stop-motion animations}

A growing number of studies indicate that generation of SMAs can help students to develop their conceptual understanding of various science topics, for example, chemistry (Akaygun, 2016; Yaseen, 2018), cell biology (Deaton, Deaton, Ivankovic, \& Norris, 2013; Kamp \& Deaton, 2013), astronomy (Nielsen \& Hoban, 2015), earth science (Mills, Tomas, \& Lewthwaite, 2019), engineering science (Church et al., 2007) and even the nature of science (Kottova, 2015). One research group has focused on its utility for enhancing primary science teacher students' understanding (Hoban, Loughran, \& Nielsen, 2011), and another has investigated its potential in educational stages as early as preschool (Fleer \& Hoban, 2012).

Although stop motion is not a new technique for making animations, its applicability in classroom teaching has increased with the introduction of digital resources in schools (Luckin et al., 2012). Digital cameras and free stop motion software enable everybody to become animators (Church et al., 2007; Hoban, 2007). Generating a SMA has been made much simpler through the introduction of digital photography. In the days of yore, the animator had to use analogue film to take pictures of models that were moved slightly between each shot. When the film was developed the result could be inspected and put together on a reel and displaying the pictures sequentially gave the impression of movement. With digital photography each photo is directly available for inspection on screen and can be adjusted directly if something went wrong. Also, if some form of stop-motion software is used, the animation can be previewed as it progresses, and the beginner using the technique for the first time can learn important factors, e.g., the optimal size of models' movements between shots, as the project proceeds.

Stop-motion differs from generating animations completely digitally in that it is an old-school, hands-on technique for producing animations, with flexibility evidenced by the range of topics it has been used to cover (Farrokhnia et al., 2020). This flexibility lies in the ability to use any material for generating models, including everyday objects or prefabricated models. Sets can be built either in $3 \mathrm{D}$ (with the camera on the side) or $2 \mathrm{D}$ (with the camera above), and diverse materials can be used. For example, cut-outs, drawings, clay figures or wire figures can be fruitfully used, and the flexibility stimulates creativity.

In a recent review of research on SMAs in science education, Farrokhnia et al. (2020) support the claim that student-generated SMAs can promote deep learning but point out that it is too early to make general claims of the effectiveness of this approach due to lack of comparative quantitative studies. 
However, in addition to gains in domain-specific knowledge, it can reportedly increase engagement, motivation and interest is found in the literature (Farrokhnia et al., 2020). Furthermore, it is claimed that this approach stimulate skills prioritized in the, $21^{\text {st }}$ century, like communication, collaboration and creativity (e.g. Karakoyun \& Yapici, 2018).

The field of student generated SMA has been dominated by a team of researchers based in Australia, led by Gary Hoban. He pioneered an innovative method for generating animations called slowmation, an abbreviation of slow-motion animation (Hoban, 2007) which involves taking fewer digital photos than with standard stop-motion animation, and thereby accelerating the animation process (Hoban \& Nielsen, 2010). By showing an animation at two frames per second (fps) while in normal movies pictures changes at $25 \mathrm{fps}$, the models move very slowly in a slowmation. The rationale for playing the animations this speed is that research on other stop-motion techniques, like claymation, indicate that one of the drawbacks of the stop-motion technique is that it is time consuming (Hoban, Nielsen, \& McKnight, 2010). The animations have intended uses as teaching resources in the teacher students' future classrooms.

\subsubsection{Learning from SMAs}

SMAs' promotion of learners' conceptual development is attributed to students reflecting on a concepts in multiple ways (Ferry et al., 2009; Hoban, 2007). Participating learners must repeatedly re-represent focal concepts and each representational form (mode) offers different representational affordances (Ainsworth, 2006; Prain \& Tytler, 2012) and thus requires metacognitive activity (Gilbert, 2005; Van Meter \& Garner, 2005).

Another model for learning from creating SMAs, building on the $5 \mathrm{R}$ (Reporting, Responding, Relating, Reasoning and Reconstructing) framework has been proposed by Kidman, Keast, and Cooper (2012). Based on experience of using and researching slowmation with secondary science teacher students, this model is called MMAEPER (pronounced mapper), and has Meaning, Making, Animation, Editing, Presentation, Explanation, and Reflection components. Like Hoban and Nielsen's approach, it is influenced by Peirce's semiotic triad (Object-Representation-Interpretation) and Vygotsky's ideas about semiotic meditation (Kidman et al., 2012). Inter alia this highlights the importance of group activity in the animation generation process.

An important issue addressed in my research was whether this approach could be used for teaching and learning secondary science, including ENS (one of the most notoriously difficult topics in science education) and chemical redox reactions. 


\section{Biology education, explaining evolutionary change}

Evolution is a core element of biology (Dobzhansky, 1973), and associated theory has major implications for understanding not only human origins, but also major socio-economic and ecological challenges we face connected, inter alia, to environmental change in terms of losses of biodiversity and global warming. Evolutionary principles are crucial for addressing such fundamental issues as food production, farming and use of pesticides. In medicine, understanding evolution can help efforts to understand threats posed by antibiotic resistance and pandemic spread of viruses. Furthermore, they strongly influence disciplines outside biology (Pugh, Koskey, \& LinnenbrinkGarcia, 2014), like economics, psychology, and even computer science, where principles of variation, selection and heritability are applied in learning algorithms. As evolution by natural selection (ENS) has major social and economic implications, there are strong reasons to spend time teaching it, and researching how learners conceptualise and learn this topic.

\subsection{Evolution in modern biology}

Natural selection is the theory proposed by Darwin and Wallace in 1858 (Kutschera \& Niklas, 2004) that broke with various forms of natural theology and teleology that had been previously used to explain the history of life. It provided a mechanistic explanation of "the seeming harmony and adaptation of the organic world" (Mayr, 2004, p. 109). Speciation and gradual evolution were given a mechanism. Today, evolutionary biology is the study of the history of life and the processes that lead to biodiversity. Building on adaptation, randomness, and history the evolutionary biologist strives to explain characteristics of organisms and reconstruct the patterns and mechanisms that can make sense of all living things ancestral relations from our common origin. In essence, evolution consist of two processes: transformation of lifeforms over time, and their diversification in space, both ecological and geographic (Mayr, 2004).

Although the principles postulated by Darwin and Wallace have not been refuted, our modern view of evolution has been modified and enriched by the development of molecular biology. More evolutionary mechanisms have been discovered and methods for studying the history of the diversification of life have given us a more detailed picture of the evolutionary processes. One aspect of evolutionary theory that has changed since the end of the $19^{\text {th }}$ century is the notion of a perfect adaptation mechanism, which Darwin initially held (Mayr, 2004) and has been abandoned by modern biologists. The constraints of the material that natural selection acts upon make any claim of perfection unrealistic. The history of a species and the developmental process from zygote to adult are just two factors that prevent perfect adaptation (Gould \& Lewontin, 1979). Chance also plays a greater role in evolution than Darwin portrayed, or he wanted. For example, experiments by Luria-Delbruck during the 1940 s showed that the sources of variation in the form of mutations, for example, appear randomly in populations with no causal relation to the environment. 


\subsubsection{The modern synthesis}

The two key hypotheses proposed in The Origin of Species (Darwin, 1859) are that evolution usually occurs gradually and natural selection is the most important mechanism through which adaptive evolution occurs. Darwin had no knowledge of how traits were inherited and accepted the Lamarckian model of soft inheritance, i.e., that traits gained during life may be transferred to the offspring (Mayr, 2004). However, after Darwin's death Mendelian genetics were rediscovered and synthesized with natural selection by the work of Weissman in the 1890 s (Bowler, 2009). The resulting Neo-Darwinism was contested by other types of selectionism, like Lamarckism, Orthogenesis and Transmutationism (Kutschera \& Niklas, 2004). The controversy was resolved by the modern synthesis between 1930 and 1950, a work that had no single great portal figure like Darwin for natural selection, instead it was the result of a collective enterprise by scholars like Fisher, Dobzhansky, Huxley and Mayr (Bowler, 2009; Kutschera \& Niklas, 2004; Mayr, 2004). Their work solved the problem of inheritance, showing that new variation could arise in a population through mutations, as well as the enigma of speciation. Results of the collective process of synthesizing the new knowledge regarding the evolution of lifeforms can be summarised in the following six-point list (Kutschera \& Niklas, 2004):

1. The units of evolution are populations of the same species of interbreeding organisms (or strains of asexually reproducing organisms) and not types.

2. Genetic and phenotypic variation arise through genetic recombination and random mutations.

3. Natural selection is the most important directional force in evolution, although random genetic drift may be significant in some populations.

4. Speciation occurs as steps in evolutionary processes, which may be either allopatric or sympatric processes.

5. Evolution is mostly gradual. New species evolve from previous variants.

6. Macroevolution is an extrapolation of microevolution.

The description of the DNA molecule and the following revolution of biochemistry from the 1960s also strongly influenced the methods and models of evolutionary biology. One could imagine that the development of a completely new field of biology like molecular biology would challenge and disprove theories from the $19^{\text {th }}$ century. If anything, however, the DNA revolution has reinforced the centrality of ENS in the life sciences.

In general accounts of the history of science this crucial work of developing the theories of evolution is often neglected. Instead, there has been a strong focus on the contribution of Darwin, which has perpetuated a simplified view of the epistemic practice of science, leading to a distorted image of science as an individual rather than collective enterprise and raising risks of separating evolution as a historical idea of little relevance in modern biology education. This fails to give evolution the central and ubiquitous role it should have in biology. One further risk is that in practice, the understanding of how genes and 
DNA work is kept separate from evolution in the public mind (Kalinowski, Leonard, \& Andrews, 2010).

Efforts to understand ENS thoroughly did not stop in the mid-20 ${ }^{\text {th }}$ century, they have continued, and now evolutionary concepts have influenced most biological, and many other, fields. It should be noted that even fundamental aspects of evolution are still being considered. For instance, Kutschera and Niklas (2004) raise the need to adjust the model developed in the evolutionary synthesis of the 1950 s to include the majority of lifeforms, which are not multicellular and do not reproduce sexually. Moreover, there are diverse mechanisms of evolutionary change, including genetic drift or neutral evolution (which does not involve selective pressures), and stabilizing, kin, or sexual selection.

Considering this, it is appropriate to point out that natural selection and evolution are not interchangeable, which it sometimes seem to be considered as in science education (Anderson, Fisher, \& Norman, 2002). However, I chose to use the term evolution by natural selection (ENS), thus wanting to emphasize that an educational goal for general science education is to understand evolutionary changes by applying the model of natural selection. With this focus one risk foregoing other evolutionary mechanisms, however natural selection is both fundamental and the most far reaching mechanism (Pugh et al., 2014).

\subsection{Teaching and learning evolution}

Numerous factors may influence a learner's comprehension of ENS, because it is not a simple model that merely explains how the world works, it raises major existential questions about who we are, how we ended up here, what we ought to do with our time on earth, and our relations to other forms of life. Reviews of research on evolution education (e.g.M. Smith, 2010b) clearly show the resulting complexity of trouble that students experience, which has been researched from cognitive, epistemological, religious and emotional perspectives. The diversity of this research shows that teaching this topic places the teacher in a situation that goes beyond presenting facts about the world. Sinatra et al. (2008) point out that learning to understand ENS is not only a matter of adding new information to what is already known but calls for a shift in the learner's worldview.

According to a framework of constraints that influence learning ENS, suggested by Rosengren and Evans (2012), factors that may constrain or facilitate learning operate on three levels: the environment and, the organism (the learners biology), and the task. These interact in complex ways to create individual learning situations and teachers need understanding of the major constraints in order to facilitate each learner's progression. Historically research has generally focused on single constraints, Rosengren and Evans (2012) advocate inclusion of multiple constraints to stimulate understanding of how they are intertwined. In this thesis constraints of all three levels are considered to some extent. 


\subsubsection{Key-concepts}

Within the tradition of research on conceptual change, evolution through natural selection (ENS) is often structured around a list of concepts that are referred to as key-concepts (Anderson et al., 2002; Nehm \& Reilly, 2007). These are often used in conceptual inventories designed to assess students understanding of evolution, however, there is not always a consensus about which concepts to include or what to call them (Kuschmierz et al., 2020).

Briefly, ENS can be described as a change in a population due to variation in the characteristics of members of the population, which causes different rates of reproduction, and which is inherited (Godfrey-Smith, 2007). Three simple requirements for a trait to evolve are variation of the trait within the population, hereditability of the trait, and influence of variation in the trait on individuals' reproductive (Evans et al., 2009; Tibell \& Harms, 2017). This description of natural selection is deceptively simple (Gregory, 2009) and applying the principle to concrete examples have been proven difficult. Each of these three requirements encompasses various more specific concepts. A more nuanced account of ENS that closely follows Darwin's argumentation by Mayr (1982) includes five observations and three inferences, as shown in Table 1:

Table 1. Key-concepts (in parenthesis) based on Observations and inferences regarding ENS recognized by Mayr (1982).

\begin{tabular}{|l|l|}
\hline Observation & Inference \\
\hline $\begin{array}{l}\text { All populations have the potential to } \\
\text { grow at an exponential rate. (Biotic } \\
\text { potential) }\end{array}$ & $\begin{array}{l}\text { Most populations reach a certain } \\
\text { size, and then remain stable over } \\
\text { time. (Population stability) }\end{array}$ \\
\hline $\begin{array}{l}\text { Natural resources are limited. } \\
\text { (Limited resources) }\end{array}$ & $\begin{array}{l}\text { Not all offspring survive to reproductive age, } \\
\text { partly because of competition for natural } \\
\text { resources. (Limited survival) }\end{array}$ \\
\hline $\begin{array}{l}\text { Individuals in a population are not } \\
\text { identical but vary in many } \\
\text { characteristics. (Individual } \\
\text { variation) }\end{array}$ & $\begin{array}{l}\text { Survival is not random. Individuals with } \\
\text { characteristics that provide them with some } \\
\text { advantage over others in their specific } \\
\text { environment are more likely to survive and } \\
\text { reproduce than others. (Differential } \\
\text { survival) }\end{array}$ \\
\hline $\begin{array}{l}\text { Many of the characteristics are } \\
\text { heritable. (Inherited variation) }\end{array}$ & $\begin{array}{l}\text { Populations change over time as frequencies } \\
\text { of advantageous alleles increases and } \\
\text { accumulate over time. (Change in } \\
\text { population) }\end{array}$ \\
\hline
\end{tabular}

Mayr based his account on Darwin's writings and leave important elements from the evolutionary synthesis implicit, consequentially Anderson et al. (2002) added Origin of variation and Speciation to make it a list of 10 key-concepts when developing the much used Conceptual Inventory of Natural Selection (CINS). This conceptual inventory consists of 20 multiple choice items with distracters based on known misconceptions associated to ENS. One alternative to this inventory is the Open Response Instrument (ORI), consisting of six items 
witch gradually varies from familiar and concrete, to unfamiliar and complexity (Nehm \& Reilly, 2007), and the analysis of students' answers was originally based on seven key-concepts in this case.

The variety of concepts used in different studies makes it hard to evaluate and compare results. Furthermore, there is a lack of evidence regarding which of these concepts is essential, and perhaps more or less difficult, to learn (M. Smith, 2010b). In the end, it is also possible that the key to successful teaching and learning of ENS is not limited to these key-concepts but in proposed, general and abstract threshold concepts (Meyer \& Land, 2005; Ross et al., 2010; Tibell \& Harms, 2017), a notion that was introduced in section 2.3.1, and is considered in more depth in the following section.

\subsubsection{Threshold concepts and evolution education}

Decades of research focusing on the key-concepts of evolution through natural selection have identified deficiencies in students' conceptual understanding and pointed out the area of evolution as troublesome for learners (Gregory, 2009; Harms \& Reiss, 2019; M. Smith, 2010b). Inspired by the framework of threshold concepts (Meyer \& Land, 2003) scholars have recently began to argue that evolution educators need to look beyond the key-concepts for another category of concepts (Ross et al., 2010; Tibell \& Harms, 2017). What is a threshold for one student may not be for another (Ross et al., 2010). Consequently, different scholars propose different candidates as threshold concepts.

In my studies, the four suggested threshold concepts randomness, probability, time, and spatial scale (Tibell \& Harms, 2017) are treated. One group of biology educators propose that Variation is a threshold concept not only for ENS but biology as a whole (Batzli, Knight, Hartley, Maskiewicz, \& Desy, 2016). Variation, they argue, is an important factor at all levels of biology, from molecules to species and ecosystems, and have been shown to be both challenging, transformative, and integrative in earlier research (Gelman \& Rhodes, 2012; Shtulman, 2006). In contrast, Ross et al. (2010) seem undecided about its conceptual nature as they list variation as both a discipline concept and a threshold concept. As variation is treated so often as a key-concept of ENS in the research literature, and the thresholds I sought are not purely biological but more general and implicitly addressed in biology education I have chosen to include variation among the key-concepts. In accordance with (Tibell \& Harms, 2017), the term threshold concept has been reserved, in both this thesis and the underlying studies, for concepts that have an abstract and non-concrete nature. 


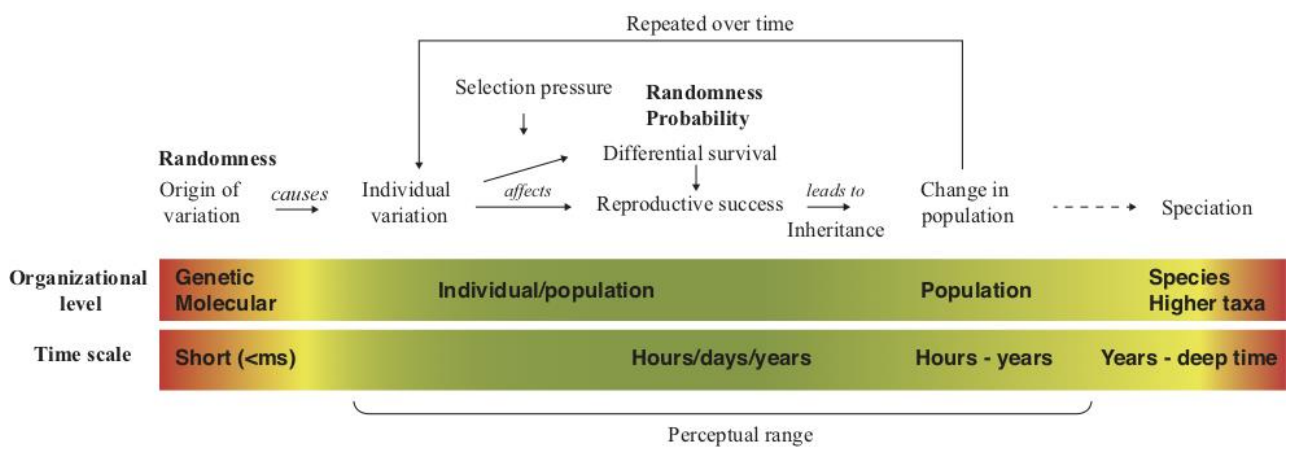

Figure 4. Representation of the process of ENS integrating key-concepts and the four proposed threshold concepts (Göransson, Orraryd, Fiedler, \& Tibell, 2020). Within our perceptual range we can directly observe that individuals in a population have variable traits. These traits may affect chances of survival and reproductive success and can be inherited. Beyond our perception are the causes of variation at a molecular organizational level and short time scale. On the other end of the spectrum, also beyond our perceptual range, changes in populations and speciation occur in timeframes of years to millennia and perhaps at geographical spatial scale.

It should be noted, as already indicated, that the threshold concepts are intertwined (Ross et al., 2010) and might be hard to separate from each other in the complex process of ENS. Roles of individual threshold concepts in supporting students' understanding and reasoning about evolutionary changes are also unclear. Thus, research that explores these issues is warranted, as is finding ways to make the necessary threshold concepts tangible for learners so they can grasp their significance (Tibell \& Harms, 2017)

The following paragraphs describes how all four thresholds, randomness, probability, spatial scale, and temporal scale, relate to evolution education. However, the latter two are the main focus in this thesis.

\subsubsection{Randomness and probability}

One often heard argument from critiques of evolution is that complex life hardly can have been created by chance, that randomness have an important role when explaining the diversity of life with its seeming purposeful forms of adaptations, can be difficult to accept as plausible (Garvin-Doxas \& Klymkowsky, 2008). This indicates a confusion about the role of randomness and probability in evolution of life (B. Andersson \& Wallin, 2006; Bishop \& Anderson, 1990). Such confusion may lead to a rejection of (ENS) as a possible explanation for the diversity of life. Thus, randomness and probability are likely candidates for being threshold concepts in biology education (Ross et al., 2010; Tibell \& Harms, 2017).

Probability and randomness are two faces of chance (in opposition to determinism and design) with relevance to evolution (Johnson, 2015), and importantly a dimension that is not explicitly part of the key-concepts. Perhaps because biologists have thought of it as a mathematical concept and therefore not relevant to biology education.

In evolution, chance as randomness is associated with the causes of variation, which at the end of the $19^{\text {th }}$ century was unknown and sometimes random chance was used interchangeably with "we do not know". Darwin pointed this 
out but was determined that chance created new variants that could be worked on by selection, driving life's evolution (Johnson, 2015). In communication between scientists there likely is basic consensus about what the words randomness and probability mean. In the classroom the educators need to be aware of the different conceptions of the words chance and randomness that students may have (Mead \& Scott, 2010). In everyday use of the word randomness it can mean different things (Rector, Nehm, \& Pearl, 2013). Randomness in this context refers to non-deterministic, and without purpose or a goal (relates to the alternative conception of teleology, see section 4.3.1.). It describes that the outcome of a single event lack predictability (Tibell \& Harms, 2017). Probability is a measure of the likelihood of events. The latter may range from close to zero (e.g., for survival of a given individual of a species that produces huge numbers of offspring) to very close to one (e.g., that an individual will eventually die).

Evolution is a process influenced by both random, unpredictable events, as well as events with a more predictable probability. it is important to understand the role both types of events play in ENS. Genetic drift is only random and therefore unable to produce adaptations (Coyne, 2010), sexual selection and natural selection on the other hand, are not governed by randomness alone but also by probability. In combination these can lead to adaptations through "non-random survival of random variants" (Dawkins, 1997). That is variation arises in a random process, while selection is directed, not by any force outside the system, but as an emergent result of the selection process based on events with different probability of occurring. A recent study give empirical support for the role of statistical reasoning for understanding ENS (Fiedler, Sbeglia, Nehm, \& Harms, 2019). A large sample of American undergraduate students was tested on understanding of evolution and statistical proficiency. The analysis revealed a correlation between the two, indicating the need for incorporating quantitative thinking in evolution education.

\subsubsection{Different scales}

Biology is a discipline that spans phenomena from atoms to biospheres (Tsui \& Treagust, 2013) as well as from molecular processes in parts of seconds to speciation during thousands of years. The physiology of our senses limits our ability to observe phenomena at both ends of this spectrum (Fig. 4). When we cannot observe something directly, we need to invent some new way of thinking and communicating it. Language have developed based on our perceptions, thinking about things outside this perceptual range petition representation in novel ways, e.g., analogies or images (Niebert \& Gropengiesser, 2015). Communication about science requires precision to be effective, and thus use of strictly defined concepts to handle imagined phenomena. Thus, learning science entails learning to use and handle concepts regarding phenomena that occur on spatial and temporal scales far outside our perceptual range.

Furthermore, coping with different scales of space and time create the problem of choosing between overview and detail. When looking at the genes, you easily 
lose track of the population, or when the focus is on evolution over thousands of years, the mechanism of selection is lost. This creates another challenge of coordinating different scales. Experts seamlessly swich between scales (Harrison \& Treagust, 2000a), beginning learners however, struggle to connect different scale levels or even realising the need to do so.

\subsubsection{Spatial scale and organisational levels}

Phenomena involved in evolutionary processes range from molecules to continents, from gene mutations (Kalinowski et al., 2010) to geographical distribution of species. This spectrum encompasses several layers and keeping track of what level you refer to is important. The three categories, sub-micro, micro, and macro are often used to organize the levels of biology (Tsui \& Treagust, 2013). Biology students share the challenges associated with processes at an invisible sub-micro level and the representational level used to visualise them, with chemistry students (Taber, 2013). The invisible genetic basis for inheritance and origin of variation is challenging to comprehend (Pinxten, Vandervieren, \& Janssenswillen, 2020). Coupling mutations to the phenotypic variation at a visible macro level in explanations of ENS is challenging for students (Jördens, Asshoff, Kullmann, \& Hammann, 2016; Kalinowski et al., 2010).

However, evolutionary explanations require a category for larger entities as well. For example, populations, species, or higher taxonomic units, which mostly fall outside the perceptual range. Therefore, it is motivated to introduce a supermacro level for these entities. Moving out from an individual perspective to population thinking is challenging but crucial for generating an evolutionary explanation (Shtulman, 2006). In an explanation it is an important to differentiate between Cheetah the species and Cheetah the individual animal, if the two levels are confused, the explanation may be misunderstood. Populations evolve as a result of individual's different success in a struggle to live and reproduce (R. A. Cooper, 2017). The individual does not evolve in an evolutionary sense. This means that this type of phenomenon needs a special form of explanatory model, different from an intuitive, narrative one.

Difficulties are related not only to the very small and very large scales involved, but also to coordination of events at multiple levels. Some approaches for addressing the challenges of different organisational levels in evolution education have showed promising results. For example, adoption of a 'yo-yo strategy', shifting attention systematically on phenomena at ascending and descending levels, may also help students overcome problems associated with events occurring at different scales (B. Andersson \& Wallin, 2006). Furthermore, explicitly revealing to students that considered phenomena are associated with different spatial scales can lower the manifestation of misconceptions and increase understanding (Jördens et al., 2016; Kampourakis \& Zogza, 2008a). This underline the need for making this threshold tangible, e.g., by using appropriate visual representations (Tibell \& Harms, 2017). 


\subsubsection{Time}

Time is abstract, we all know what time is, but it can be difficult to explain. In the same way that biology stretches over many levels of organizations in space it also covers phenomena with timescales ranging from nearly instantaneous (molecular events) to thousands and millions of years (e.g., the evolution of species) (Fig. 4). Time makes evolution possible and gives a framework for events in the history of life. Understanding evolutionary time is important for understanding evolution itself, however, to grasp extremely fast and the glacially slow processes is challenging and demands a degree of imagination as it is beyond what we experience in our daily life. It should be an obvious goal of evolution education that the student understand that, given enough time, improbable events do occur, furthermore that small changes accumulated over time lead to large alterations (Catley \& Novick, 2009). The idea of gradualism, that life evolve by small modifications to the already existing (Dawkins, 1996) that over time accumulate and cause large alterations in a species anatomy and physiology is a transformative realisation to many students (Wallin, 2004).

Evolutionary time is measured in number of generations. When focusing on species that reproduce sexually this is clearly important, as each generation provides new variation through mating and recombination of DNA. For organisms that reproduce asexually, generations are less exact indicators of evolutionary time, but many models of bacterial growth still use numbers of divisions as indicators of time, equivalent to generations. As organisms have different generation time, evolutionary time may not be an absolute measure. One year may be one generation for some creature while it is tens of generations for another. Moreover, evolutionary processes are sometimes divided into micro evolution and macro evolution, creating a dichotomy of one phenomenon stretching over several scales of time. With micro evolution phenomena like evolution of resistance against antibiotics among bacteria, or different pigmentation between groups of humans living at different distances from the equator. Micro evolution concerns smaller changes of one or a few traits in a population over relatively few generations. Concepts in focus are natural selection and adaptation (Catley \& Novick, 2009). Furthermore, these changes can be observed among organisms with short generation time. Macro evolution concern speciation and the evolution or extinction of taxa. These processes require longer time (deep time), and evidence for it occurring is indirect in the form of fossil records etc. However, there is no principle difference between the two forms of evolution, the basic driving mechanisms are the same, the difference is which time scale is observed (Coyne, 2010).

Understanding macroevolution and 'deep time' poses sometimes overlooked problems in evolution education. Solely focusing on natural selection is not sufficient for a public understanding of biology (Catley, 2006). Zetterqvist (2003) showed that most Swedish upper secondary teachers focus their teaching on descriptions, proofs, and the chronology of evolution, so their students meet a view of evolution as a progressive process, following lines of development. Therefore, they have little conception that the mechanism of natural selection 
stretches beyond our perception of time in both directions, into the short timeframes of molecular changes and into large geological timeframes. However, making sense of short timeframes may be more challenging than deep time (H. S. Lee, Liu, Price, \& Kendall, 2011). This makes it even more challenging to connect different timeframes, to metaphorically zoom in time.

\section{3 Difficulties learning evolution}

Selective pressures have driven the evolution of a nervous system and senses that enable us to explore the world. Using these senses and our personal experience, when faced with a situation or phenomenon that is new and unfamiliar to us we can make fast judgements and create a workable explanation by relying on some basic assumptions (Sinatra et al., 2008). These assumptions work in most situations we encounter, but science has revealed some phenomena where our intuitive assumptions lead us to erroneous conclusions. Consequently, various researchers have addressed how learners at all levels of the educational system tend to use pre-Darwinian reasoning, based on intentionality, teleology, anthropomorphism and essentialism, when they try to explain evolutionary changes (Gregory, 2009). In this way, students' conceptual development is superficially similar to the development of concepts in the history of biology. Over 90\% of undergraduate students agreed with at least one pre-Darwinian statement, when asked to what degree they agreed with statements about biological processes (Coley \& Tanner, 2015). Discouragingly, the subgroup of biology majors preferred statements representing misconceptions more frequently than the group of non-majors. Indicating that biology education stimulates misconceptions.

Misunderstandings that a teacher may encounter among the learners can for example take the form of confusion about the reach of the theory of evolution. To be clear, evolution is not a discipline of faith, it is not a theory of the origin of the first living entity (M. Smith, 2010a), it is an account and explanation of how the diversity of life have evolved to the diversity we find today, from a common origin (Mayr, 2004). Moreover, not recognising that evolutionary time encompass thousands of generations can lead learners to explain evolution as an event rather than a gradual process of accumulated changes over long time.

There is a difference between how learners and biology experts explain evolutionary change. Learners seem to enter the biology classroom with conceptions not compatible with a scientific view. Therefore, "(h)elping people to understand evolution, then, is not a matter of adding on to their existing knowledge, but helping them to revise their previous models of the world to create an entirely new way of seeing" (Sinatra et al., 2008). However tenacious these alternative conceptions appear to be, there are reports on inconstancy in the explanation pattern students exhibit. This "causal flexibility" (Evans, 2008) or "lack of explanatory coherence" (Kampourakis \& Zogza, 2009) become motivated to investigate further. In this thesis I approach this issue from an alternative perspective to conceptual change, by exploring if the proposed threshold concepts spatial scale and time are problematic to represent. Perhaps 
the difficulties arise in the limited format of written explanations. Making the alternative conceptions a matter of limited representational methods and competence rather than only conceptual understanding.

\subsubsection{Acceptance of evolution}

Even though natural selection is thoroughly accepted as a central mechanism in explaining evolution, the theory has philosophical implications that can affect people's acceptance of its validity. As the theory is purely materialistic, it has no room for spirits or souls, further it is both directionless and purposeless, there is no built in strive for a better, higher state of harmony in nature. All instances of apparent ingenious purposefulness are simply the consequence of individuals seeking to maximize their genetic heritage in their local environment. As an answer to the meaning of life the theory of natural selection is poor and may leave a feeling of resentment. Accepting a mechanistic explanation to the evolution of life can thus be hard, which also might hinder understanding (M. Smith, 2010b). The idea that all lifeforms evolved from a common decent was received without many controversies in Darwin's time, with one exception. The thought that humans have common ancestors with other primates was, and still is, controversial in some circles (Kampourakis \& Strasser, 2014). Modern biochemical analysis, however, supports this theory developed in the 18-th and 19-th centuries, to the full.

Although religious belief and acceptance of evolution may influence learning, these aspects are not confronted further in this thesis. Attention is instead directed on conceptual understanding and how students can express their understanding using different modes of representation. Often reported misconceptions indicted by earlier research is considered in the following.

\subsubsection{Teleology}

This type of reasoning has roots to ancient times and mean that events or properties of objects are explained by their outcomes or functions. A distinction between a mechanistic causal explanation and a teleological one can be found in the following two ways of explaining why $A$ happened. One does this causally by discussing what happened before $\mathrm{A}$, while a teleological explanation explains $\mathrm{A}$ by talking about the consequences of A (Wright, 1972). A more concrete example, to explain cheetah's extreme running speed causally could look like this: The cheetahs are so fast runners because in previous generations the fastest individuals were more likely to survive and to a higher degree contribute to the present gene pool. A teleological explanation could look like this: The cheetah is fast because it needs to be fast to catch the fast antelopes to get something to eat. This example also point to that the order of events is important. For example, in the scientific causal explanation variation occurs independent of and before selection pressure act on a population, while the teleological explanation, focusing on the outcome, dictate that a new trait appears in response to the pressure of the environment. These non-scientific ideas resonate well with how we tend to see intentions and aims with phenomenon in nature, and therefor use teleological explanations (Kelemen, 2004). 
Philosophers have strived to eliminate teleological expressions from all scientific explanations (Mayr, 2004). In a recent paper Kampourakis (2020) problematizes students' use of teleology in their explanations. He argues that a distinction between explanations of the distribution of a trait in a population because of the benefits it provides its bearer (a teleological but scientifically acceptable argument), and explanations suggesting need, intention or design cause the spread of a trait (teleology without scientific support). Teleology is not bad per se, but when it turns into a design stance it can become a problematic misconception (Kampourakis, 2020).

A study on 14-15-year-old students' explanations of homologies and adaptations were influenced by the problem context and the information given in each task (Kampourakis \& Zogza, 2008b). Their study show that teleological reasoning highly influences students' explanations but to a lower degree if the task contained more information about the adaptation that was given. Furthermore, task context seems significant, both familiarity with the organism subjected to natural selection as well as the type of adaptation, be it trait gain or trait loss. In a large sample of US and Korean students Ha and Nehm (2014) found that cases of trait loss (like loss of functional eyes among cave dwelling creatures), although equally common as trait gain in nature, to a lower degree made the students generate explanations concurrent with natural selection. Instead, soft inheritance based on acquired traits, and teleology were common patterns in explanations about trait loss. It is hard to accept chance being part of any mechanism that is creating order. Garvin-Doxas and Klymkowsky (2008) found that students understand chance as ineffective while biological systems are efficient, therefore chance to some degree is irrelevant for biology as it lacks the ability to produce complex outcomes. R. L. Robson and Burns (2011) used an inquiry-based approach to change students' teleological intuitions about biological change into recognition of the role of random variation. This involved replication of a historical experiment showing that bacteria can randomly acquire resistance to viral bacteriophages (the Luria-Delbruck experiment). The results revealed that students chose the correct Darwinian alternative more than twice as often in a post-test than in a pre-test. This improvement was unrelated to the students' religious conviction.

\subsubsection{Anthropomorphism}

The misconception of anthropomorphism refers to reasoning about other organisms by analogy to humans and human qualities (Coley \& Tanner, 2015). It is connected to teleological explanations and sometimes put together under the umbrella of intentionality (Harms \& Reiss, 2019). As already mentioned, our cognition evolved due to the selective advantages it provides in finding our way in the world as humans, and as the social primate we are, we understand the world around us in a frame of what it is to be human (inter alia: being aware of a self, feeling, thinking having desires, and making plans to reach goals).The ability to project these experiences to others is crucial for social animals whose survival may depend on its capability to cooperate with others. 
This tendency to ascribe intention to others may, however, lead us to do so inappropriately. It is, for example, common to hear in a chemistry classroom that an atom 'wants' to have an eighth electron in its outer shell. This is a misattribution of feelings to the atom. Sometimes it may not even be a physical actor/object that is attributed human qualities, humans are no strangers to the idea of metaphysical controlling agents like nature or life. For example, a common sentiment is that nature strives to maintain balance in an ecosystem, depicting nature as an agent with feelings or desires.

It should be noted that some authors have advocated lifting the taboo on teleology and anthropomorphic reasoning in biology education (Zohar \& Ginossar, 1998). They argued that learners would keep encountering such formulations in other sources even if they were eradicated from the classroom. In addition, some scientists promote the heuristic value of anthropomorphic and teleological reasoning. These scholars base their argument on empirical findings that when learners accept formulations of teleology and anthropomorphism in explanations it does not necessarily mean that the learners' reason in that way too. Furthermore, Zohar and Ginossar (1998) found that being taught with a textbook with anthropomorphic and teleological formulations did not cause increases in frequencies of students applying such formulations in their own explanations.

\subsubsection{Essentialism}

This represent the tendency to attribute an organism (or objects) identity and character to some underlying metaphysical property (Shtulman \& Schulz, 2008) Ignore the odd and emphasising the normal are functional elements of our cognition that help us organise phenomena around us (Coley \& Tanner, 2015). One important part of the argument by Darwin and Wallace was that natural selection works on populations, not individuals. In their text entitled "Two thousand years of stasis", Gelman and Rhodes (2012) point out that essentialism is rooted in the definitions of species used in taxonomy, leading scientists to ignore variation and observations of hybrids. In such a framework, where hybrids are treated as exceptions that prove the rule of a species, the mutability of species is ignored. This foster a perception of species as static, a view that was not challenged until the end of the $19^{\text {th }}$, century when thoughts regarding evolution of life on earth were taking form and humble suggestions of a mechanism that could explain this process were proposed.

In the context of evolution such an essentialist mindset may lead to the assumption that all individuals in a population get the same adaptations (Bishop \& Anderson, 1990). Students who did not recognise variability in animal traits also demonstrated an alternative understanding of evolution (Shtulman \& Schulz, 2008). Disregarding the odd cases as irrelevant, only focusing on the perceived essence, remove a fundamental part of the theory of natural selection(Gelman \& Rhodes, 2012). 


\subsection{Representing the model of evolution by natural selection}

The language Darwin used in On the Origin of Species (1859) was rich in metaphors. Coyne (2010) points out that in the totality of the volume, Darwin does not use a single equation. Numbers are unnecessary to clearly state the theory of evolution. Thus, someone who believes that science is all about numbers evolution can seem rather unscientific.

Language has been developed, through millennia for telling stories rather than expressing scientific theories (Bruner, 1986). Therefore, it does not naturally offer many resources for representing scientific explanations, especially complex dynamic phenomena. Indeed; "Darwin repeatedly uses anthropomorphism and teleological expressions" (Pramling, 2009, p. 542), although in a reflective way, commenting on potential problems of the metaphors. For example, the concept natural selection itself is a metaphoric application of the human action in selective animal or plant breeding (AlZahrani, 2008). In addition, 'Evolution by elimination' of the poorly adapted' may be better than 'Natural selection of the best adopted' (Mayr, 2004, p. 135), because in such an formulation might better reflect the process in most cases and potentially, there is a pedagogical gain in not using the word selection that indicates an active and directed process. However, it seems that metaphors are necessary; after all, what words can be used to describe what has never been described before?

Variation and probability are mathematical concepts that are needed to describe natural selection satisfactorily (Garvin-Doxas \& Klymkowsky, 2008). Words like adaptation and fitness appear both in everyday language and biology (Bishop \& Anderson, 1990), but with slightly different meanings. The ambiguity of words may create additional confusion when trying to learn a new, abstract concept like natural selection (Rector et al., 2013). "When biologists say that selection is acting on a trait, they are merely using shorthand to say that the trait is undergoing the process [of NS]" (Coyne, 2010, p. 117). How should we then distinguish between learners using these expressions metaphorically and literally? Using multiple representations is suggested to facilitate clarifying if teleological explanations are used metaphorical (Kampourakis, 2007).

\subsubsection{Visual representations of ENS}

It has been stated that visual representations are indispensable in biology as a science and in the education of it (Lynch, 1991; Treagust \& Tsui, 2013). However, Darwin did not use any visual representations of his theory when it was first published, words were all that he needed. This neglect of visual representations seems to have influenced biology education research today, although the possibilities to distribute visual representations afforded by new digital visualisation technologies of genetic, cellular and molecular biology-level phenomena are thoroughly exploited in the floods of research papers (S. W.-Y. Lee \& Tsai, 2013). Visual representations of macro-scale phenomena like evolutionary processes and their educational applications have received relatively attention, despite their potential utility. However, the public 
understanding of evolution is known to be strongly influenced by historical, preDarwinian imagery (Archibald, 2014). For example, $42 \%$ of undergraduate students asked to draw an image of evolution in a study by Matuk and Uttal (2012, p. 122) generated some variant of the iconic 'March toward Man' image. The perception that life evolves on a ladder, in a linear manner, is common and referred to as the great chain of being (Abrams \& Southerland, 2001).

However, Darwin did adopt the tree metaphor for representing the diversification of species from a common ancestral origin in later editions of The origin. In a study of visual representations in biology textbooks the most common representation was some form of cladogram (Catley \& Novick, 2008). They notated that no guidelines for how to interpret the diagrams was to be found in any of the 31 analysed books. Moreover, "The apparently linear views of human evolution in museum exhibits and in popular culture may have confirmed belief in a deterministic, progressive, teleological pattern of evolution-evolution with humans as its goal" (Clark, 2001, p. 1290). This was empirically confirmed by Matuk and Uttal (2012) who showed through interviews that a schematic cladogram presented to college undergraduates evoked a narrative mode of thinking that conflicted with the conceptual diagram's scientific meaning. Instead of portraying the relatedness of taxa, as intended, the cladogram was interpreted by the students as showing actors achieving goals, a sequence of transformative events, or a plot with a starting condition and determined end. This linear narrative interpretations of the complex relatedness of taxa can impede understanding of ENS and even reinforce misconceptions about evolution (Matuk \& Uttal, 2012). Changes along the vertical axis of the diagram (from the bottom to the top) fitted well with the idea of simple organisms evolving to become increasingly complex and well adapted. The students did interpret changes along the horizontal axis students as anagenetic (showing that species give rise to newer ones in a transformative linear manner across the branch tips). The diagonal line progressing onward and upward was given meaning in narratives of the type of a hero's journey, whereby a species through acts of will conquers challenges, overcomes hardship and emerges in a new more sophisticated form. Similarly, Catley et al. (2010) found that participating college students conceptualise the evolutionary process represented in noncladogenic diagrams learners encounter in biology textbooks and elsewhere, as either anagenic or teleological.

In addition, Matuk and Uttal (2012) found that directing students' viewing of a cladogram in animations (for example first showing the top with several species and then gradually revealing their common ancestry) led some students to adopt a narrative of a food chain or families grouping together. Interpretations of cladograms are also strongly dependent on viewers' visual literacy and prior knowledge. Novices will metaphorically map relational structures of their narrative understanding onto their spatial structure, while prior knowledge of the content and similar representational systems creates contexts for interpretation. Moreover, the intuitive symbolizations are flexible, which means that it is possible to learn to interpret cladograms correctly. 
Available visual representations of evolution, cladograms and phylogenetic trees, for example, can be difficult to interpret (Catley et al., 2010). However, a cladogram or phylogenetic tree is constructed to represent the history of the unity and diversity of living organisms, not the mechanisms responsible for changes in species (Matuk \& Uttal, 2012), at least not without supplementary information. Consequently, several misunderstandings related to the interpretation of temporal aspects of evolutionary trees have been reported (Gregory, 2008), and they do not seem to facilitate an explicit understanding of temporal aspects of evolution (Stenlund, Schönborn, \& Tibell, 2020). Recent developments have provided interactive digital trees that visualizes phylogenetic relationships between living and extinct organisms through an interactive multi-touch zooming interface where time is expressed explicitly at internal nodes. This application succeeded in providing information about relatedness, and the zooming feature offers a powerful interactive opportunity for communicating evolutionary time. However, time is not mapped onto any clear axis, which means that different branches appearing at the same vertical tree level do not necessarily infer a simultaneous occurrence. Consequently, the zooming did not lead to a full understanding of temporal aspects. In contrary, it in fact introduced new misinterpretations related to evolutionary time (Stenlund et al., 2020)

\subsection{Multiple representations in evolution education}

Although visual representations of macro-scale phenomena like evolutionary processes and their educational applications have received relatively attention, there are numerous representations of the mechanisms involved, including a plethora of animations and simulations available as educational resources on the internet. However they have diverse features and are not bound by disciplinary rules, as shown by Bohlin, Göransson, Höst, and Tibell (2017). They found that 60 animations available on the internet could be clustered into groups: one focused mainly on ecology and phenotypic level natural selection, and another focused on DNA and mutations (Bohlin et al., 2017). Very few detected online resources focused on relevant connections between levels of organisation.

One reported alternative to computer-based simulations and animations is a classroom experiment in which students build and study how organisms built of Lego-bricks evolve (Christensen-Dalsgaard \& Kanneworff, 2009). Each organism is built using six bricks with five 'alleles' (gene variants) coupled to morphological variation, represented by different colours of the bricks. The fitness of each organism (measured as mobility) determines its contribution to the gene pool for the randomly assembled next generation. This activity was included in a teaching and learning study where 18-year-old students engaged in laboratory tasks of artificial selection with a focus on connecting the genetic and phenotypic levels reported on increased coherence across levels in students explanations (Jördens et al., 2016). 


\subsection{Student generated representations of evolution}

Regarding the need for multiple representations to grasp ENS, (McLure, Won, \& Treagust, 2020) recently presented results of a study in which they applied a Thinking Frames Approach for teaching grade 10 Australian students ENS as an emergent phenomenon. In a three-lesson quasi-experiment they focused on social construction of understanding and consolidation of understanding through transfers between representations and oral, drawn and written explanations. The approach involved students generating explanations cooperatively during small-group work. The collaborative explanations were then presented to the whole class and the teacher Socratically challenged naive conceptions and encouraged an ontological shift from agent-based or purposedriven linear reasoning to a scientific emergent model (Chi et al., 2012). After this the students individually constructed pictorial and written explanations, in a sequence that included a pictorial timeline followed by a list of keywords to be used in an explanation in the form of a written paragraph. Finally, the students evaluated the success of their explanations, and learning gains were assessed using the CINS and the 'How did the cheetah evolve its speed?' question (Nehm \& Reilly, 2007). Overall, the authors found that their approach helped many students adopt population-based thinking about evolutionary change (McLure et al., 2020).

For dynamic mechanisms of evolution however dynamic representations might be suitable. The visual representation also offers a possibility to connect different special scales and organisational levels through for instance zooming. In a dynamic representation Time can be stretched out, and a fast process may be made perceptible in slow motion or time can be compressed so that slow processes can be studied in a faster tempo through time laps. However, studies on the use of stop-motion animations (SMA) in biology education either focuses on cellular level (Kamp \& Deaton, 2013) or the lifecycle of insects (Hoban \& Nielsen, 2013).

The fact that small, random changes in genes can affect the reproductive success of individuals so that over generations the relative frequency of certain genotypes change within a population leading to differentiation and speciation is of course complex. What scientists often do with complex issues is to make a graphical representation. Evolution biologists use cladograms. For dynamic processes and its' mechanisms like ENS however, dynamic representations might be suitable (Tversky et al., 2002). Since evolution works by small changes that accumulate over time and as stop-motion animators make things come alive through repeatedly making small changes to their models, the analogy seems almost too perfect. And yet, there are no studies on student generated animations of evolution, the central theory in biology. This thesis and accompanying studies aim at remedying this. 


\section{Chemistry education}

In a way, chemistry represents the essence of what it is to do science: wearing white lab coats, using goggles, and mixing stuff that changes colour and sometimes even goes Bang! But chemistry is also one of the more demanding subjects in science curricula. The difficulties begin when the colour changes and bangs have to be explained theoretically.

Besides being used as a caricature of science, chemistry has great impact on society and our everyday lives. Chemical technologies are a coin with two sides, first advances in chemistry provide substitutes for diverse natural substances and myriads of new materials that both have huge numbers of beneficial applications and pose serious risks. For example, artificial fertilisers both help efforts to feed billions of humans and can cause severe eutrophication of lakes and seas. Similarly, the creation of pesticides has provided new possibilities to fight disease-spreading insects and crop pests, but these new substances have opened possibilities for vast monocultures, and the spread of harmful substances with unpredictable effects on ecosystems. We all enjoy products made from new materials used in construction and consumer goods, but their production involves high energy consumption, health risks for the workers and pollution of our environment by substances that may decompose very slowly and/or release toxins when combusted. It is a complex situation as chemistrybased technology is causing major problems but understanding the principles of chemistry is an essential part of the solution. All this is true, however, the principles of chemistry form foundations of the scientific discipline chemistry and associated practices that generate knowledge, in the form of facts and theories that expand our understanding of, and ability to change, the world (Gilbert \& Treagust, 2009b). What we decide to do with this knowledge is up to us. However, in order to participate in a debate about how to use chemistry and chemistry technology in society chemical literacy is required.

"Chemical education involves an introduction to a core of ideas" (Gilbert \& Treagust, 2009b, p. 2). Among these are that all matter is particulate in nature, compounds consist of atoms of two or more elements, and there are both energetic and geometric barriers to chemical reactions. These core ideas can help explain the wide array of phenomena discussed earlier.

"If in some cataclysm, all of scientific knowledge were to be destroyed, and only one sentence passed on to the next generations of creatures, what statement would contain the most information in the fewest words? I believe it is the atomic hypothesis (or the atomic fact, or whatever you wish to call it) that all things are made of atoms- little particles that move around in perpetual motion, attracting each other when they are a little distance apart, but repelling upon being squeezed into one another. In one sentence, you will see, there is an enormous amount of information about the world, if just a little imagination and thinking is applied." (Feynman, Leighton, \& Sands, 1963, pp. 1-2) 
With a few theories, chemists can produce explanatory models for a wide field of applications. For instance, all the chemical reactions that occur in the world around us every second, in processes ranging from digesting breakfast to the corrosion of a bridge's girders, can be classified as representatives of just four types: sharing of electrons, sharing of electron pairs, transfer of protons, and transfer of an electron.

\subsection{Explaining chemical change}

Chemistry has roots in crafts such as, metallurgy, and glass making. In that respect it is appropriate that chemistry education focuses on practical laboratory exercises. Many of the names of compounds and elements still have names from ancient times, based on their colour. Through the diligent work of alchemists, new compounds were distilled and synthesised and a system of signs was developed to denote different substances. The philosophy and language of the alchemists have to some degree been inherited by modern chemists (Talanquer, 2007). However, the theories that could explain the experimental results began to form in the $17^{\text {th }}$ and $18^{\text {th }}$ centuries, with the development of atomic theory. One of the rejected ideas of what drives chemical reactions was the idea of phlogiston, a hypothetical material postulated to be a part of reactive substances that was transferred to the air during a chemical reaction. This could explain why the ash left after a piece of wood has burned wights less than the wood before the combustion. Through the development of more accurate analysis and synthesis methods, new experiments refuted this idea. The current scientific explanation for processes such as corrosion involves the theories that matter is composed of small particles called atoms, and chemical reactions involve the breakage and formation of chemical bonds driven essentially by differences in free energy (enthalpy and entropy) between possible states.

\subsection{Teaching and learning chemical reactions}

Chemistry education includes learning some of the basic techniques for separating, synthesising and analysing substances in the laboratory. Beside the practical skills for performing such procedures, learning about the observable aspects of phenomena is also challenging, since it involves relating the experienced phenomena in terms of observational descriptions using everyday language (e.g., a white substance, a colour change or bubbles) to abstract concepts such as substance, compound, chemical reaction and so forth.

It is difficult to imagine any phenomena at the level of atoms and molecules (Cokelez, 2012; Griffiths \& Preston, 1992; Harrison \& Treagust, 2002). These difficulties is rooted in a naïve realism, that imply that all that is worth knowing is perceptually perceptible, and that "explanations should be based on the analysis of perceptible features" (Talanquer, 2006, p. 813). Regarding models, the naïve realist view models as a close copy of the reality, not as a workable approximation there off. Hence, in a study of 12th grade student's conceptions about the character of atoms and molecules, 11 categories of misconceptions were found (Griffiths \& Preston, 1992). For example, interviewed learners described a mixture of water and other substances as meaning that the other 
substances are mixed in the water molecules, or attached to their surface. This indicates that students can be uncertain about the organisational levels of atoms and molecules, many simply tend to think of both as the smallest parts of matter (Griffiths \& Preston, 1992). In the same vein, Cokelez (2012) found that 12 and 13 year-old students thought that there is air between the nucleus and electron shells in an atom. In a concluding remark, Griffiths and Preston (1992) noted that several of these misconceptions parallel theories from the history of chemistry (like reported misconceptions in evolution education), including that shapes at a macro level reflect molecular shapes, that matter is continuous, and that the particles are alive.

Based on a review of the research literature, Talanquer (2006) categorised alternative conceptions about the sub-micro world of chemistry into five implicit assumptions of students, designated Continuity, Substantialism, Essentialism, Teleology, and Mechanical causality. The first two relate to the difficulties of conceptualising the invisible sub-microscopic world of atoms and molecules. Conceptions of substantialism are manifested in learners' attribution of material properties to abstract concepts, e.g., heat is thought to be a fluid, or chemical bonds are solid structures. Continuity (learners' frequent assumption that matter is continuous and similar at different scales) impedes learning about the canonical sub-microscopic structural models that are ubiquitous in chemistry. Instead of particles with atomic properties, learners holding this conception understand atoms as small pieces of matter with the same macroscopic qualities. For instance, almost $50 \%$ of $10^{\text {th }}$ grade participants in a study by Ben-Zvi, Eylon, and Silberstein (1986) thought that copper atoms share the properties of a copper wire, including its colour, high electrical conductivity, and malleability. From this it follows that atoms can change size when heated and they remain stationary when the entire object is not moving. A related conception is the idea that there cannot be any space between atoms in objects. For example, Griffiths and Preston (1992) found that when asked to draw several molecules, students made sketches of molecules with no space between them, indicating that they thought molecules of water are in contact.

The last three categories of alternative conceptions listed by Talanquer (2006) - Essentialism, Teleology, and Mechanical causality - have also been frequently encountered in studies of biology students' conceptions, as already discussed. Their manifestation in chemistry contexts is discussed in the following text.

\subsubsection{Essentialism}

This is the idea that "objects and materials in the world have an underlying quality or inherent essence" (Talanquer, 2006, p. 813). For example, sodium chloride should retain properties that are inherent qualities of sodium and chlorine, but this obviously impedes understanding of transformations of solid substances into invisible entities like gases through combustion, implying that matter is destroyed and not conserved. Similarly, the view may hinder understanding of processes such as photosynthesis, because bits of black carbon 
cannot be fixed from the air. As suggested by Talanquer (2015), essentialism is apparently a problematic conception in students' chemical thinking that needs to be replaced or developed into thinking based on variation and populations of atoms. Moreover, the conception of a metaphysical essence may contribute to the idea that atoms of copper share the same properties as the piece of metal, e.g. being malleable, conducting electricity and being copper coloured (Ben-Zvi et al., 1986).

\subsubsection{Teleology}

In chemistry, teleology is manifested in the idea that processes occur to meet some purpose or need - so systems change because they need to minimise energy. In a study where university students answered a multiple-choice test with causal and teleological statements about redox reactions, $80 \%$ preferred the teleological alternative describing electron exchange as driven by the reactants' need for stability (Talanquer, 2013). Furthermore, this commonsense view implies that objects and materials tend to exist in 'natural' states (normally stationary and inert). Only their abnormal properties and behaviours require explanations. However, some like to point out that teleological explanations provide a means to transform complex chemical formulations to simpler ones (Kampourakis, 2007) and so can function as educational tools. Similarly Talanquer (2007), argued that teleological explanations can have heuristic value in chemistry education. Nevertheless, the frequent explanation that atoms form bonds to satisfy the octet rule in many cases can be misleading (Özmen, 2004).

\subsubsection{Mechanistic causality (Anthropomorphism)}

This refers to the idea that an active agent is needed to bring about a change in a system. So, for example, in a reaction between an acid and a metal the acid attacks the metal. By inventing an active agent, the learner ignores the mutual exchange that occurs in a chemical rection. When asked about the properties of a water molecule, half of the students interviewed by Griffiths and Preston (1992) explained chemical change in a way that the researchers thought suggested that atoms are alive. The idea that sub-micro particles should have any intentions or desires are in direct conflict with the mechanistic causal model adopted by chemists.

\subsection{The chemistry triplet}

Since chemistry is a domain of science that is concerned with small atoms and their interactions, chemical processes act on spatial scales that are imperceptible to the human senses. Ways to represent such processes are intertwined with the models chemists use to understand, explain, and communicate them (Kozma et al., 2000). For these purposes, chemists through the centuries have used representations developed by their predecessors and when those old representations have been found wanting, the chemists have invented new forms of representation that could convey their new ideas. Moreover, as the science of chemistry expanded subfields emerged, with requirements for representations to convey different information. Due to this 
fragmentation a carbon atom can be represented in several ways depending on whether it is produced by (or for) biochemists or physical chemists, for example. The technical vocabulary and other symbolic representations connecting the sub-microscopic and macroscopic conceptualisations are results of this epistemic work by generations of chemists.

One model for describing chemistry and the relationship between observable phenomena and explanations at the atomic level presented by Johnstone (1991), is the notion that chemistry involves three levels of knowledge: a descriptive (macro)level, a symbolic level, and an explanatory (sub-micro) level. This model has been widely adopted in chemistry education research and used in curriculum projects. It is now widely accepted that learning chemistry involves learning to identify and understand the meaning of each of these levels, as well as their interrelations, i.e., to represent and translate chemical problems between the levels of the chemistry triplet (Gilbert \& Treagust, 2009b; Johnstone, 1991; Kozma \& Russell, 1997). However, Taber (2013) argues that the three levels are not as distinct from each other as suggested by the model. First, the macro level can refer to both the chemical phenomena studied in chemistry and the concepts used to formalise knowledge about those phenomena. Second, the symbolic level is not distinct from either the macro or sub-micro levels (Taber, 2013). In order to address these two problems, Taber (2013) elaborates upon Johnstone's model and, instead of the symbolic level, introduces an experiential level, allowing the symbolic level to instead form a bridge between the macroscopic and sub-microscopic conceptualisations of chemical phenomena (Fig. 1).

Hence, learning chemistry involves learning to coordinate understanding at two levels: to 'see' something as something specific in relation to a macroscopic framework of theoretical concepts, and as events at the sub-microscopic level explained by theoretical models. For these reasons, development of the ability

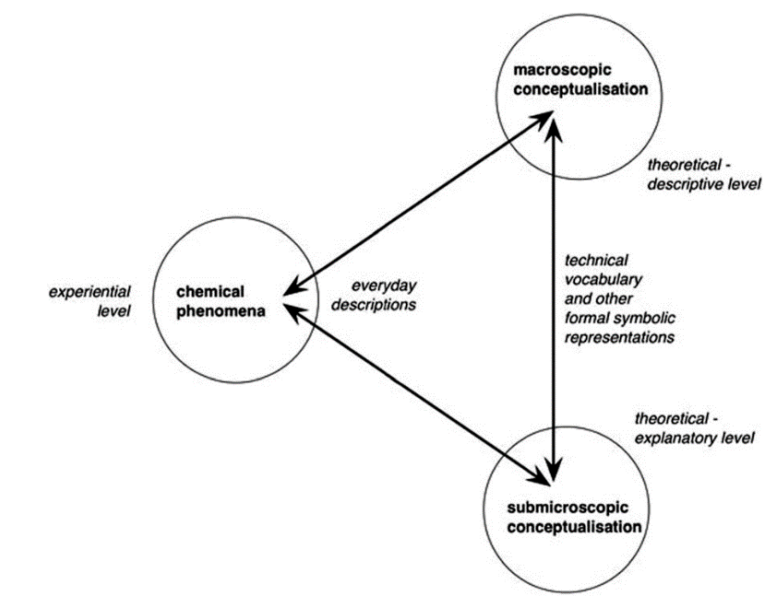

Figure 5. A revised model of the three levels of chemistry (Taber, 2013)

to coordinate phenomena associated with the sub-microscopic world of atoms 
and the macroscopic world of humans is crucial in learning chemistry. Moreover, similarly to the organizational levels of biology, chemists need to be clear about the level that their reasoning concerns. For instance, it is important to clearly distinguish between the metal silver, a silver atom, and the colour silver (like the importance of clarifying whether cheetah refers to a single animal or the entire species). Interestingly, (Cokelez, 2012) found that students aged 12-13 years preferred detailed abstract representations to simplified ones, possibly at least partly because it avoids some of these potential problems.

Further difficulties for learners are posed by distinguishing between physical change (e.g., melting) from chemical change (e.g., corrosion). Superficially there is no way for a novice to distinguish these processes as the two types of changes may appear equally dramatic (or mundane) as both result in a 'new' type of matter. We can only see that there is a difference between the two processes when we apply prior knowledge about the sub-micro models of the substances involved, and the conceptual difficulties are increased when notions of protons and electrons are introduced (Talanquer, 2018).

\subsection{Time}

The explanatory foundations of chemistry concern sub-micro level phenomena an include theoretical models of abstract particles, describing properties and interactions of atoms, ions, molecules, and electrons. One important feature of this world is that sub-micro particles are dynamic. Atoms and molecules move and react with each other very rapidly. However, students tend to think that particles in solids are static and only move if the object is moved, or that molecules in gases float in the air much like a small piece of dust (Özmen, 2013). Unlike evolution where time is relevant at both short and long frames, chemistry explanations are mostly limited to the very short timescales.

\subsection{Understanding symbolic representations of chemical reactions}

The central phenomena in chemistry are processes of chemical changes. These are represented by the ubiquitous chemical equations, which are so familiar to the science teacher (and other experts) that they may underestimate the abstract and complex nature of this representation of a chemical change (Taber, 2009). This familiarity with the subject and conventions enables experts to look beyond the symbols and make sense of the representation, not solely the presented information. For chemistry students, this is one of the most demanding systems of symbolic representations, where a number of interlocking conventions apply (Taber, 2009). These equations have both specific symbols and a formal grammar that make learning to understand and use them much like learning a language.

Furthermore, like the invisibility of evolutionary mechanisms in the intradisciplinary representations of cladograms, the mechanisms of particles moving in chemical reactions are hidden behind the arrow in a chemical equation. The arrow is also a common representation of direction, purpose and progress that fits a teleological frame of reasoning (Talanquer, 2007). This is not problematic 
if the learner conceptualises the representation as symbolic, because (s)he can then use it as a model for reasoning about chemistry. However, this is unlikely to be the case unless (s)he gets to practice reasoning with and through representations.

To use the language of chemical change a learner needs t: learn which symbols are allowed and what they represent, understand the grammar of the chemical language, and know enough chemistry to separate true reactions from those that would not be feasible (ibid.). In addition to learning the symbols and grammar to make sense of what is signified by a chemical equation, a learner must grasp grips how matter is conserved in reactions, how energy changes can be represented, and as if this were not enough, in organic chemistry and redox reactions, electrical charge must be balanced! Consider the following example:

$$
\mathrm{Mg}->\mathrm{Mg}^{2+}+2 \mathrm{e}^{-}
$$

The represented 'half reaction' (a special form of reaction used to represent oxidation) results in products including free electrons which could never occur in normal chemistry. The learner is expected to understand that this does not represent a stand-alone process and that it must be coupled with a matching half reaction that results in a negatively charged acceptor of the released electrons, as part of a redox process.

Different dialects of this symbolic language have developed in different disciplines of chemistry, each focusing on specific types of compounds or processes, contributing to an apparent arbitrary use of symbols. For biology students it is even more confusing. Chemical equations like these are used, but as the communicative needs of biologists differ from those of chemists, the symbols are modified and what they signify can be hard to understand if you have just learned the basics of representing inorganic redox reactions.

As we can now see, interpreting chemical equations representing redox reactions is not a simple feat (Delisma, Wiji, \& Widhiyanti, 2020). As they occur at the sub-micro level, chemical reactions must be visualised, rather than observed.

\subsection{Student generated representations in chemistry}

In chemistry, several studies have shown that generating drawings of chemical processes at the sub-microscopic level can help students to interpret visualisations, make connections with prior knowledge, and promote understanding and model-based reasoning (Ainsworth et al., 2011; Akaygun \& Jones, 2014; M. M. Cooper, Stieff, \& DeSutter, 2017; Zhang \& Linn, 2011). It can be argued that chemistry learners are already required to generate representations of chemistry concepts, but according to (M. M. Cooper et al., 2017) this is more for copying and memorising canonical representations than for promoting students' model-based reasoning. They showed that if sketching is centrally integrated into classroom practice (rather than introduced as a separate, isolated activity), it can support model-based reasoning. 
Davidowitz, Chittleborough, and Murray (2010) came to a similar conclusion in a study with almost 400 South African first year university students learning chemical equations through interpreting and constructing diagrams of chemical reactions. The student's development of conceptual understanding of chemical reactions and stoichiometry was monitored with tests throughout a semester. The students-generated diagrams representing phenomena at the sub-micro level and related them to chemical equations at the symbolic level. The studentgenerated diagrams were shown to be useful tools for solving problems, recognising misconceptions, and making the students recognise the value of multiple representations of chemical reactions. They provided a more complete picture of the reactions than the formal equations, thus affording a deeper conceptual understanding.

\subsubsection{Student-generated animations in chemistry education}

Studies of students generating their own animations indicate that this helps students to explore the sub-micro world mainly in two ways. First, it provides a means for engaging with the dynamic features of chemical reactions (e.g., Akaygun, 2016). In a comparison of $10^{\text {th }}$ and $11^{\text {th }}$ grade students' static and dynamic representations of atomic structure, participating students were introduced to one of three animation software packages for representing atoms. Before and after generating an animation, the students were asked to draw the structure of an oxygen atom. Analysis of the drawings revealed that all groups generated more refined representations, with more dynamic features, after they had designed the animation. Interestingly, the student generated animations revealed misconceptions that was not manifested in the static drawings (Akaygun, 2016).

A study with year 11 Turkish science students also showed that representing submicro level conceptualisations in an animation provides opportunities to represent and discuss dynamic aspects. The students were divided into groups of three and explored states of matter through generating animations, using KSketch. With scaffolding from the teacher, the students were able to generate accurate representations of solids, liquids and gases (Yaseen, 2018).

Moreover, use of animations can help students to develop descriptions of the particulate nature of matter (and concepts such as substance, mixture and, phase changes). For example, Chang et al. (2010) investigated if designing and evaluating molecular animations of chemical phenomena (using the Chemation software) promotes students understanding of the particulate nature of matter. Seventh-grade students (247) were divided into three groups, one of which designed, interpreted, and evaluated animations, another designed and interpreted animations, while the third group only viewed and interpreted animations. Assessment of their learning, measured by pre- and post-tests, revealed that designing and viewing animations was less effective than just viewing animations. However, designing coupled with peer evaluation was the most effective for developing the students' understanding of the particulate nature of matter. Schank and Kozma (2002) asked students to generate 
drawings and animations cooperatively and videotaped the following sessions. From subsequent analysis of student interactions during the videotaped sessions, the authors concluded that generating animations required the students to consider sub-micro level aspects (e.g., the number of molecules involved, or the sequence of steps in a reaction) in a way that they would not normally do.

Clearly, generating animations can help students to visualise important aspects of sub-micro phenomena. However, in order to make sense of chemistry, a learner also must be able to make connections between the different levels described in the chemical triplet (Johnstone, 2010; Taber, 2013), and there are indications that animation may encourage students to link different levels of explanation of chemical phenomena. For example, in a study by Chang, Quintana, and Krajcik (2014), $7^{\text {th }}$ grade students were encouraged to create either animations or static visualisations of chemical reactions at the sub-micro level to compare the effects on conceptual understanding. The results showed that only eight (of 30) students were able to connect their molecular visualisation with focal macro-level phenomena. Notably, students who had chosen to generate dynamic visualisations outperformed those who had chosen static visualisations on linking sub-micro processes and macro-level phenomena. The authors concluded that this indicates that lack of a dynamic view of sub-micro processes may affect the ability to make connections between sub-micro visualisations and macro phenomena.

The results of Chang et al. (2014) are corroborated by an analysis of senior high school students' conceptual learning while creating animations of phase changes. In their animations, the students tended to focus on either the macro or sub-micro level, but rarely used representations of both levels in a single animation, despite being encouraged to consider it (Albert, 2012). This points to students' difficulties in relating observed phenomena to theory.

\subsubsection{Generating stop-motion animations: a collaborative task}

Another important aspect of student-generated animations in chemistry is the peer interaction it affords in the classroom. Yaseen (2018) and Yaseen and Aubusson (2020) argue that peer interactions contribute to learning about states of matter at the sub-micro level through cooperatively generated animations. In a study of collaborative student-generated SMAs animations of chemical processes Wishart (2017) found that that opportunities for peer discussion that arose during the animation process were valued as the most important learning activity by the students. Content analysis of the students' discussions showed that the main topics concerned how to make the animation (debating the best way to represent the science concept being modelled), followed by the science behind the concept. Wishart (2017) concluded that the animation task forced students to think through the concept from these two perspectives, which prompted discussion. However, she did not analyse or discuss whether the task led to learning at the sub-micro level and/or its relation to observed phenomena (no experiments were conducted in the study). 
Yaseen and Aubusson (2020) present a closer analysis of discussions when students watched each other's animations and critiqued expert-made animations, a learning situation in which the students asked questions, clarified, and explained their ideas. The cited authors found that the imperfections and errors often stimulated most discussions and learning opportunities. 


\section{Crosscutting perspective across evolution and chemistry}

The above reviews of research on evolution and chemical education indicate that both are hampered by similar misconceptions, including ascribing intentions to non-sentient entities in the forms of teleological and anthropomorphic conceptions (Harms \& Reiss, 2019; Talanquer, 2013). Furthermore, there seem to be connections between essentialism in both biology and chemistry (Coley \& Tanner, 2015; Talanquer, 2006).

If the same type of misconceptions figure in different areas of science, causes of the difficulties may be found at a cross-cutting level that spans different types of content. That is why the interpretation of threshold concepts by Tibell and Harms (2017) is interesting. As already discussed, they propose that the trouble learners encounter when learning about evolution can be related to four suggested threshold concepts: randomness, probability, time, and spatial scale. As these concepts are connected not only to ENS but also concepts of numerous other processes, they may potentially influence understanding of other scientific topics, for example chemical reactions. Of the four proposed threshold concepts, reasoning about levels of organisation and time have been shown to be facilitated by multimedia representations (Mayer, 2005), thus they were particularly interesting in my doctoral work. The roles of randomness and probability have been explored previously within the EvoVis project (Fiedler, Tröbst, \& Harms, 2017), so the focus here is in time and spatial scale.

The two topics of evolution through natural selection (ENS) and chemical redox reactions are good candidates for scientific content to explore roles of organisational levels in space and time in students' explanations, and how the multimedia format of stop-motion animations (SMAs) can stimulate and/or obstruct the generation of explanations. Both topics that concern systems with numerous interacting variables that may be spread across space and time, without simple direct cause-effect relationships within the normal perceptual range of time and space. They also both concern dynamic processes involving events at multiple organisational levels, in which causes, and effects are often separated by scale or time. In short, the topics are complex (Grotzer, Derbiszewska, \& Solis, 2017) and have features that visual representations can help reasoning about (Gilbert, 2005; Phillips et al., 2010).

Both chemical reactions and ENS occur in timeframes that are beyond our daily experience. Thus, one challenge for students trying to portray either of them in an animation in both cases is to alter the rate of the events so they can be perceived by a viewer of the animation. In chemistry the trouble with the atomic level is that things happen rather fast, but the effect on the level of the nail corroding may take several days. In a parallel biological problem, some new genetic variation may arise at fertilisation of eggs of a sexually reproducing organism but become important later in the lives of the resulting offspring. Moreover, consequential adaptations in the population may only become readily apparent after generations, a timeframe far beyond the length of an animation. This leads to a problem of transforming time into something meaningful to the 
viewer, requiring specific solutions for each topic as the processes are similar but not the same.

There are also challenges with spatial scales in both topics. Within our perceptual range, variation between individuals in a population can be observed, but this variation is caused by sub microscopic, molecular-level processes. Making connections between macroscopic and sub-microscopic levels is similar when chemical reactions are to be represented. In evolution additional challenges occur on the other side of our perceptual range, as populations and species rather than individuals are the objects of evolution. This makes the problem of connecting different special scales, in the same way as time, similar but not the same in the two cases.

However, within their disciplines, both ENS and redox reactions are communicated with representations that are difficult for learners to comprehend. Both are processes that are canonically represented by arrows or lines within their respective disciplines: the chemical reaction diagram with chemical symbols and an arrow representing the process is analogous to the representation by a simple line of the complex process of speciation in a cladogram illustrating biological evolution. The chemical equation is too abstract for many learners to create an understanding of the processes in the chemical reaction that the arrow represents (Taber, 2009). Similar challenges for learners are posed by the lines of evolutionary diagrams (Gregory, 2008), which college students reportedly interpret as representing evolution as teleological (Catley et al., 2010). This indicates the need to introduce complementary representations in education (Davidowitz et al., 2010), including encouraging students to generate their own representations of scientific models, such as SMAs.

That similarity of misconceptions displayed in different disciplines of science, here biology and chemistry, indicates that the misconceptions originate from how learners apply informal, intuitive ways of thinking about the world, so called cognitive construals (Coley \& Tanner, 2015), in a manner that is inappropriate in a formal science setting. In this argument Coley and Tanner (2015) align with those that argue that misconceptions are caused by coherent cognitive frameworks. However, the data on the character of knowledge in the brain is inconclusive, and others pertain to the hypothesis that learners generate explanations based on dynamic, fragmented pieces of knowledge (diSessa, 1993; Gouvea \& Simon, 2018).

If the same misconceptions appear in different tasks, this would talk for the framework perspective (Chi, 2008). One way to shed empirical light on this question would be to compare the consistency of the alternative conceptions displayed by students by changing the task context. Land and Meyer (2010) argue that applying the threshold concepts framework in assessing learning can reveal variation in the progression pathways of learners. They raise the need for new creative methods of assessment and alternative ways of visualizing learning that enable us to move away from ways of assessing that allow students to 
produce the right answer while still holding fundamental misconceptions (Land \& Meyer, 2010). It is possible that the proposed thresholds open up this way of explaining the world (Tibell \& Harms, 2017).

One further way of probing the depth of the learner's conceptions would be to change the mode of representation (Kampourakis, 2007). While scientists and science educators use graphical representations to handle complexity and clarify connections that would be hard to communicate using only words or numbers, students are rarely given the opportunity to communicate using multi-media. Pedagogues often use various graphical representations to help learners grasp important concepts, but students are encouraged to generate such graphical representations to develop and communicate their understanding to peers and teachers less often, and generally (if at all) in later educational stages, when the difficult concepts are usually introduced.

Thus, in my studies I explored the potential utility of student-generated SMAs for teaching and learning ENS and chemistry, paying particular attention to the mentioned threshold concepts. This involved setting students' ENS and chemistry tasks, which were similar in that they both included creation of a representation of a process in an unconventional way. However, there are also fundamental differences in ways that the process of evolutionary change leading to adaptation and chemical oxidation can be visualised using this animation technique. 


\section{Methods}

This section outlines how I addressed the research questions stated in section 1.3. The work evolved from the original wondering about why some concepts in science are so arduous to learn and how some of the challenges could be overcome. My evolving understandings led to new questions, branching out in a tree of investigations. Some branches have led to manuscripts that can be found in the wild ecosystem of science education literature, while others are yet to be written about.

\subsection{Methodological approach, design-based research}

To explore the issues and address the research questions described above, an approach loosely based on design-based research was chosen, partly because an important objective of both my studies and design research is to solve problems in practice (McKenney \& Reeves, 2012). I strongly share the aim of the initiator of design-based research, Ann Brown, stated in the description of her work as "intended to transform classrooms from academic work factories to learning environments that encourage reflective practice"(Brown, 1992, p. 174).

One trait of design based research is that it is interventionistic (Cobb, Confrey, diSessa, Lehrer, \& Schauble, 2003) which the studies in this PhD-work also have been. However, lacking a long-term collaboration with practicing teachers to develop a teaching learning design with, it might be more appropriate to view this work as a series of naturalistic case studies (C. Robson, 2011) applying a variety of data collection and analysis methods. Inspired by the design-based methodology.

For the two of the data collections (DCs 2 and 3), I created interventions and applied them in practice in order to give students the opportunity to communicate their understanding using the dynamic multimedia format that the student-generated stop-motion animations (SMA) approach afford. Would it be feasible in a secondary school classrooms and what measures would have to be taken to make it so? The intervention in this case was to ask students to generate animations to explain a science concept. Additional interesting issues that emerged included how an approach to teaching such as this changes discussion in the classroom and what type of learning it afford.

In the next two data collections (DCs 4 and 5) there was a shift in focus, from the outcome of the intervention to what changes aspects of the setup of the intervention that could modify the outcome. In these rounds, the SGSMA approach was integrated into a course in which I at least partially acted as a teacher, as well as a researcher, thereby adopting elements of action research (C. Robson, 2011). However, the research was still driven by the same interest as that of many design-based researchers, "to investigate the possibilities for educational improvement by bringing about new forms of learning in order to study them" (Cobb et al., 2003, p. 10). Furthermore, the research had an iterative, reflective, and practice-oriented nature, which are also features of much design-based research. 
In studies of learning and how to support it numerous factors should be considered, including for example tasks, tools provided to tackle the tasks, and norms of participation. This multitude of factors has been called a learning ecology (Cobb et al., 2003). When planning a design-study the researcher confronts the same issues as all educational scholars trying to make sense of a multi-faceted phenomenon such as leaning. These can be boiled down to two main methodological issues to resolve. The first issue whether a laboratory or classroom setting should be used. A laboratory allows isolation and detailed study of variables, while a classroom allows study of complex social interactions and naturalistic phenomena. Brown (1992) concludes that the two approaches provide complementary information, both can lead to theoretical advances, and neither is more correct than the other. The chosen setting needs to be described together with the results. The second issue Brown (1992) raises is whether to include small or large samples in a study. The optimal choice depends on what the aspiring researcher is planning to study. A small sample allows close attention to each subject's characteristics, while large samples enable more general analysis of selected factors' effects (and hence whether qualitative or quantitative methods should be used). According to Brown (1992) neither

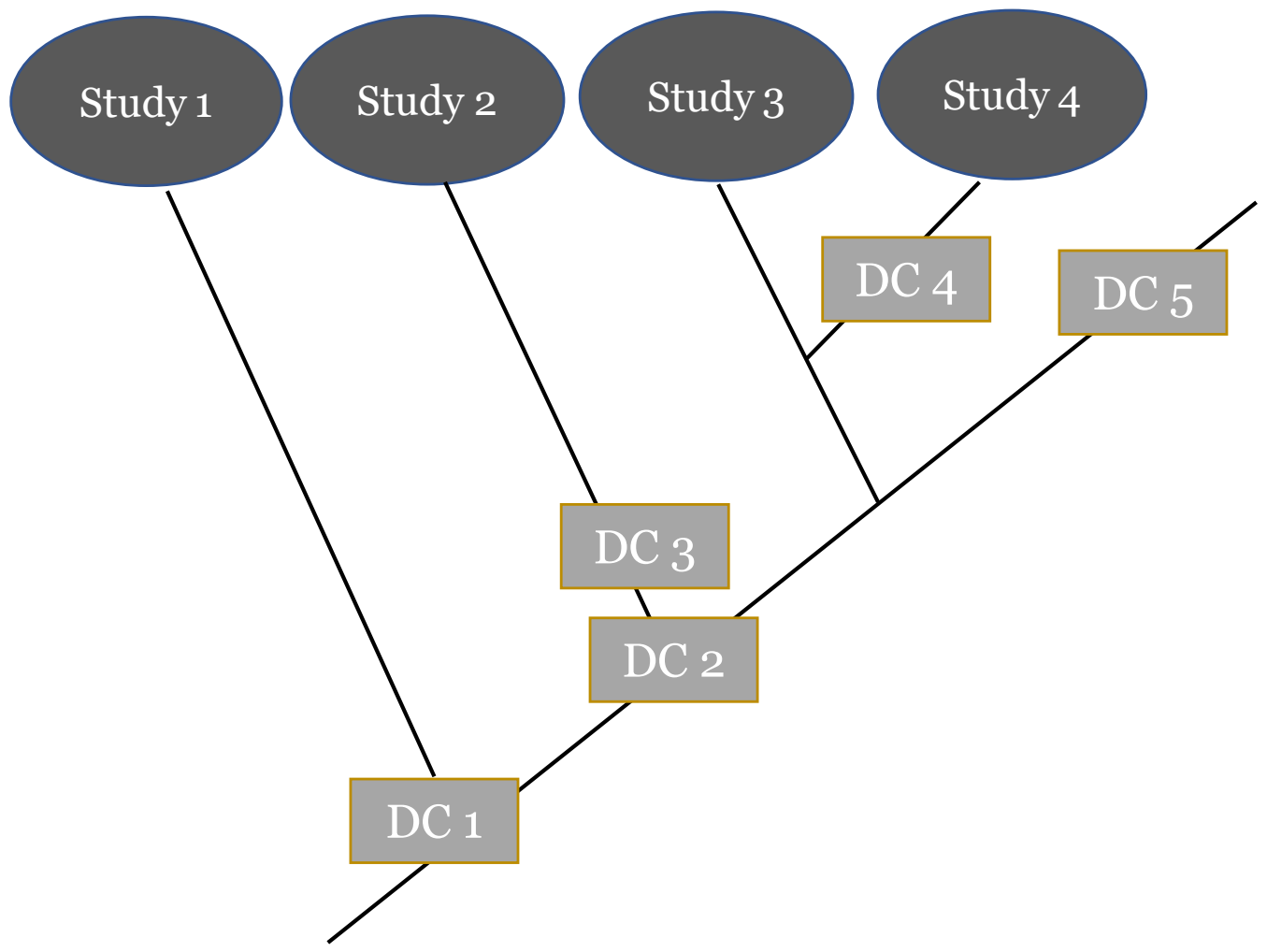

Figure 6. Cladogram representing the work underlying the thesis, which encompasses five rounds of data collection (DC1-5) and four studies. Data collected in DC1-4 have been analysed in studies designated Studies 1-4, which are appended this comprehensive summary. Data from DC5 was partly lost and constitute a barren branch in this tree. 
option is superior to the other. Instead, embracing the strengths of each and combining them in a mixed methods approach is often optimal. Combining results from testing and case studies allows the researcher to make stronger claims about the results of the design.

A criticism of the design-based research approach is that it does not have a welldefined methodology (Prediger, Gravemeijer, \& Confrey, 2015). Its proponents have responded that there is a core of methodologies that unifies design-based research, and have suggested lists of commonalities (Cobb et al., 2003). However, some still frown upon the idea of having their research being put in a box and point out that despite attempts like that by Cobb et al. to summarize the ingredients of design-based research, it lacks a single generally accepted description (McKenney \& Reeves, 2012). Moreover, perhaps there should not or cannot be a single description of an approach aiming to capture as much as possible of the complex processes and interactions that occur in different classrooms.

\subsection{Overview of data collection and manuscripts}

The following subsection outlines the evolution of the work underlying this thesis. As shown in Figure 6, data collected in four rounds (designated DC1DC4) were considered in four studies (Studies 1-4). Data collected in a fifth round (DC5) have not been published. Studies 1 and 2 focus on students' conceptions and ways of testing them, and are thus placed together to the left, as in a biological cladogram. Studies 3 and 4 address the process of generating SMAs from a meaning-making perspective and are thus placed to the right next to each other. Continuing the biology analogies, Studies 1 and 2 reside in one habitat, while Studies 3 and 4 reside in another part of the science education ecosystem. Some of the data collected in $\mathrm{DC}_{5}$ fell victim to a hard drive crash, a catastrophe that often causes extinction of data. Homologies, convergences, and important divisions between these studies are treated in more depth in the following Results and Discussion chapters.

\subsection{Rationale behind and descriptions of the data collection rounds}

The collections of data have been carried out over a period of three years, with five groups of students (ranging from 14-year-olds to university students). Methodologically, the first data collection round clearly differed from the others as it was an online survey, whereas the following data collections were teaching interventions. Each following round of data collection addressed aspects of student generated animations, but with a slightly different designs (Table 2) as each round prompted modifications in the following round. The context and execution of each data collection is described in detail below. 


\begin{tabular}{|c|c|c|c|c|c|c|}
\hline 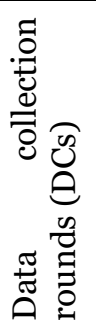 & 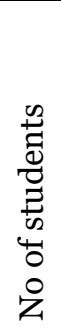 & हैं & 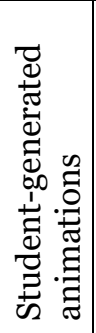 & Written tests & Video recordings & Interviews \\
\hline $\mathrm{DC} 1$ & 86 & ENS & No & $\begin{array}{l}\text { Online } \\
\text { questionnaire: } \\
\text { Multiple choice and } \\
\text { open questions. }\end{array}$ & No & No \\
\hline $\mathrm{DC} 2$ & 19 & ENS & Yes & $\begin{array}{l}\text { Pre- and post-tests: } \\
\text { Multiple choice and } \\
\text { open questions }\end{array}$ & $\begin{array}{l}\text { Yes, animation } \\
\text { workshop }\end{array}$ & $\begin{array}{l}\text { A few students } \\
\text { were } \\
\text { interviewed six } \\
\text { months after. }\end{array}$ \\
\hline $\mathrm{DC}_{3}$ & 39 & ENS & Yes & $\begin{array}{l}\text { One open response } \\
\text { item as post-test }\end{array}$ & $\begin{array}{l}\text { Yes, group discussion } \\
\text { about storyboards. } \\
\text { Animation workshop. } \\
\text { Group discussion when } \\
\text { viewing animations. }\end{array}$ & No \\
\hline $\mathrm{DC}_{4}$ & 26 & Redox & Yes & & $\begin{array}{l}\text { Yes, laboratory, } \\
\text { storyboard, animation } \\
\text { workshop and } \\
\text { presentations }\end{array}$ & No \\
\hline $\mathrm{DC}_{5}$ & 37 & ENS & Yes & $\begin{array}{l}\text { Pre, mid and post } \\
\text { tests }\end{array}$ & $\begin{array}{l}\text { Yes, recordings were lost } \\
\text { in a digital incident }\end{array}$ & $\begin{array}{l}\text { Yes. } \\
\text { Recordings } \\
\text { were lost in a } \\
\text { digital incident }\end{array}$ \\
\hline
\end{tabular}

In design-based research experiments and explorative studies there are general recommendations, which I followed, to collect various kinds of data (Cobb et al., 2003). Throughout my doctoral work an approach for collecting several different types of data was applied (Brown, 1992). The student-generated animations were important sources of data. Beside video recordings of the work involved in generating the animations as well as the whole class presentations and discussions of the finished animations, pre-and post-tests applied to document conceptual development. The students were asked to complete written evaluations after DCs 2, 3, 4, and 5. Observations and reflections of the researchers attending the individual interventions provided supplementary data.

\subsubsection{Data collection round 1}

The question in what ways representing troublesome science concepts through generating stop-motion animations could be useful in science education arose from the engagement in the EvoVis project (Swedish Research Council, grant number 2012-5344). This project aimed at enhancing understanding of evolution by visualisation (Evo Vis) by challenging threshold concepts in the life sciences (Tibell \& Harms, 2017) by exploiting known advantages of multimedia for learning (Mayer, 2005). 
At the outset of the project there were needs to find and develop tests that could be used for assessing students' use of threshold concepts in reasoning about evolution by natural selection (ENS). A substantial number of studies investigating students' conceptions ENS were reviewed and test items were collected. The statistical concepts randomness and probability were given particular attention and a battery of test items was developed by the research group. Complemented with the existing probes from the open response instrument (ORI) (Nehm \& Reilly, 2007) the probes we developed were piloted in an on-line survey with secondary and university students from Sweden and Germany. The survey was accessed via a web address, where all the entered answers made up a data base for the researchers to explore. The sample collected in Sweden were distributed through the research groups' network of contacts and was completed voluntarily and anonymously by the participants.

The study aimed to explore whether commonly used assessment items also elicit threshold concepts in students' explanations of natural selection and to characterize the way students expressed those threshold concepts. A subset of the survey with open ended questions about three different cases of evolutionary change (Antibiotic resistance in bacteria, Cheetah running speed, Loss of sight in cave salamanders), produced by 247 university science students, were picked out for analysis and is presented in Study 1. The qualitative analysis of the students' explanations showed that small proportions of them explicitly used the proposed threshold concepts when generating written explanations of evolutionary change. The use also varied depending on the context of the explanation. This finding motivated me to explore if the pattern would be different if the students could use multimedia to express their understandings. In the following studies the affordances and constraints of using the medium of stop-motion animations for communicating evolutionary change and chemical reactions were explored.

\subsubsection{Data collection round 2}

Information gleaned in DC1, together with the reviews of tests and ways to visualize ENS initiated another branch of investigation, concerning how students themselves would visualize ENS. Inspired by a paper describing how students could represent their understanding of scientific concepts through creating stop motion animations (Hoban, 2007), the potential of student generated stop-motion animations (SMAs) aroused my curiosity. If writing explanations of evolutionary change were notoriously troublesome and gave varied results over different task contexts, what would student-generated multimedia representations of ENS look like? How would a change of format effect the patterns of explanations? To address these questions, a class of 19 upper secondary students was invited to create expository animations of evolutionary changes at a media education centre that regularly invites classes to create SMAs. The animation task became a complement of their regular biology course. 
The intervention in DC2 began with a pre- test on the participating students' understanding of ENS and some questions on their experience of working with digital media. The educators at the media education centre gave the students 15 minutes instruction on how to generate SMAs and provided technical support. In line with one of the goals of a representation-construction approach, to practice science communication/reasoning (Prain \& Tytler, 2012) the participating students in my study were divided into small groups of 2-5.This decision was endorsed by the media educators working at the centre. Knowing how much work is needed to make an animation, working in groups is vital to be able to generate an animation with any substantial content. A further benefit of students working in groups is that it permitted acquisition of hopefully interesting data on students' interactions while they discussed the work. However, from a research perspective it also introduces the challenge that it is difficult to assess the contribution and knowledge of each individual student. For this purpose, activities and interactions of some of the student groups were recorded during the animation workshop by two digital video cameras filming each group from different angles, with built-in microphones capturing the sound.

Each group was asked to represent natural selection by producing a SMA. The task was formulated as follows "Organisms can undergo evolutionary change. Generate an animation that shows how this process works." It was up to the students to choose one or more organisms, materials, story and context, and the intended audience consisted of peers in a parallel program who did not take the biology course. The following day they showed their animations in a movie theatre. For this premiere they were supposed to prepare a presentation of their idea and describe what they were satisfied with about their animation and what was difficult to show. The presentations were intended to provide opportunities for the students to discuss ENS and the difficulties of representing the process, but the students' presentations were brief and with lacking substance. They may have been allowed too little time for preparations.

The whole class also completed a post- test and evaluation (Fig. 7).

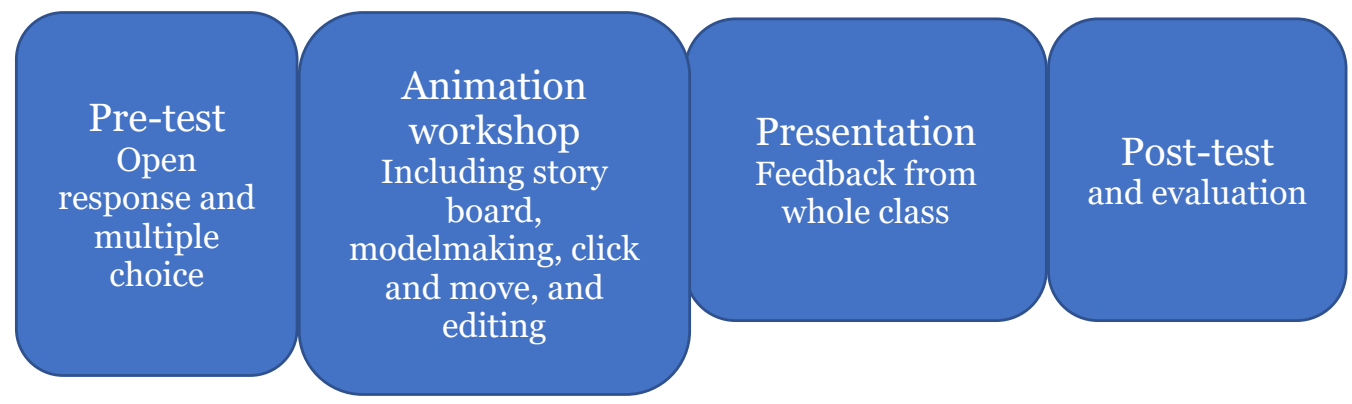

Figure 7, The outline of data collection round 2

In summary the data sources included: test results, written evaluations, studentgenerated animations, video recordings of four groups generating SMAs, video 
recordings of presentations and video recordings of interviews with four individual students. The analysis of the animations is presented in Study 2 and the recorded animation workshop is presented in Study 3 and in the result section.

The evaluation the students completed after the project showed that they enjoyed the intervention and it differed from regular lessons. Analysis of the animations' ENS content and comparison with the students' written explanations revealed that the collaborative SMA method afforded the students to represent key-concepts to the same or slightly higher degree than individually addressing traditional, open response items. Encouraged by this finding, another data collection round that could provide more animations was planned.

\subsubsection{Data collection round 3}

For this data collection round a larger group of students (39) from a private school was recruited. These students, like those engaged in $\mathrm{DC} 2$, were attending the national science program, year one of upper secondary school. The instruction of the task was the same as in the previous round, and they generated animations in a three-hour workshop in cooperation with of a media education centre. The task was a part of their school day, during the time scheduled for biology lessons. One factor that may have affected the students' engagement with the animation task was that the teacher of this class, in the middle of the project, declared that this task was not going to be included in the course grade.

Other adjustments to the procedure were made as a response to the experience that several groups in DC2 did not generate storyboards as recommended (Hoban \& Nielsen, 2010). Attempting to remedy this, the work on the storyboards was broken out from the animation workshop so that the

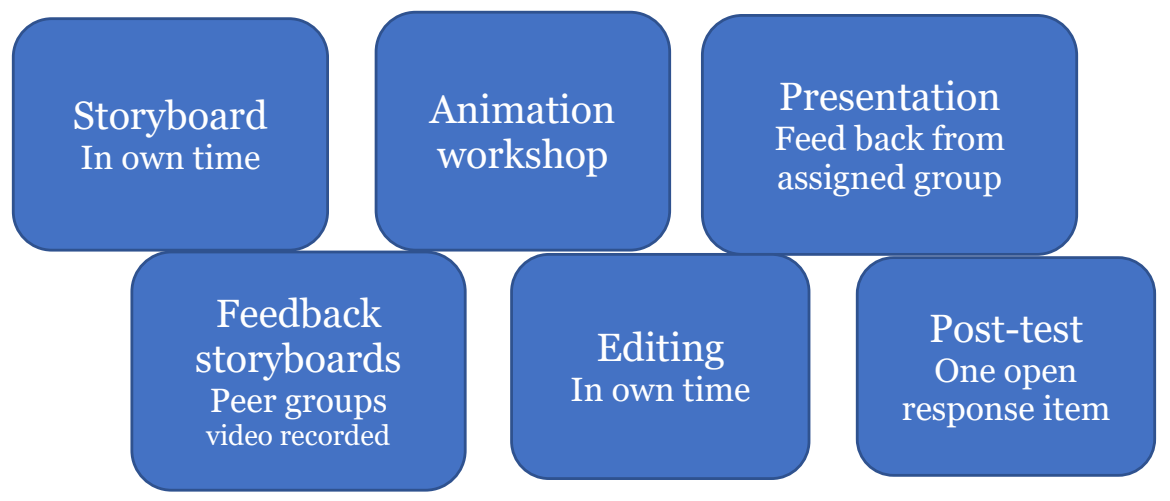

Figure 8. Outline of data collection round 3.

storyboards were prepared before the actual animation workshop in this intervention (Fig. 8). As previous research on student-generated animations has shown that adding peer evaluation in the design process can be beneficial (Chang et al., 2010) a feedback session was also included in the procedure this 
time. We hoped that would add a forum for productive, meaningful, contentrelated feedback in the process.

In summary the data that was collected consisted of, post-test, Studentgenerated animations, Video of four groups generating stop motion animations. Video of presentations. Audio from feedback sessions. The analysis of the animations is presented together with animations from DC2 in Study 2, and parts of the recorded animation workshop is presented in the result section.

As the purpose of these two data collections (2 and 3) primarily was to find out what students' own animations explaining ENS would look like, I as a researcher did not intervene in the animation process. And the media educators that supported the students were instructed to try not to influence the content of the animations by limiting the support to technical issues.

Analysis of the peer feedback provided by the students showed that it was very polite, did not really challenge ideas of the other groups and was unlikely to have helped them refine their storyboards. This observation makes me confident that despite the adjustments to the procedure the student-generated animations from both $\mathrm{DC}_{2}$ and $\mathrm{DC}_{3}$ could be treated as being produced under similar circumstances.

\subsubsection{Data collection round 4}

In the following data collection round, the topic of the task was changed from evolutionary change to chemical reactions. The aim also changed from focusing

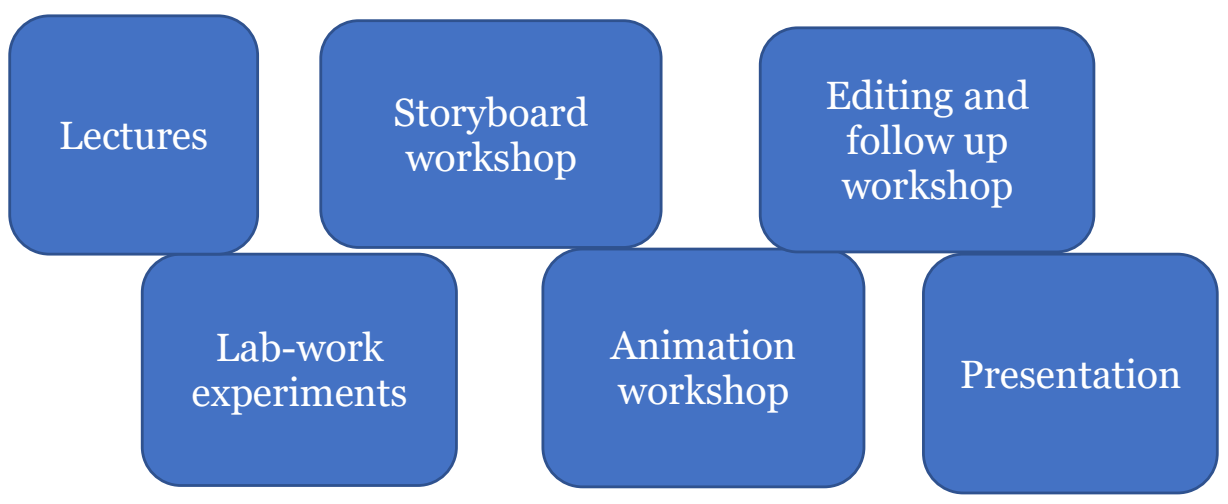

Figure 9. The outline of data collection round 4.

on the animations, the aim was to study the process of meaning-making afforded when a task of generating SMAs was introduced in a university chemistry course. Consequently, the data were collected during an extended period of four weeks. The participants were pre-service primary and middle school science teacher students, 37 in total, aged between 20 and 35 years. Only a couple of the students had previous experience of generating animations, and none had done it in this context (with the purpose of explaining scientific content). The animation task was integrated with a laboratory task. The students performed 
several laboratory exercises and selected one of them, for generating multimedia instruction for a fellow teacher, describing how to perform the laboratory exercise and a complementary animation explaining what happened at a submicro level. The stop-motion element of the task was to generate a chemical explanation of what happened in the studied reaction.

Based on our experiences from DCs 2 and 3, the activity of the generating animations was divided into two workshops, the first focusing on storyboard generation and the second on generating an animation. This meant that the students had more total time for generating the animations and generating a storyboard was not skipped (as it was by several groups in DC 2).

In summary the data that was collected consisted of, video recordings from six groups during story board workshop, and six groups during the animation workshop, and written evaluations. The presentations in full class were also videorecorded but have not been analysed. The results of an analysis of this data are presented in Study 4.

\subsubsection{Data collection round 5}

Unlike DCs 2 and 3, the animation task was in this round an integrated part of the section on evolution and diversity of life in a biology course. A teacher at a secondary school was positive to cooperating for this intervention and had a suitable group of year eight students ( $\mathrm{n}=27$, age 14-15). The task this time was to generate an animation about a specific evolutionary scenario involving singlecell algae in the ocean, in order to keep the organisms simple, thereby simplifying the model-making and allowing many model creatures to be created in a short time. As in $\mathrm{DC}_{4}$, the aim was to explore if including a SMA task in a course would lead to learning. This was planned to be done by analysing the process of generating animations as well as with a pre- and post-test design.

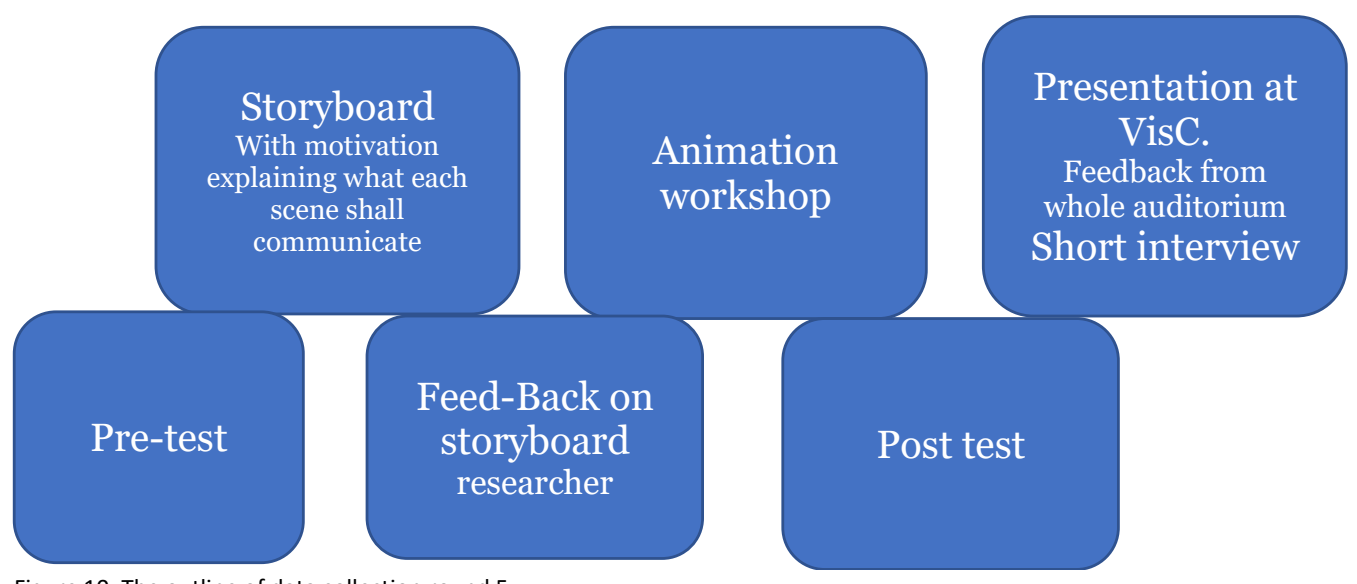

Figure 10. The outline of data collection round 5.

An additional feature of this round was inclusion of teacher (researcher) feedback on the storyboards before the animation workshop. (Appendix 1) for an example of the feedback the students received. 
The intention with this data collection was to study the process of generating animations and reasoning about ENS, however the external drive on which the video recordings were stored, crashed and this data was lost. Consequently, the research evolution along this branch stopped here. Despite that the video data was lost some data was saved, which consisted of, pre- and post-test results, and student-generated animations. An analysis of these is presented in the result section.

\subsection{Data analysis}

The explorative nature of the data collections performed during my doctoral work made it appropriate to collect different kinds of data, and though one would want to present it all, this is not possible. To sort through and select data for further analysis and finally presenting in a research paper or book chapter, is an inescapable part of qualitative research (Saldaña, 2016). The data collected in the data collection rounds were analysed in four studies, using varying methods depending on their aims as described in the following section.

The work I have done have focused on analysis of products of thinking, as represented in writing, animation, and in the social interaction while those products were generated, particularly qualitative changes in students' representations and reasoning. Thus, qualitative analytical methods clearly seemed most appropriate, and the main selected method was content analysis (Krippendorff, 2013) of text and animations as well as videorecorded discussions.

Table 3. An overview of the analysis that was performed in each study.

\begin{tabular}{|c|c|c|c|c|c|c|}
\hline \multirow[t]{2}{*}{ Study } & \multirow[t]{2}{*}{ Topic } & \multicolumn{2}{|c|}{ Content analysis } & \multirow{2}{*}{$\begin{array}{l}\text { Thematic } \\
\text { content } \\
\text { analysis } \\
\text { Video } \\
\text { analysis }\end{array}$} & \multirow{2}{*}{$\begin{array}{l}\text { Pre- } \\
\text { post- } \\
\text { test }\end{array}$} & \multirow[t]{2}{*}{ Media } \\
\hline & & Written & $\begin{array}{l}\text { Animati } \\
\text { on }\end{array}$ & & & \\
\hline 1 & ENS & Yes & & & & Online survey \\
\hline 2 & ENS & Yes & Yes & & & $\begin{array}{l}\text { SM/ Written } \\
\text { Open response }\end{array}$ \\
\hline 3 & ENS & & & Yes & & $\begin{array}{l}\text { SM/ Written } \\
\text { Open response }\end{array}$ \\
\hline 4 & $\begin{array}{l}\text { Chemistr } \\
\mathrm{y}\end{array}$ & & & Yes & & SM \\
\hline & ENS & & Yes & $\begin{array}{l}\text { Would have } \\
\text { been }\end{array}$ & (Yes) & $\begin{array}{l}\text { SM/ Written } \\
\text { multiple choice }\end{array}$ \\
\hline
\end{tabular}

\subsubsection{Content analysis of written explanations and animations}

Overall, the written explanations and the student generated animations were analysed using the same principles. Both deductive and inductive approaches was combined in the studies. The content analysis was systematic and performed in several rounds (Saldaña, 2016) as the coding schemas were developed. The content analysis in Studies 1 and 2 examined students' written 
explanations and animations of instances of evolutionary change, using a directed content analysis approach with deductive use of theory (Hsieh \& Shannon, 2005) in both studies. The analysis focused on the manifest content in each representation (Graneheim \& Lundman, 2004), trying to avoid adding meanings that may or not be implied in the content. The unit of analysis was defined as one representation, one written explanation. Each written answer or animation was considered in its totality for any occurrence of the codes, and several code (sometimes conflicting, e.g., both Individual variation and Essentialism) could be assigned to a unit of analysis.

The deductive codes were based on previous research on students' understanding and developed from a compressed version of a criteria catalogue developed by Tibell and Harms (2017) and Bohlin et al. (2017). Our deductive coding scheme was used to identify sets of variables corresponding to the two dimensions, key-concepts, and threshold concepts (Tibell and Harms, 2017). The variables were operationalized as binary variables, coding concepts as present (1) or not present (0).

Table 4. Overview of the codes used in Studies 1 and 2.

\begin{tabular}{|c|c|c|c|c|}
\hline & Codes & Definition & Study 1 & Study 2 \\
\hline \multirow[t]{7}{*}{$\begin{array}{l}\text { Key- } \\
\text { concepts }\end{array}$} & $\begin{array}{l}\text { Origin of } \\
\text { variation }\end{array}$ & $\begin{array}{l}\text { Mention of genetic process } \\
\text { underlying change in a trait. }\end{array}$ & $\mathrm{X}$ & $\mathrm{X}$ \\
\hline & $\begin{array}{l}\text { Individual } \\
\text { variation }\end{array}$ & $\begin{array}{l}\text { Any indication that individuals } \\
\text { vary in their traits. }\end{array}$ & $\mathrm{X}$ & $\mathrm{X}$ \\
\hline & Inheritance & $\begin{array}{l}\text { Traits are inherited from } \\
\text { parent to progeny. }\end{array}$ & $\mathrm{X}$ & $\mathrm{X}$ \\
\hline & $\begin{array}{l}\text { Differential } \\
\text { survival }\end{array}$ & $\begin{array}{l}\text { Individuals vary in their } \\
\text { survival chance due to } \\
\text { variation in their traits. }\end{array}$ & $\mathrm{X}$ & $\mathrm{X}$ \\
\hline & $\begin{array}{l}\text { Differential } \\
\text { reproductive } \\
\text { success }\end{array}$ & $\begin{array}{l}\text { Differences in reproductive } \\
\text { success between individuals } \\
\text { due to traits and/or genes. }\end{array}$ & $\mathrm{X}$ & \\
\hline & $\begin{array}{l}\text { Selection } \\
\text { pressure }\end{array}$ & $\begin{array}{l}\text { Abiotic or biotic factors } \\
\text { affecting survival and/or } \\
\text { reproduction }\end{array}$ & $\mathrm{X}$ & \\
\hline & $\begin{array}{l}\text { Change in } \\
\text { population }\end{array}$ & $\begin{array}{l}\text { Change in proportion of } \\
\text { individuals with certain traits } \\
\text { and / or genes in a population }\end{array}$ & $\mathrm{X}$ & $\mathrm{X}$ \\
\hline \multirow[t]{2}{*}{$\begin{array}{l}\text { Alternative } \\
\text { conceptions }\end{array}$} & $\begin{array}{l}\text { Intentionality, } \\
\text { incl. teleology } \\
\text { and } \\
\text { anthropomorp } \\
\text { hism }\end{array}$ & $\begin{array}{l}\text { Directed evolution where a } \\
\text { new trait appears after a } \\
\text { change in the environment. } \\
\text { Indication that changes occur } \\
\text { because of an ultimate goal or } \\
\text { by human-like intentions and } \\
\text { ability to plan for a far future. }\end{array}$ & & $\mathrm{X}$ \\
\hline & Essentialism & $\begin{array}{l}\text { Transformation of all } \\
\text { individuals in a population. } \\
\text { Unifying essence instead of } \\
\text { variation. }\end{array}$ & & $\mathrm{X}$ \\
\hline
\end{tabular}




\begin{tabular}{|l|l|l|c|c|}
\hline & $\begin{array}{l}\text { Natural } \\
\text { selection as an } \\
\text { Event }\end{array}$ & $\begin{array}{l}\text { Major evolutionary changes } \\
\text { occur in less than three } \\
\text { generations. }\end{array}$ & $\mathrm{X}$ \\
\hline $\begin{array}{l}\text { Threshold } \\
\text { concepts }\end{array}$ & Randomness & $\begin{array}{l}\text { Mention of relevant stochastic } \\
\text { events in evolution. Typically, } \\
\text { random origin of variation, } \\
\text { random death, random } \\
\text { mating, etc. }\end{array}$ & $\mathrm{X}$ & \\
\hline & Probability & $\begin{array}{l}\text { Outcome of several stochastic } \\
\text { events. The system / } \\
\text { population does not behave in } \\
\text { a deterministic way. Mention } \\
\text { of probability in relevant } \\
\text { context e.g., chances of } \\
\text { survival, probability of a } \\
\text { mutation etc }\end{array}$ & $\mathrm{X}$ & (x) \\
& Spatial scale & $\begin{array}{l}\text { Link between cause and effect on } \\
\text { different levels of organization or } \\
\text { spatial scale } \\
\text { (Connections } \\
\text { organizational levels, from genes } \\
\text { to population) }\end{array}$ & $\mathrm{X}$ & $\begin{array}{l}\text { Expression of time as a factor. } \\
\text { (Illustration/manipulation of } \\
\text { tempo. Fast forward or slow } \\
\text { motion) }\end{array}$ \\
\hline & Temporal scale & $\mathrm{X}$ & $(\mathrm{x})$ \\
\hline
\end{tabular}

The codes used in Studies 1 and 2 differed in the following ways. Seven keyconcepts were used in Study 1, two of these were not included in Study 2. Selection pressure and different reproductive success was excluded. Threshold concepts were explicitly addressed in Study 1, while they were more indirectly treated in Study 2, which included analyses of alternative conceptions that was excluded from the analysis in Study 1 (Table 4). The codes include five concepts related to natural selection (E1- E5) and three alternative concepts (A1-A3) (Harms \& Reiss, 2019; Nehm \& Reilly, 2007) Representations that conveyed concepts were coded accordingly to allow qualitative description of whether and how students included the underlying key-concepts and alternative conceptions in their representations.

In Study 1, a larger number of answers was considered, and the coding was performed by four researchers, so interrater reliability was evaluated. In Study 2 the sample was smaller and could be read several times and analysed iteratively by two independent coders. Then their analytical results and interpretations were compared. In most cases, the codes identified by different coders were the same or similar. In the few cases where there were disagreements, the data were reanalysed until full agreement was reached.

\subsubsection{Thematic content analysis of student work}

The video camera is like a microscope for interaction. It is more exact, comprehensive and objective than a human observer can ever be, so the 
acquired data are not dependent on the collector of the material. Another strength is that it allows collection of natural data (or interactions in authentic settings). Moreover, the inherent sequentiality of a video recording matches the sequentiality of recorded social activities, which greatly facilitates analysis of acquired data (Knoblauch, Schnettler, \& Raab, 2006). A risk is that it is easy to be overwhelmed by all the data that can be collected. Video recordings can provide rich detail, but issues of sampling, authenticity and ethical issues must be considered (Fitzgerald, Hackling, \& Dawson, 2013).

The aim of the analysis was to explore which evolution and chemistry content was constituted during the process of generating the SMAs and in what ways the representational activities afforded the students to discern and reason about this content. In Study 3, I present a video analysis of the animation process (DC2). This was an early work focusing one of the groups generating an animation. The analysis was done by verbatim transcription of student dialogue, and the transcripts were then scanned based on ENS content, based on key-concepts.

In Study 4, a thematic content analysis of the video recordings was conducted by three researchers $(\mathrm{AB}, \mathrm{DO}, \mathrm{AJP})$ in four phases. Phase 1: we divided the recordings into five parts corresponding to the five representational activities (RA1-5). Phase 2: for each of the five RAs, we firstly identified student interactions in which some reference to chemistry content was noticeable. Secondly, we segmented these identified interactions into episodes independent units consisting of pieces of dialogue that shared the same focus (Gee \& Green, 1998). Boundaries were set by shifts in the dialogue and/or activities. Phase 3: we transcribed each of the episodes. Phase 4: The content was coded using the coding scheme. We formed five codes. These concerned reasoning with reference to the different levels of chemistry content in Taber's model (2013): experiential, macroscopic and sub-microscopic, as well as their relations. Guided by Prain and Tytler (2012), we define chemistry content as aspects of the phenomenon to be explained and aspects of the representations needed to make sense of that phenomenon.

Since then, more animation work from more student groups in $\mathrm{DC} 2$ has been analysed, some using the computer qualitative data analysis MaxQDA, following the same procedure as was applied in Study 4 but based on evolutionary content. These additional analyses that was not included in Study 3, are partly presented in the result chapter of this comprehensive summary.

\subsubsection{Statistical analysis}

In Study 1, differences in proportions of participants using a specific concept across the three items (concerning bacteria, cheetahs, and salamanders) were studied using the Cochran's $Q$ test. The test is suitable for comparing a dichotomous outcome variable in related samples, such as differences in pass/fail frequencies on different test items (Siegel \& Castellan, 1988). Cochran's $Q$ test was applied for each concept (key and threshold) and Bonferroni correction was used to adjust for the number of comparisons within 
each sample (12 different variables), $\alpha=0.05 / 12=0.004$. If a significant effect of item context was found, subsequent pairwise comparisons were performed (Dunn's post hoc test, nonparametric) using built-in alpha adjustment for multiple comparisons in SPSS.

The result of the pre- and post-tests in DCs 2 and 5 have been analysed and is reported with descriptive statistics. Due to the relatively low number of participants and the qualitative approach, analytical statistics have not been used.

\subsection{Trustworthiness}

There are two opposing drivers in design-based research: the aims of being relevant and rigorous (McKenney \& Reeves, 2012), and ideally a suitable balance between rigour and relevance should be sought (Reeves, 2011). When the object of study is a complex classroom it is practically impossible to keep track of all variables that might influence the results. By prioritizing ecological validity (the ability to generalize results to real world settings) the design-based researcher must be aware that this comes at a cost of methodological rigour, which in turn limits the value of the theoretical contribution of the research. This does not, however, remove the demand for well-supported arguments to support any knowledge claims, accompanied by high degrees of transparency and honesty of researchers reporting educational studies. Scholars emphasize that in order to establish findings' trustworthiness and credibility, design-based researchers must provide rich descriptions of the context of interventions (Barab \& Squire, 2004; Cobb et al., 2003; Prediger et al., 2015). These descriptions should cover the context, guiding and emerging theory, design features of the intervention, and effects of these features on participation and learning. It is important to clarify which aspects of a design are the target of investigation (e.g. feedback) and which are background conditions or may be accidental (e.g. classroom or other setting) (Cobb et al., 2003). It is also important to recognize, as Cronbach (1975) famously wrote about educational treatments: "when we give proper weight to local conditions, any generalization is a working hypothesis, not a conclusion" (p. 125).

Risks of the Bartlett effect, i.e., the problem of confirmation bias when a researcher is sorting through large amounts of data, should also be acknowledged (Brown, 1992). It is always easy to select examples that confirm the hypothesis one is supposedly testing and ignore others. To avoid cherrypicking sections of a transcript that provide good evidence for a point the researcher wants to make, and neglecting sections that may refute it, is difficult (Louw, Todd, \& Jimarkon, 2014). A suggested strategy is appending full transcripts to papers, but this is rejected by Brown (1992) as practically unrealistic. Based on the time required to analyse qualitative data, no scholars would have time to check all such material. Louw et al. (2014) present a method for objective excerpt selection based on keywords and quantitative analysis, which is promising, but may not be applicable in all studies. In the studies 
underlying this thesis we strove to apply recommendations of the cited authors to avoid the mentioned pitfalls, but the possibility of failure cannot be dismissed.

The strategy applied in the studies in this work have been to work with other researchers, presenting data at work seminars in the research groups I have been associated with, as well as presenting preliminary results at conferences. Through the work of analysing the recorded interactions, episodes that showed how the animation process led students to challenge, discuss and develop their understanding, emerged. These were not selected to be representative with a purpose of showing typical behaviour and interaction that could form a base for generalisations. Instead, the episodes give us insight into how this activity provides opportunity for reasoning and learning (P. J. White, Tytler, \& Nielsen, 2020). The examples open connections to and can develop theory (MacLure, 2010).

Aims to maintain ecological validity and practice-orientation often lead to studies both on an intervention and through the intervention (McKenney \& Reeves, 2012), so a design-based research approach often raises a challenging need to study several phenomena simultaneously. Ways that different aspects of the intervention change its reception by the learners, effects on learning outcome and participants' behaviour all may require attention. In relation to this it is worthwhile to point out that an intervention creates a gap between the natural classroom and the classroom with a designed reform. Of course, the achievable learning goals are highly dependent on the available resources, but in reality, schools are often expected to deliver better results with the same or less resources. I had these constraints in mind when intervening with the classes that participated in this research.

The episodes of student dialogue presented in the Studies were translated to English by the authors. I wish to emphasize that nuances of the original may have been be lost in translation. In Study 4 the translations were validated by a person who is a native English speaker with a high level of fluency in Swedish, and who also possess knowledge of the research context. Validation was made using back translation, and a few inconsistencies were identified and corrected in this process.

\subsection{The reach of the studies}

Iteration is indispensable when designing complex systems of any kind: software, cars or educational innovations. To obtain good results long-term approaches are preferable (Brown, 1992) as development in education takes time. This is one of the drawbacks of the designed-based approach. Ideally, it would involve many resource-consuming iterations of design, development, and revision. Conducting such projects is not feasible for a single PhD student (McKenney and Reeves (2012). Within the time available, studying large developmental patterns of students' thinking is not feasible. The alternative is a microgenetic design (Brown, 1992) focusing on students' learning of a specific concept. According to McKenney and Reeves (2012) it is more likely that a 
couple of micro-cycles or a meso-cycle with a few iterations can be covered in the timespan of a doctoral project. My project covered three cycles, with modifications to increase understanding and the potential learning outcomes of students generating animations of ENS. To reach further, I have not worked in solitude, the project group in the EvoVis project and the cooperation with Astrid Berg and colleagues at LiU made it possible for this project to increase the understanding and the potential learning outcome of student generated animations of subjects challenging spatial and temporal scales.

"Research studies with a focus on learning processes can take place in laboratory (interview) settings and in classroom settings." (Prediger et al., 2015, p. 882). There are a limited number of previous studies on the work process of students generating stop motion animations. These have been done on small groups in laboratory style settings (Hoban \& Nielsen, 2013; Macdonald \& Hoban, 2009). So, I wanted to build on that and chose to do my studies in classroom setting, and in this way contribute to a larger programme of introducing student generated animations in science education.

\subsection{Ethical considerations}

The collected material was treated according to the guidelines of The Swedish Research Council (2017) Students were informed that the task as such was a compulsory part of the course, but that our wish was to document their work using video and audio recordings depending on their written consent. This research was conducted in a way that was transparent for all participants. During the teaching sequence, we continued to verbally inform them that each participant was free to interrupt her/his participation at any time.

The role of researcher and teacher needed to be balanced during DCs 2 through 5. Perhaps most in the last two, where the animation task was more integrated in the teaching-learning sequence. We did not want to interfere with the student's creative process, but we also had to answer questions that arose. To the largest part these could be avoided by returning the question and ask about the students' own idea, and in that way just give them the small nudge needed to be able to proceed. In some cases, the gaps in the students' understanding were too large and we could not leave the students to their own shortcomings. We had a responsibility as educators to explain some facts, while being cautious not to interfere or steer how the representational task should be solved.

Studying students in school, doing school things, is not to be considered a problematic research from an ethical perspective. There exists a risk however low, that ethically sensitive situations might be captured on video when young students interact over a period of several hours. A researcher who plans to collect data in this way need to be aware of this and be prepared to handle this issue if such a situation should appear. This never became an issue during my work.

The GDPR legislation was not effective at the time the data was collected. Measures to not publish pictures of faces or any personal information about the 
participants in the studies were made even though many have given consent to the recorded video material to be shown in presentations of this research. Files with original names and additional personal information of participants have been stored on separate hard drives. 


\section{Appended studies}

These papers collectively address the main research questions, and following more specific questions, using data collected during the doctoral project as specified in the previous chapter.

Study 1: Göransson, A., Orraryd, D., Fiedler, D., \& Tibell, L. A. E. (2020). Conceptual characterization of threshold concepts in student explanations of Evolution by natural selection and effects of item context. CBE-Life Sciences Education, 19(1), ar1. Reprinted under the following license https://creativecommons.org/licenses/by-nc-sa/3.0/

I conceptualised the study and collected the data in cooperation with the coauthors. Analysed part of the data and contributed suggestions for revisions of the manuscript.

Study 2: Orraryd, D. \& Tibell, L. A. E. What student generated animations reveal about student's conception of evolution by natural selection. (Submitted to Evolution: Education and Outreach)

I conceptualised the study, collected the data and analysed the data in cooperation with the co-author. I also wrote a major part of the paper and led its revision.

Study 3: Orraryd, D. (2013) Elevers animationer av evolution. in Modeller, analogier och metaforer i naturvetenskapsundervisning. Fredrik Jeppsson and Jesper Haglund (eds.) Studentlitteratur. Reprinted with permission from the publisher.

This study is based on additional data collected in connection to Study 2. I conceptualised the study and analysed the data partly in cooperation with Lena Tibell. I also wrote the paper.

Study 4: Berg, A., Orraryd, D., Jahic Pettersson, A., Hultén, M. (2019) Representational challenges in animated chemistry: self-generated animations as a means to encourage students' reflections on submicro processes in laboratory exercises. Chemistry Education Research and Practice, 20, 710. Reprinted under the following license: https://creativecommons.org/licenses/by-nc/3.0/

I conceptualised the study and collected the data together with Astrid Berg. I also analysed the data in cooperation with Astrid Berg and Alma Jahic Pettersson, wrote the paper and participated in the revisions together with Astrid Berg and Magnus Hultén. 


\section{Results}

In this section I present results from the studies presented in the appended papers and previously unpublished data to illustrate the opportunities and challenges students face when trying to create a stop-motion animation (SMA) representing evolution by natural selection (ENS) or chemical redox reactions, focusing particularly on spatial and temporal scales. In accordance with the main research questions, after presenting results concerning students' general conceptions of the focal topics, results concerning student-generated stopmotion animation for probing understanding and the process of generating stop-motion animations to support learning are sequentially presented.

The starting point for the doctoral work was the data collection and analysis of data presented in Paper 1 , in which volunteering university students from different educational programs in Sweden and Germany wrote explanations about evolutionary changes in three contexts. Analysis of their explanations showed that the threshold concepts were mentioned to different degrees in responses to the three test items. Some of the differences related to the taxa

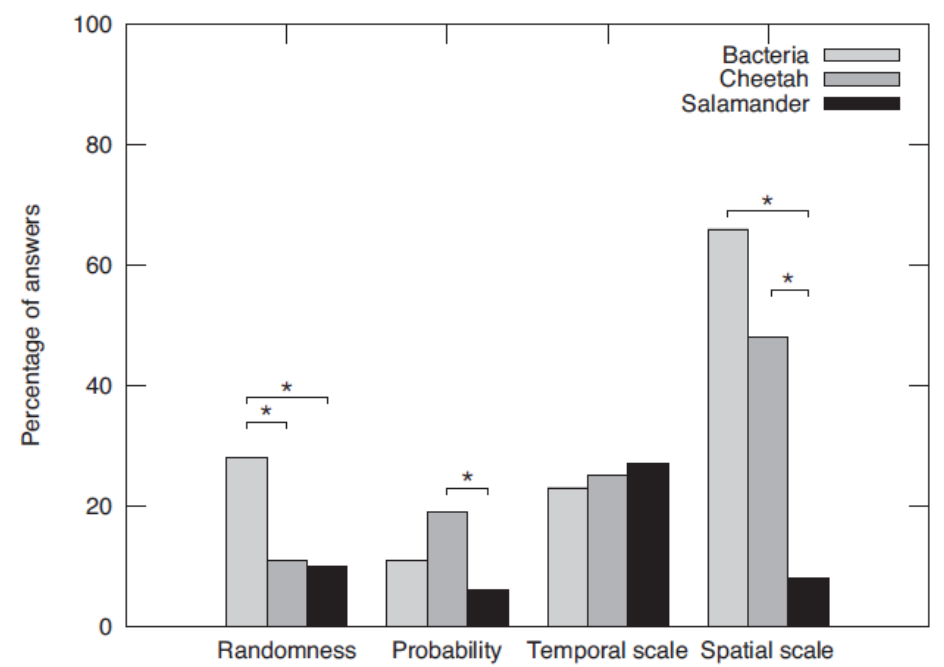

Figure 11. Frequencies (percent) that indicated threshold concepts appeared in students' responses to items asking how bacteria acquire antibiotic resistance (Bacteria), cheetahs gained their speed (Cheetah) and cave salamanders lost their sight (Salamander).

involved, and the item asking about the loss of a trait (eyesight in cave salamanders) elicited the lowest frequencies of both threshold and keyconcepts, possibly with the exception of selection pressure and time (Figures 11 and 12). This indicates that this item posed more challenges for the students than the items regarding gain of traits (cheetahs' gain of speed and bacterial acquisition of antibiotic resistance).

Randomness and probability were the least frequently mentioned threshold concepts. However, randomness was more frequently in responses to the bacterial question, while probability appeared more frequently in answers to the 
cheetah item. Spatial scale connected to the origin of variation at a submicroscopic level was more frequently mentioned in responses to the bacterial question than in responses to the questions concerning animals, which elicited no connections between macro and sub-micro phenomena. This clearly revealed a strong influence of context. Temporal scale was often mentioned in a nonspecific way, generally in claims that evolution takes time. Overall, time was mentioned equally frequently in responses to three items $(\sim 25 \%)$.

Previous studies had also shown that the items we used could elicit different frequencies of references to the key-concepts (Nehm \& Ha, 2011), but the variation in frequencies of elicitation of threshold concepts varies was a new insight. The low elicitation of threshold concepts generally, and the effects of contextual factors (taxa and direction of changes) on their use in students' explanations required further examination.

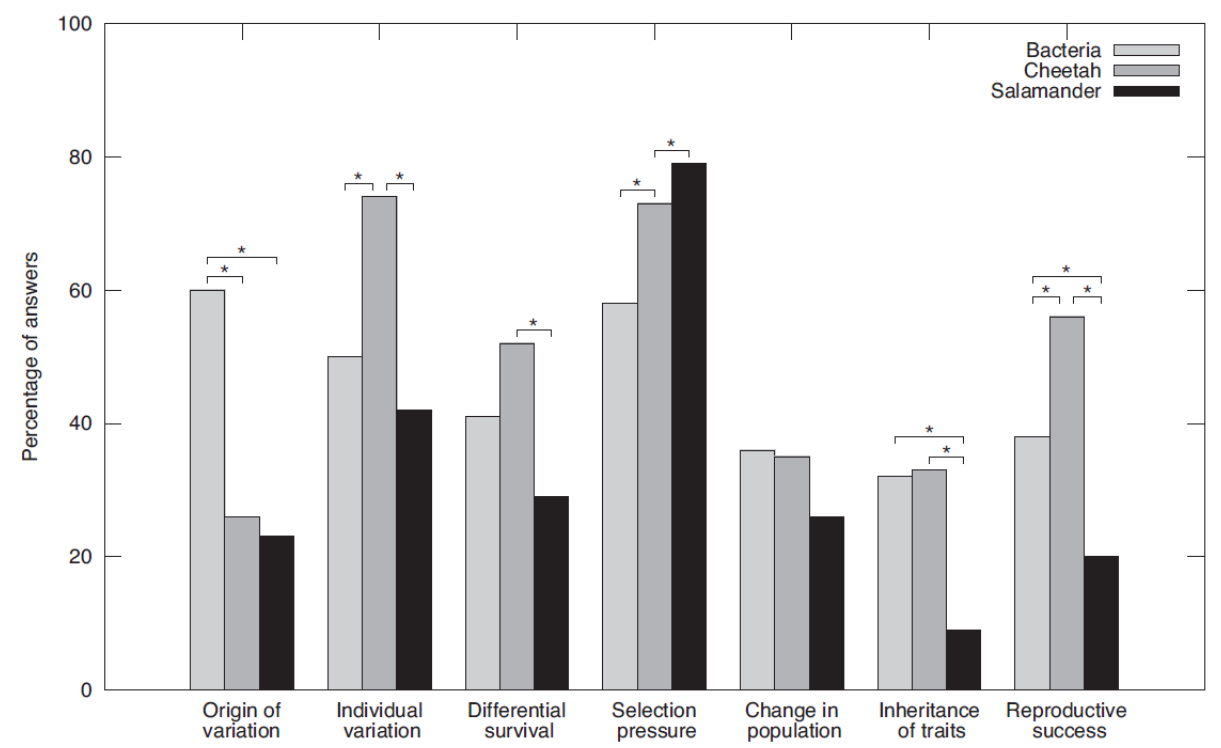

Figure 12 Frequencies of concepts that appeared in students' responses to items asking how bacteria acquire antibiotic resistance (Bacteria), cheetahs gained their speed (Cheetah) and cave salamanders lost their sight (Salamander).

Inter alia, we found that time was represented at relatively low frequencies in response to all three items, while representation of spatial scale (organisational levels) varied substantially across items. The finding raised the possibility that the inconsistency in students' expression of concepts could be dependent not only on context, but also modality. Allowing students to represent evolutionary change in a context of their own choice and using a multimedia format could potentially tell us more about how students conceptualise ENS. This led me to explore student generation of SMAs as an alternative method for probing students' understanding. In addition, to widen the content and further explore how generating multimedia explanations may afford reasoning opportunities 
that support the specific demands of representing processes that fall outside our perceptual range, students' representation of chemical reactions was also explored.

\subsection{Student-generated stop-motion animations for probing understanding}

This section focuses on the animations as products of a representational activity and what they can tell us about students' understanding of ENS and chemical reactions in relation to different organisational levels and dimensions of time. The SMAs the students generated are seen in both cases (biological and chemical contexts) as digital multimedia explanations (Nielsen et al., 2020). Study 2 focused on probing students' understanding of ENS. In contrast, the purpose of Study 4 was not to analyse their conceptions of redox chemistry, either as expressed in the animations or during the process of making the animations. Rather, it was to explore how the making of the animation enabled them to construct an integrated explanation of the chemical phenomena, relating processes at different spatial scales: sub-micro, macro, and experiential level (Taber, 2013). Hence, spatial scale constituted common ground content in both the ENS and chemistry animations. As such, it may be a focus of comparative analysis in this thesis.

Regarding the conceptualization of ENS, time is an important factor in both the instantaneous origination of variation, e.g. through mutations, and how changes in a species may accumulate over thousands of years. However, time is also an important aspect of chemical processes, as changes at the sub-micro level will sooner or later emerge as discernible changes at the experiential level. Thus, time also qualifies as a focus of comparative analysis. However, I begin by presenting the evolutionary content found in the animations in Study 2 and data collection $5\left(\mathrm{DC}_{5}\right)$.

\subsubsection{Evolution content in animations}

To complement the results from Study 1, an analogous content analysis was performed on 18 student-generated animations explaining ENS in Study 2. The students found the descriptive concepts, variation, and different survival easiest to represent. Hence, they were represented in a majority of both the written answers and animations. This is consistent with previous findings regarding students' understanding (e.g. Nehm \& Reilly, 2007) but now we showed that this pattern is the same in student generated SMAs. (Fig. 13)

Concerning the context, the students (upper secondary school students) creating SMAs, without exception, chose to work with animals or organisms with animal characters. Plants were only present in their SMAs as decoration, food, or something to hide behind. Notably, even the secondary students participating in $\mathrm{DC} 5$, who were given a specific task of explaining evolutionary change in single-cell algae, represented them with typically animal characteristics, even faces.

The change of an organism's traits shown in most of the SMAs was of the gain of trait or growth. There were few examples of a new trait negatively affecting 
individuals' survival (e.g., an animation of chameleon-like organisms). However, generally evolutionary change was represented as a process of improvement. In combination with the finding in Study 1, that the question about trait loss was most difficult, this result is interesting and strengthens the claim that students have difficulties conceptualising evolution in ways that are not goal oriented (Ware \& Gelman, 2014).

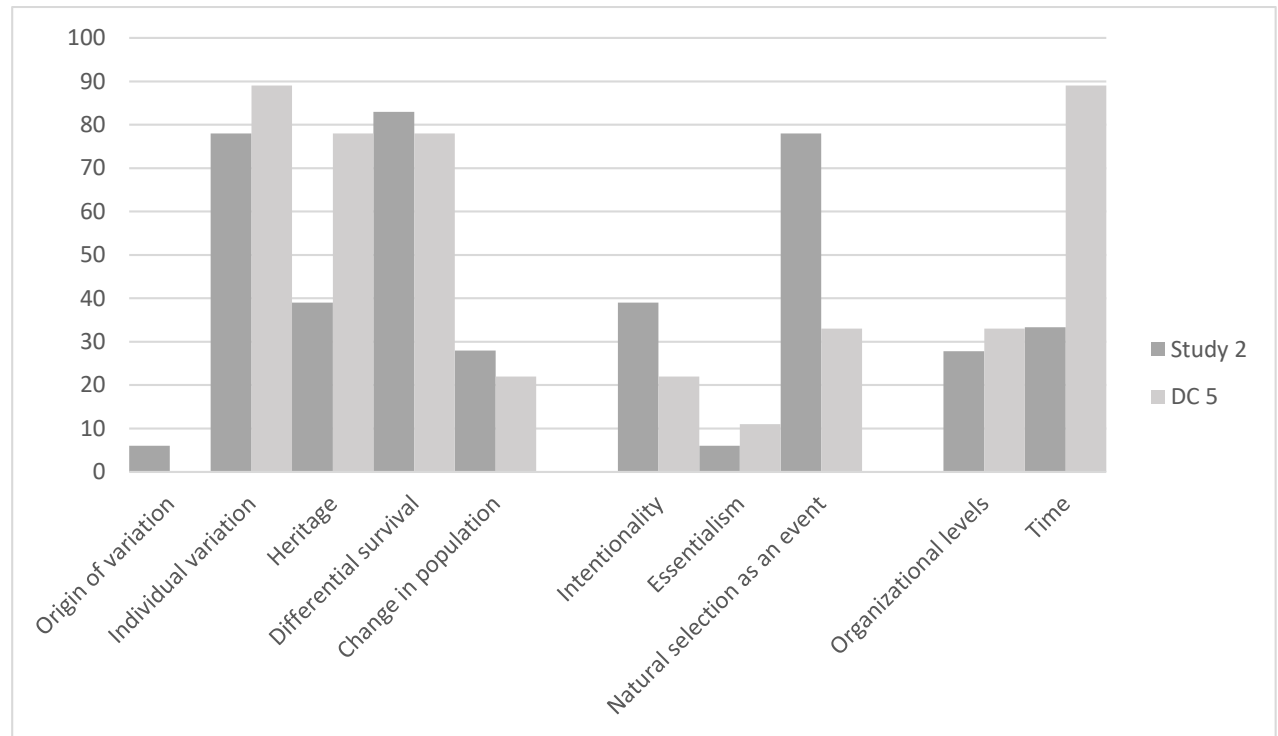

Figure 13. Frequencies (percent) of appearance of key and alternative concepts of ENS in the SMAs produced in Study 2 and DC5.

\subsubsection{Spatial scale in the animations}

Representing evolution or chemical reactions, brings a need to move out of the perceptual range. In the case of ENS this means moving in two directions in terms of scale: outwards from individual organisms to populations, and inwards to the genetic level (Fig. 4). The animations that the students generated in DC2 and $\mathrm{DC}_{3}$ to explain evolutionary change all depict macroscopic level phenomena, showing individuals and populations. However, the populations often consisted of less than 10 individuals. A few animations depicted single individuals. In chemistry the challenge is mainly to visualise the sub-micro level of atoms and molecules.

\subsubsection{From individual organism to molecular level representations of evolution}

As with the written explanations examined in Study 1, the origin of variation was very rarely represented in the animations. None of them made this connection visually (one mentioned mutation in the narration). Students' rare connection of the genetic-level phenomena to evolutionary explanations is reflected in the general separation of genetics and evolution in biology textbooks (Kalinowski et al., 2010) and online animations (Bohlin et al., 2017). To make such a connection would have required a jump in spatial scale from the macro scenes they created to a sub-micro scene. The results from Study 1 indicate that the 
smaller step to a genetic scale in the context of the bacterial question facilitated conceptual movement to it. However, all animations displayed an animal context. Therefore, it is perhaps not surprising that only one animation made this connection, through narration while the visual set was paused. A sophisticated connection between the two levels was accomplished in this case, showing the potential of a multimedia format for expressing complex concepts like this. Some of the animations in $\mathrm{DC}_{5}$ did represent mixture of genes from sexual reproduction symbolically, e.g., by mixing clay with different colours in the model organisms. This resulted in a sort of hybrid representation, where events on different levels were represented together, simultaneously in the animation. The problem of connecting different spatial levels was also addressed in Study 4, concerning chemical reactions.

\subsubsection{From observation to the sub-micro level in chemistry}

In the context of chemical reactions, the task was more explicitly focused on connecting the macroscopic experiential level (within the perceptual range) with the sub-microscopic level of atoms and molecules. Consequently, both levels were present in all the chemistry animations. To move from the experiential to the sub-micro level, several groups applied some variant of zooming-in approaches, while others simply cut directly to a scene with atoms and ions.

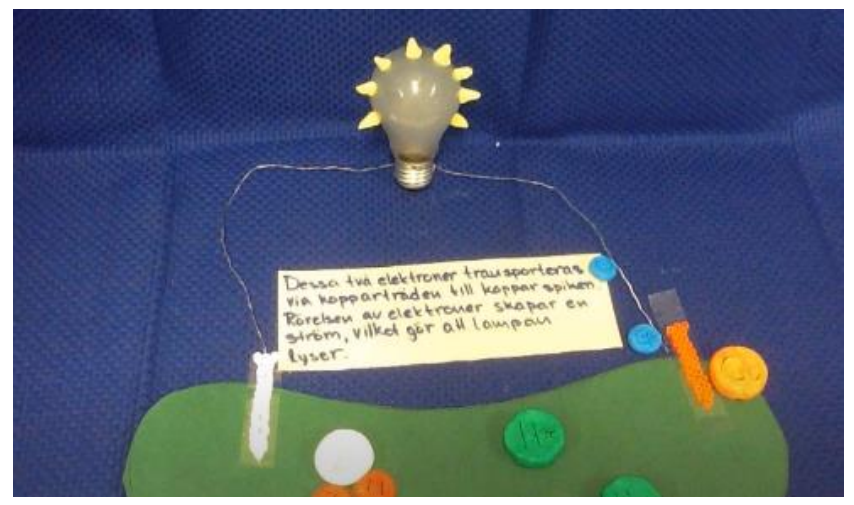

Figure 14. Photo of a scene in one of the chemistry animations (DC4) depicting both the experimental setup of a cucumber battery and the molecules and electrons in the circuit. A hybrid representation, merging the experiential and submicroscopic levels.

Like the findings from the ENS animations, the most fruitful approach (according to our analysis presented in Study 4) for the students generating chemistry animations was a hybrid representation. This allowed the students to generate animations without aiming to be true to the scale of objects and prioritising conceptual clarity, combining objects from different scales in the same picture. For example, one group produced an animation of a galvanic cell in a pickled cucumber (Fig. 14), and to illustrate the whole process the students found that merging objects that were only visible at different spatial scales was essential. 


\subsubsection{From individual organism to population level in evolution}

Perhaps, because the populations the students created were so small, the variation between individuals was of an either-or type: an individual either had

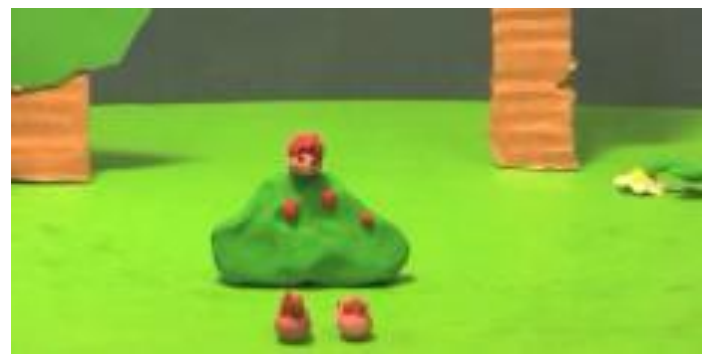

Figure15. Photograph of a scene in an animation (produced in DC2) depicting continuous variation of the trait spikes. The three mouse-like individuals on and in front of the bush have different numbers of spikes on their backs.

a visual trait or did not. For example, one population consisted of balls of clay rolling along the ground, except for one ball that was jumping along. A predator comes and eats the individuals on the ground, but the jumping individual escapes by jumping up a tree. This sort of variation is more like superhero mutations than the typical variation of traits in natural populations, of which is of continuous rather than discrete nature (Dawkins, 1996). This made it difficult to represent change in a population, so this key-concept was not as commonly displayed as variation and differential survival in the animations. Only one of the groups represented continuous variation when animating their scenario (Fig. 15).

\subsubsection{Representing time in the animations}

The analogy in the processes of incremental change over time in evolution and making models move through long series of small movements in the animation technique did not help the learners in this study to represent time in the desired way. Students struggled with the dimension of deep time, and few of their animations displayed the key-concept related to time, change over time. When generating SMAs few groups found ways to break free from the natural time of the animation and represent time symbolically. Instead, the time-consuming animation method led many groups to display natural selection as an event (Gregory, 2009) rather than depicting evolutionary change in a gradual way. One exception, that did show gradual change of an organism was one showing transformation of a terrestrial animal into a dolphin. In that animation the viewer must assume that (s)he is watching a process that has been accelerated.

Other groups found ways to make time explicit to the viewer, for example by complementing the visual display with text (Fig. 16). One group stood out by including a fast-forward segment in their animation, (Fig. 16) in which two arrows appear in the top left corner and the models start to move very fast, a clever way to summarize a process that takes a lot of time. The obvious drawback with this is a lack of detail in the process of natural selection. (This is a 
representational constraint discussed further in the following section on the process of generating animations)

The evolution animations produced in $\mathrm{DC}_{5}$ stand out in terms of representing time in several generations (Fig. 13). To simplify the modelling, the task was constrained by asking students to illustrate ESN of single-cell algae. This enabled the students to represent several generations of the modelled organism, and they were further encouraged to do so by feedback they received from a researcher reviewing their storyboards before the animation workshop.

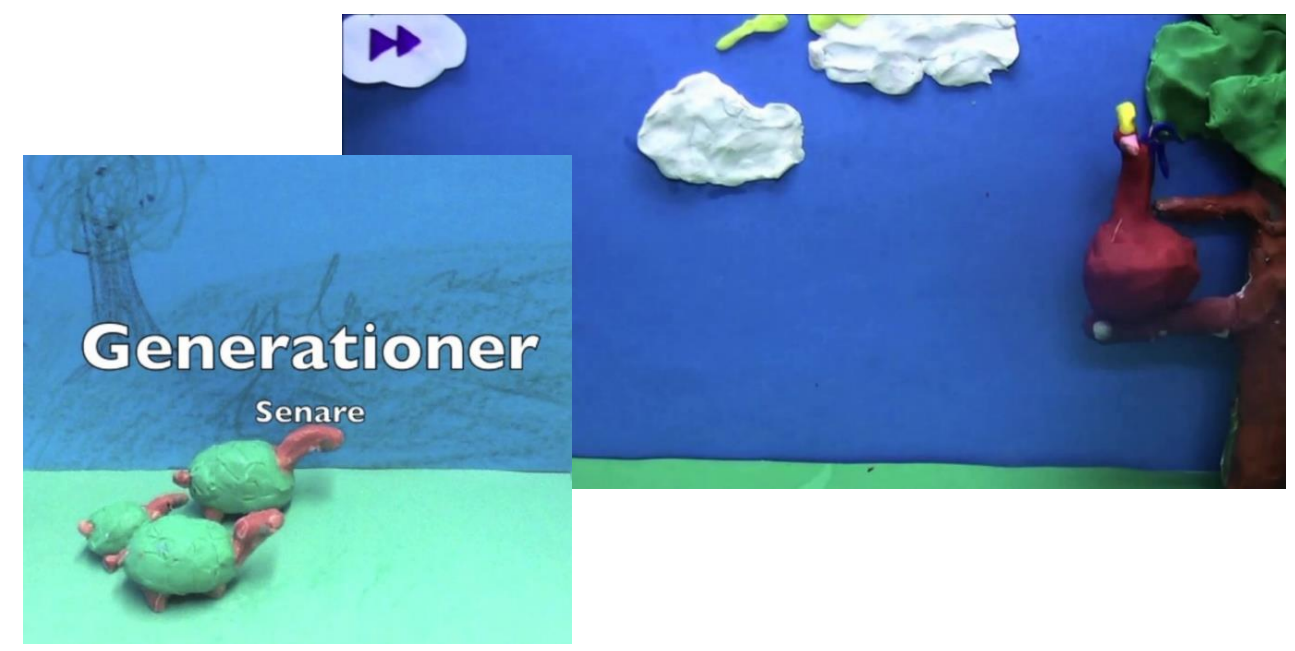

Figure16. Two scenes from animations produced during DC3. Left panel showing integrated text declaring that generations have passed. The right panel display a bird-like creature in a tree, while in the top left corner a double arrow indicating a fast-forward mode in the animation.

Time was not an explicit focus in the task of animating chemical reactions in Study 4. However, representation of atoms' movement in a chemical reaction (comparable to that of sub-micro scale mutations in DNA molecules) requires slowing of the movements. All the groups that animated particles participating in chemical reactions made the particles (even electrons) move slowly, but none of the students commented on this change of time, and they apparently changed it without reflection.

The experiential level video material records of the school experiments showed that some groups addressed the problem of shortening the time it took for a piece of metal to corrode by making a cut in the video and explaining in text or narration that time had passed (in a similar manner to the written text showing that time had passed in some of the evolution animations). Other ways of showing this would have included some time-lapse animation or (as in the bird animation) fast-forwarding a sequence of the video, but there were no such examples in the chemistry study. 


\subsubsection{Alternative conceptions in the animations}

Both ENS and chemical reactions are processes for which science educators struggle to get students to adopt scientific explanations and abandon anthropomorphic and teleologic explanations that come more naturally. In Study 2 we found that erroneous explanations were displayed less frequently in collaboratively generated SMAs (Fig. 13) than in written test responses analysed in a previous study by (Coley \& Tanner, 2015). The difference was greatest for the essentialist conception which only one of the $18 \mathrm{ESN}$ animations showed (and only one of nine of the animations produced in $\mathrm{DC}_{5}$ ).

The fact that both variation and essentialism sometimes occur in the same written explanation may seem odd as they represent two qualitatively different ways of understanding evolutionary change (Shtulman, 2006). A possible explanation is that essentialism may often be used metaphorically in written explanations, complicating attempts to obtain a clear audit of students' understanding in this regard. Similarly, the ENS animation displaying essentialism, also displayed variation. In the first part of the animation a population of three giraffe-like individuals with different neck lengths enter, (showing individual variation). After a short time, the individual with the shortest neck starves to death because it cannot graze from tall trees in the set (showing differential survival). The two remaining giraffes then go on evolving longer and longer necks (showing essentialism). The animation shows the selection process once and then the story is speeding up (without explicitly indicating this) only showing the outline of the evolutionary change. At that faster rate, changes in properties at the population level are apparently transferred to the individual level.

One of the chemistry animations produced in DC4 (Fig. 17) shows atoms changing colour, like a corroding metal coin did at the experiential level. Instead of representing the change in the colour of the coin as a result of a chemical reaction between copper and oxygen atoms, these students displayed a transformation of the copper atoms to a new dark type. In this case the students transferred a macro level property (colour), as it appeared at the experiential level (the copper coin got darker) to the sub-micro level (Ben-Zvi et al., 1986), making the atoms change colour. In an analogous essentialist explanation of ENS, would show population-level increase in an organism's average running speed by increasing the running speed of each individual (Gregory, 2009). This is what students did in their written explanations of the increase in cheetahs' speed, their explanations gave the impression that all individuals became faster over time. Note that the example in Figure 17 was the only example of this alternative conception in Study 4. Generally, using a pictorial mode of representation allowed the students to represent both the individual and population levels simultaneously, showing the level at which, the change appears. 
Furthermore, in the analysis of the ENS animations it became clear that most animations showed variation first and a subsequent selection. This contrasts with the teleological need misconception (Southerland, Abrams, Cummins, \&
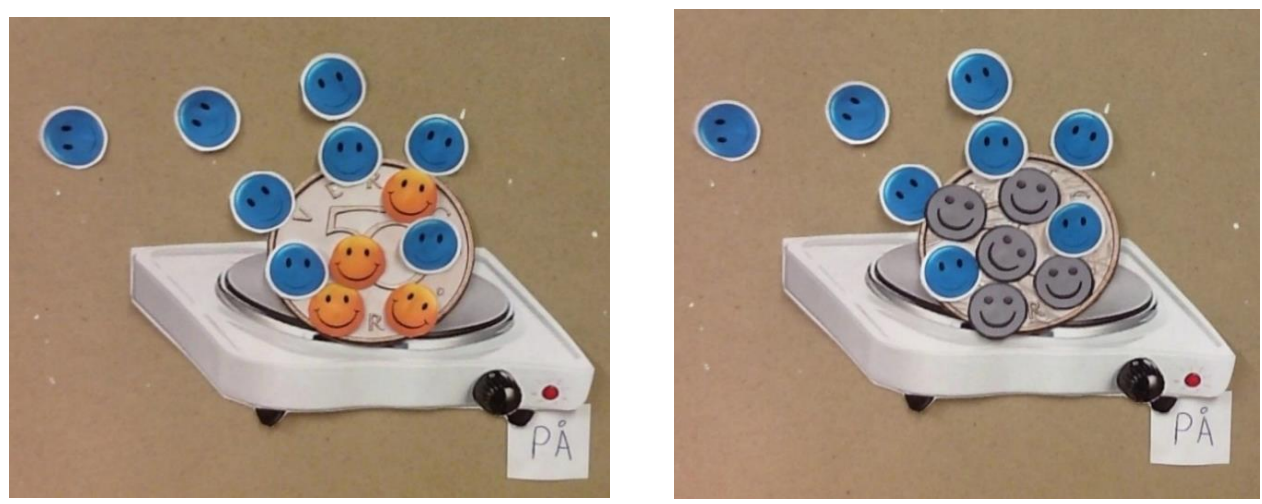

Figure 17. Two scenes from the same chemistry animation (DC4) explaining why a copper coin turns dark when heated. The orange atoms turn grey in the same way the coin does. In addition, this animation displayed anthropomorphic atoms with faces.

Anzelmo, 2001), which was frequently expressed in the same students' written answers (Study 2). While the students often wrote that cheetahs needed to get faster, the animations generally showed a population (often small) of similar individuals, except for one that had a clearly differing trait. Then the selection occurred in the form of a predator hunting, leaving the individual with the odd trait as a survivor.

In Study 2, most participating student groups made animations showing ENS as an event rather than accumulative change in a population over generations. In the written explanations this misconception was less frequent, leading us to hypothesise that the discrepancy was due to the mode of representation. Accordingly, as already mentioned, simplification of the modelling in $\mathrm{DC}_{5}$, by asking students to illustrate ESN of single-cell algae, and provision of feedback regarding their storyboards, enabled the students to represent several generations of the modelled organism and reduced expression of this misconception.

When words for describing a phenomenon are lacking, gestures and physical models can function as resources for communicating ideas. This was exemplified in Studies 3 and 4, as described in more detail in the next section on the process of generating animations. These resources may also make anthropomorphic and teleological expressions superfluous to some extent. When the students generated animations explaining chemical reactions, the visual mode made anthropomorphic use of words for atoms moving and actively taking up electrons unnecessary. However, as the mechanism could be shown directly anthropomorphism could be clearly used as a metaphor, as the physical models in a SMA are lifeless and cannot move without a mover. Thus, although one the animations displayed anthropomorphic atoms with faces (Fig.17), and anthropomorphic features (such as thought bubbles and clothes on animals) 
were commonly included in the evolution animations, there were few clear indications of intentional design of the next generation. So, they did not seem to reflect an intentional explanation.

\subsection{The process of generating animations}

When students generate SMAs they act as cocreators of content rather than being passive recipients of information, so there is a clear need to study the process of generating a SMA to explain a scientific phenomenon, and how it may support students' reasoning about spatial and temporal issues. Thus, in this section I present findings regarding how the generation of SMAs to explain ENS and chemical redox reactions facilitated students' engagement in collaborative reasoning about levels of organisation and dimensions of time. Results presented in Study 4 clearly indicate that creating SMAs helped students to develop their conceptual understanding of chemical reactions, in accordance with indications from other studies that the process facilitates understanding of scientific content (Akaygun, 2016; Macdonald \& Hoban, 2009; Nielsen \& Hoban, 2015). However, during the evolution animation workshops there were few instances of students challenging each other's ideas or clarifying and justifying their own ideas. Instead, several groups took a superficial route (Kidman et al., 2012), and only discussed aesthetic and comic features of the animations, which provided no support for claims that the process fostered deep reasoning and learning, although this could have been due to insufficient guidance regarding the key aspects to consider.

Similarly. during the animation process, many student groups in DCs 2 and 3 (addressing ENS) tended to focus more on superficial aspects of the phenomenon to be represented in the animations than the scientific aspects. Humour and the visual appeal of models were the main criteria considered in students' interactions. A further indication of superficial focus is that the students generating ENS animations in Study 3, measured the progress of the animation work, not by the coverage of the concept, but in terms of the amount of animation (in run-time) that had been produced: a quantitative rather than qualitative measure.

In the following text I present excerpts from student dialogue to illustrate their discussion of three issues during the process of generating SMAs: organisational levels, time (only during the generation of ENS animations) and realism.

\subsubsection{Students discussing organisational levels}

As illustrated below, the problem of representing processes involving phenomena on scales that are both too small and too large for us to perceive induced discussion as the students were faced with the task of explaining them in an animation. 


\subsubsection{Students' representation of the sub-micro level in chemistry and evolution}

Invisible, atomic-level phenomena are clearly beyond our perception, but the process of physical modelling in the approach of student-generated SMAs helped the students to reason about the particulate nature of matter and its dynamic properties on that level. Making physical models increased this abstract world's tangibility, and generating a SMA focused attention on dynamic aspects of chemical reactions. The following excerpt is part of a discussion recorded in Study 4, of a group who have generated a SMA of an electrolysis experiment, in which a key is copperplated using a solution of copper sulphate.

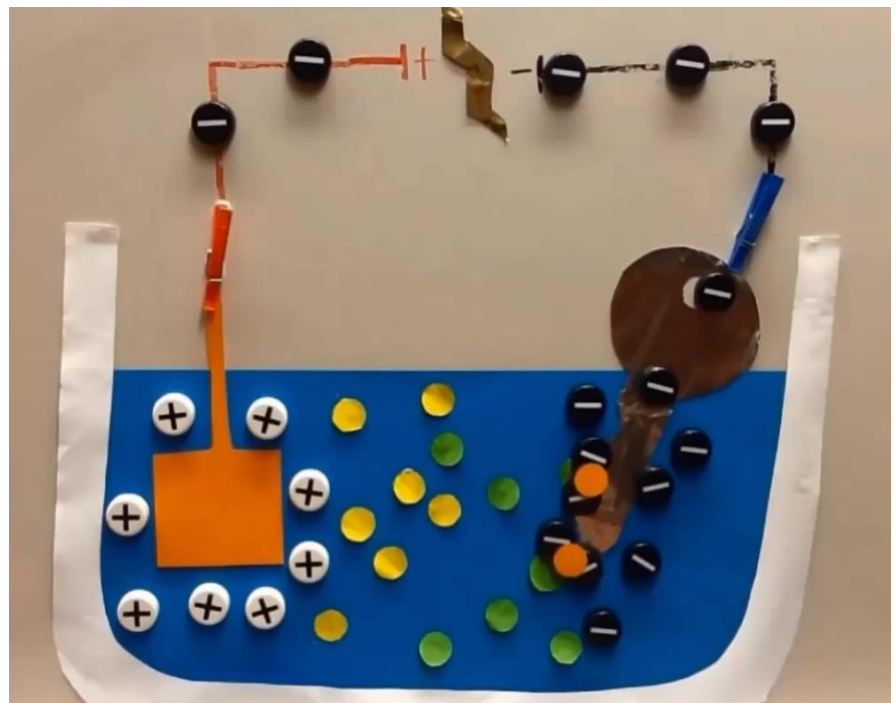

Figure 18. Scene from a SMA illustrating the copperplating of a key.

The students have made the scene with the models and started the photographic work (Fig. 18). Student 1 (S1) has moved some of their copper ion models (green circles) from the copper sulphate solution (blue, with sulphate ions represented as yellow circles) to the key, where they turn into copper atoms as electrolysis proceeds, and the number of copper ions in the solution decreases. S2 notices this, and draws it to S1's attention:

S2: There needs to be more green ones (copper ion model), right? Otherwise ...

S1: No but I think it is enough.

S2: Okay.

S1: Let's try this.

S2: Because all the green ones disappear.

S1: Yes, at the end they disappear ...

S1: But where do the yellow ones (sulphate ion models) go then?

S2: That's why I say that there must be more green ones.

S1: Yes, but where do the yellow ones go?

Initially, S1 does not see the disappearing "green ones" as a problem. However, she then focuses on the sulphate ions in the scene - "but where do the yellow 
ones go?" S2 replies "that's why I say that there must be more green ones", implying that she understands that the amount of copper and sulphate ions in the solution should be equal. This is an example of how moving the physical models in the set raised questions about the locations in space of specific particles and their spatial relation to other particles.

In relation to evolutionary change, making the sub-micro level visible should include showing genetic level events and origin of variation. As already mentioned, only one of the 18 animations in total included a reference to the origin of variation in the form of mutations. In the discussions during the animation workshops many students appeared to be aware of the mutation concept, but the depth and character of this conceptualisation were not always clear. The following excerpt from the Giraffe group (Study 3) provides an example.

S41: He doesn't grow.

S40: No.

S41: He doesn't get the mutation.

S40: He doesn't grow.

S41 mentioned a mutation that presumably gives taller necks, a concept of origin of variation that is not represented in the animation. Moreover, the way S41 uses the word mutation indicates that chance affects which individuals do and do not get it. Considering the amount of work the chemistry students needed to connect sub-micro and experiential-level phenomena, it is perhaps not surprising that a similar connection was manifested in only one of the animations produced by the evolution students. Moreover, in that animation (of purple men) the mutations concept was explicitly introduced in the narration rather than visually.

\subsubsection{The relation between macro and sub-micro levels}

In Study 4, participating students were asked not only to produce an animation but also include it in an instructional video about the school experiment. Hence, the students had to consider the relation between the experiential and submicro-level phenomena. One approach considered by several of the groups generating animations about chemical reactions was to zoom in to the sub-micro level. In the following example student $S_{3}$ tries to explain how they could zoom in from the macro level from a picture of a silver spoon:

S3: I think that you have ... if we say that we have [inaudible] this picture [starts to make a sketch of a spoon in a beaker with liquid]. [---] And so, you have this picture [puts his hand on the sketch of the spoon in the beaker]. And then zzz [makes a buzzing sound] you zoom in one more time. Here you see [draws a circle around a small part of the spoon]. [---]. You make a circle around this one [draws another circle on top of the first one]. And so, we zoom in, and then it becomes, and then we have aluminium [makes a new sketch below the first one, drawing two parallel lines] and ... 
The idea seems to be that the sub-micro level is something that may be reached by magnifying - zooming in - from the experiential level. In contrast to the chemistry study, where the students were assigned to relate spatial levels, the task of generating animations of ENS was open, so discussions about spatial levels were less prevalent than in the chemistry study. However, there were discussions about organisational levels among the students making the ENS animations. These instances were, however, coloured by the time constraint on the task, which prompted discussions concerning organisational levels as demonstrated below.

\subsubsection{Representing many, a population level}

The practical limitations e.g., the time to complete the animation task and limited access to material, prevented realization of some ideas. In the following excerpt from Study 3 we can see how the students negotiated to arrive at a compromise between what they know should happen and what they could represent.

S40: Hey, there are a lot of different ones.

S41: There is only one that is small. They will not be able to reach that one from the start, there is never that much of a difference in a species.

S40: No, I did not get, I also understand that.

S41: Yes.

S40: But, like... i don't know. It all depends on how you think. Do you mean that they, this should grow? (Points at the neck of the giraffe-like model)

S41: Mm.

S40: Ok, that's one way to do it.

S40 clearly recognises that they should represent a process that works at a population level, so they need to make several individual models. However, S41 seems to lean towards the idea that the necks can just grow, at an individual level. The spatial (organisational) level that the process should be represented needs further negotiating.

S40: Alright, let's make a population then. We doesn't need to make a whole lot. We can make...

S41: No, that would be deadly tedious. Just take two.

S40: Three.

S40 decides to give up his idea about large populations in favour of S41's argument that it would require a lot of work. Thus, the practical constraint of making a lot of giraffe models led these students to abandon the populationlevel explanation and instead generate a small group of animals. The resulting animation was a compromise in which S40's idea of selection is shown in the first part of the animation but then the evolution of long necks is continuous as S41 wanted. 
The end of this excerpt highlights one of the limitations of using clay models and SMAs to illustrate populations. It is time consuming to generate many models, especially realistic ones, and making them all move in small steps is very laborious.

\subsubsection{Students discussing time in the animations}

As we have seen, time was not always represented in a scientifically correct way in the SMAs, but this does not necessarily reflect misunderstandings and may be another effect of representational constraints. The outcome in these cases (representation of evolution as an event) may not have been what the students intended. In one passage from DC2, student $\mathrm{S}_{5} 8$ mentions that what they are representing is not a single animal morphing, but a change in a large number of generations. While looking at the animation in the middle of the process of generating it, this exchange occurred.

S58: It simply, POFF, and then it has changed

S56: Can I see?

S58: It was so cute when it sort off pranced.

S57: It is pretty cute (unintelligible)

S58: (Laughing)

S57: But (he, he) it can (unintelligible)

S58: In less than one second it have passed like. A thousand generations.

S57: Mm

S58 uses generations as the measure of time in her last utterance indicating some conception about what counts as evolutionary time. However, this knowledge was not detectable in the animation. One thought is that use of malleable clay for modelling enabled this metaphoric metamorphosis into a dolphin over a time of a 1,00o generations, but unfortunately the students did not make the metaphor explicit in the animation.

In attempts to illustrate ENS there is the problem of showing generations. When working with animal models that means both showing the relation between the parents and their offspring (genetically) and speeding up the growth process from infants to adults that can initiate the next reproduction cycle. Some of the groups got stuck on this issue, like S44 from DC2. The first idea seemed to be that the offspring could simply "pop up".

S44: But how could we do this? Would it be possible to make something like this... wait (manipulating the clay models) (unintelligible)Ypp, ypp, then they come like this (Paus, while moving the models) Would it be alright to place them like that? And then a child pops out between, and then another one pops out. And then like 'we are a family'. 
This issue became even more accentuated when a lot of work was invested in each model. For example, a group was inspired by Pokémon evolution and created three generations of fighting turtles. They were unable to continue their work before they could come up with some way of showing the turtle baby growing up.

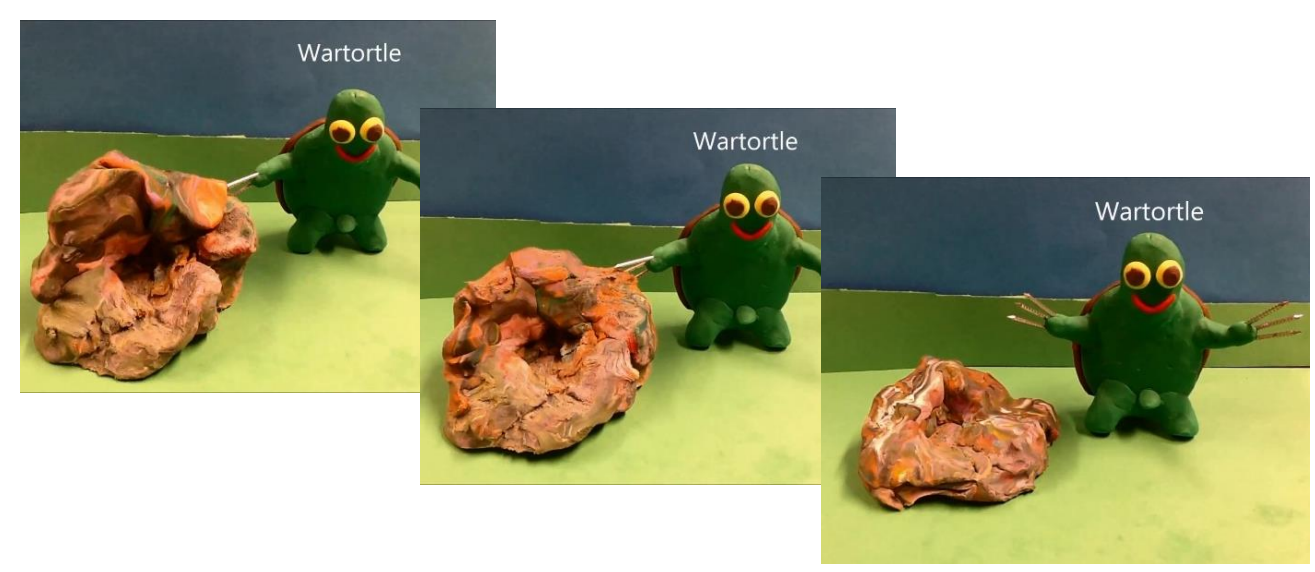

Figure 19. Scenes showing the illusion of a turtle growing up, accomplished by shrinking the object beside it.

Their solution can be seen in Figure 19. Instead of making a series of models in different sizes, they made an object beside the model and gradually made that smaller so the model of the turtle would appear to grow.

The problem these students had portraying an individual's growth indicates just part of the problem of coordinating phenomena with differing timescales to produce a clear explanation of ENS. These include instantaneous events such as mutations, through perceptual events such as a predator chasing prey or an individual finding a reproductive partner, and more prolonged processes such as growing up, to very slow processes such as cumulative change over hundreds of generations and radiative evolution. Portraying events on all these timescales is clearly very challenging and it is hardly surprising that none of the groups fully succeeded.

\subsubsection{Students discussing realism in models}

As described above, the students in my interventions often focused on superficial elements. This is exemplified by the following short exchange between two secondary students choosing material for their models.

S57: We should not take too dark (clay), a dolphin isn't as dark as this.

S58: Ah but, it can't be all realistic.

S57: But I want to be realistic.

S58: It is not made from clay if you have to be so realistic, should we get a real dolphin or what? 
S58: But there is black (clay) it's just that...

S57: How big should our dolphin be?

S58: Or it could be pink.

S57: A dolphin cannot be pink.

S58: No, that is because you lack fantasy.

S57: But a dolphin isn't pink, is it?

Creating their physical models (and having access to materials with different colours) made the students think about the size and colour of the things they wanted to represent. However, some students, like S58 in the excerpt above, realised that a model does not have to be realistic to be able to communicate a concept. The students generating SMAs about chemical reactions had similar discussions. Here is an example from the group working with the cucumber battery (Fig. 14), where they are negotiating the size of the cucumber model they are about to cut out from green paper.

S2: We cut out and make it look like nails sitting [on the cucumber] [S2 points at the green paper].

[..]

S1: We're not supposed to see the nails on the atomic level [since we'll zoom in].

S2: No, but you still need it, and then you must go in, and then you will [inaudible]. You need to show what the cucumber itself looks like. Or?

S1: Or we can make a small cucumber with two nails in it. Because then you're supposed to only see like ... [begins to place small Lego bricks in a row on the table]. If we imagine the nail looks like ...

S1 draws a straight line in the air and concludes that "you see there is a straight line, sort of, but it's built of atoms." S3 disagrees with the suggestion of using a small cucumber model and emphasizes that they should use a bigger model where they zoom in on the nails (see section 9.2.1.2)

S1: I think it won't be realistic in size. I think. Because the atom is so tiny, tiny, tiny, tiny, tiny compared to the whole cucumber. You know what I mean?

S3: But it's a model.

S1: Yes.

S3: It's a model, models are not realistic.

S1: But you can make quite realistic ones.

The students seem to be stiving to come up with a way of representing the exchange of electrons on a sub-micro level while still having visual references to the experiential level. S1 wants it to be realistic while the other two students are leaning toward a more symbolic approach. S1 makes an important point: that focusing on the two nails and the cucumber (experiential level) will make an 
explanation of the phenomena at sub-micro level unrealistic because of the different scales. They both stress important representational aspects - what features of a phenomenon a representation should and should not account for. However, they seem to have difficulties discerning which aspects are important and which are trivial, leading them to discuss what a model really is.

These examples indicate that making models affords discussion about what a representation is for and awareness about the design choices that is associated with constructing this type of representation. This relates to the idea of representational skill and show that the task prompted the students to discuss this issue, a potentially important part of this approach, which would be less prominent if the animation was generated on a computer in a special predesigned environment like Chemation (Chang et al., 2010).

\subsubsection{The storyboard: a target for teacher feedback}

As Hoban and Nielsen (2013) showed that much of the students' joint reasoning when generating an animation occurred during the storyboarding stage we wondered how this part of the task was realised in our studies. Initially, in DCs 2 and 3 the students were trusted to produce the storyboards themselves, but several groups skipped this stage altogether. This led us to include a storyboard workshop in DC4. In the analysis of the videorecorded workshop, we could see that this was a stage where the students really started thinking about the relations between organisational levels, which they had not done in the work in the laboratory. Finally, in $\mathrm{DC}_{5}$ a scaffolding revision was added after the storyboard workshop. This supportive criticism was provided by a researcher who gave written feedback regarding each storyboard. 


\section{Discussion}

"(T)he purpose of a slowmation is to explain a science concept clearly..." (Hoban, Nielsen, Macdonald, \& Ferry, 2009, p. 62) and increasing numbers of studies where student-generated stop-motion animations (SMAs) have been applied in science education, focus on learning processes or their outcomes (Farrokhnia et al., 2020). As already mentioned, one aim of challenging learners to become cocreators of content instead of passive recipients is to enable integration of learning and assessment, focusing on the learners' active construction of knowledge (Ausubel, 1968; Papert \& Harel, 1991) and probing understanding in performance (R. White \& Gunstone, 1992). This was also a focus in my work but my interest in SMA was initially raised as a complementary method for probing students' conceptions about evolution by natural selection (ENS). Potential use of the SMA approach for probing students' understanding of science concepts has largely been neglected in previous research but has recently received some increased attention. The following discussion is structured in two main sections, the first addressing student-generated SMAs for probing students' understanding and the secondly students' generation of SMAs as a learning activity.

\subsection{Student-generated SMAs for probing students' understanding}

There are many methods for investigating understanding, but written tests with multiple choice or open response questions are with clinical interviews may be the most common. Of these, multiple-choice tests have received criticism for measuring recollection rather than allowing the learner to show higher order cognitive skills (J. I. Smith \& Tanner, 2010). As curricula are focusing more on the practice of science than stacking facts, more dimensions of scientific literacy should be considered when evaluating different educational efforts. This calls for alternative forms of assessment (Laverty et al., 2016). Furthermore, many learners have an instrumental approach to education, and therefore study only to pass tests (Hoban, 2010), so the form of assessment influences what students gain from education. In the work underlying this thesis, I have (together with colleagues) explored an alternative approach for assessing cross-cutting concepts, and disciplinary core ideas related to topics that have proven to be challenging for learners.

\subsubsection{What do students' animations reveal about their understanding?}

A key question is: What information about students' conceptions did we get from the SMA approach? The first response is that it revealed similar frequencies and patterns of the key-concepts about ENS to those reportedly expressed in written tests (Andrews, Leonard, Colgrove, \& Kalinowski, 2011; McLure et al., 2020). If this was the only result from my studies, there would be little point in introducing student-generated SMAs into the classroom. However, there were also novel findings made regarding alternative conceptions and creative representations indicating the informal associations with ENS that the students bring into the biology classroom. 
It should be noted that the assessment method in our application of the SMA approach differed from traditional written tests and interviews in that besides the students generating multimedia representations of their understanding it was conducted in a collaborative setting. Ideally only one variable should be changed at a time, not two simultaneously, which affects the possibility to draw clear conclusions about understanding of either variable, but on the other hand they can be seen as a package, incorporated in this SMA approach. Collaborative generation of SMAs have been the dominant setting in previous studies as well (Farrokhnia et al., 2020) as one of the advantages of student-generated SMAs is to induce student discussion. These peer-to-peer discussions can reportedly elucidate pre- and alternative conceptions about the focal topics (Loughran, Mulhall, \& Berry, 2008) and illuminate the animators' meaning-make of a concept (Kidman et al., 2012). Furthermore, several studies have shown that collaborative approaches to learning ENS have positive effects (JiménezAleixandre, 1992). Assessing students' work when generating animations in small groups should not be problematic as students generally tend to work together in small groups in various laboratory activities that teachers already routinely assess.

\subsubsection{Alternative conceptions in a new light?}

Decades of studies on learners' conceptions about evolution have revealed that learners come to the classroom with alternative conceptions (Harms \& Reiss, 2019). Furthermore, it has been proposed that these alternative conceptions are highly tenacious because they originate from intuitive conceptual systems (Coley \& Tanner, 2015) related to teleological, anthropomorphic, and essentialist thinking.

Observations in Study 1 revealed inconsistencies in patterns of students' explanations depending on the task context, in terms of type of organism and the direction of selection (trait gain or loss). This not only applied to the keyconcepts, as found in previous studies (Nehm \& Ha, 2011), but also threshold concepts. The detection of item-effects on the explanations was interesting as it clearly conflicted with the idea that the explanations were based on a 'cognitive construal'. When the students' task was change from individually generating explanations in writing to collaboratively generating animations we found while intentional reasoning (teleology and anthropomorphism) and essentialism was common in the students' verbal and written communication, it was to some extent less evident in the visual mode in the animations. It would be presumptuous to draw extensive conclusions based on the studies presented here, but some indications of these misconceptions' nature and how they could be countered can be discussed in the light of other research.

The finding, that lower frequencies of alternative essentialist, explanations were expressed in the student-generated animations prompted us, like Gouvea and Simon (2018), to question the often-reported robustness of these misconceptions and their cognitive origins. Like (Southerland et al., 2001) we cannot, put an end to the debate about conceptual frameworks or knowledge- 
in-pieces, but our findings are harder to explain using the framework view. Thus, we lean towards regarding students' conceptions as flexible and their expression variable depending on task, context and offered means for expressing them. A consequence for assessment is that a single test gives a limited view of how a person conceptualizes a concept. Hence, I support recommendations that assessment tasks should be aligned with the way topics are taught (Lowe et al., 2017) and have broader scope than narrow conceptual understandings like communication and digital literacies (Nielsen et al., 2020).

The representational affordances offered to the respondents could also contribute to this lack of constancy (Prain \& Tytler, 2012). While essentialism is often used metaphorically in writing, the visual media afforded students to make the levels of organisation clear and distinct. As already noted, some scientific explanations are similar to narratives (Norris, Guilbert, Smith, Hakimelahi, \& Phillips, 2005; Ogborn, Kress, \& Martins, 1996), and this is certainly true for evolution (Mayr, 2004; Zabel, 2015). Furthermore, we all consume narratives in a visual/multimedia format every day watching television or YouTube, which could create a strong association between the animation format and narratives. This is potentially problematic because individual protagonists play central roles in narratives, which clashes with the Darwinian view of natural selection acting on populations, not individuals.

Another perspective on why students persist in using teleological explanations is that the they simply need to be made aware when to apply an emergent schema (Grotzer et al., 2017) or learn that such a schema is possible (Chi et al., 2012). Instead of guiding the students to explain changes in species with an emergent causal schema, they may get stuck in a narrative mode and left without scaffolding instruction represent a slow process (evolutionary change) as an event caused by the outcome of the process.

This perspective seems promising (Ferguson \& Lynch, 2014; McLure et al., 2020) but was not investigated in my studies. Although there are many emergent phenomena in chemistry (Chi, 2005), it seems that redox reactions can be productively represented in the direct causal manner using SMA. ENS in contrast was in other ways challenging for the students to represent in a SMA as a direct causal schema is not equally applicable in this case. Other studies on student-generated animations with positive results for learning have, for instance, focused on the topics of phases of the moon (Nielsen \& Hoban, 2015), and mitosis (Kamp \& Deaton, 2013) which also have direct causal explanations. For further exploration of the kinds of topics for which a SMA approach can be productively applied, a study on diffusion would be interesting.

On the issue of using SMAs for probing understanding, Keast, Cooper, Berry, Loughran, and Hoban (2010) applied the approach to probe alternative conceptions of participating teacher students. Other studies also indicate that student-generated animations can elucidate alternative conceptions (Yaseen, 2018), and our example of a heated copper coin changing colour shows (Fig. 17) that the animation format provides a direct way for communicating ideas. On 
the other hand, our analysis of animations intended to illustrate ENS indicates that alternative conceptions are expressed less frequently in animation media than in written answers (Paper 2). It could seem contradictory to use a method that reveals fewer alternative conceptions to identify alternative conceptions, but this would be a misleading interpretation: animations provide a useful and direct way to represent and diagnose learners' conceptualisation of a process (Akaygun, 2016). The key point is that some students' expressions of alternative ideas may be connected to the format of the medium available for producing explanations (Akaygun \& Jones, 2014), and an important feature of animations in this respect is their dynamic nature (Farrokhnia et al., 2020).

\subsubsection{The role of prior knowledge.}

The framing of the ENS and chemistry animation tasks differed substantially. Students were asked to explain the abstract concept of ENS with no set context. In contrast, the teacher students asked to explain a chemical reaction had concrete experience of a laboratory experiment to guide them. Moreover, although ENS is described as difficult, the analysis of the animation process suggests that the chemical topic was even more distant from the students' everyday experience. They approached almost every issue they encountered as if they were thinking about it for the first time, while the students approaching ENS seemed to have picked up ideas from popular culture that they frequently used when designing their animations. Chemistry was less familiar to the students than evolution which may at least partly explain why chemistry is less associated with misconceptions than biology (diSessa, 2009).

In the notes from the work with generating animations during data collection 5 , the importance of prior knowledge manifested in another way. The model organism dictated in the task was a hypothetical alga, instead of simplifying the work and helping the students focus on the main concepts, this raised numeral questions among the students. They had no clear perception of what kind of organism a single-cell alga is, and therefore had to spend time trying to figure this out, which may have prevented them from discussing the process of ENS. Furthermore, the apparent relative familiarity of evolution among the students in DCs 2 and 3, in some cases may have caused an illusion of explanatory depth (Rozenblit \& Keil, 2002) making them underestimate the complexity of the concept and thus not realising the usefulness of a storyboard and putting the energy on humour and appearance of the models, which may had other benefits as discussed in the next section.

\subsubsection{Students' creativity}

Expressing their understanding of a science concept in an animation affords students an opportunity to generate an explanation in a more personal way than a written answer to a test item can. This may have contributed to the finding that all the groups of students in our studies generated unique animations using their own ideas, modes of expression, creativity and imagination.

In accordance with findings by Nielsen et al. (2020), a desire to amuse seems to have influenced the students' design choices when generating multimedia 
explanations. In the evolution studies, members of the intended audience were peers in a parallel class, and the students added the goal of the animation being entertaining (in addition to providing a clear explanation of evolutionary change).

In many cases the ideas were taken from popular culture, like the march towards man trope (Matuk \& Uttal, 2012), and the Pokémon games (the 'Wartortle' animation, (Fig. 19) where the monsters evolve in a specific way. Several groups attempted to twist classical narratives for example showing an animal starting to swim in the ocean and evolving flippers, in contrast to the well-known story about aquatic animals evolving legs and living on land. A few groups also deviated from the many examples of physical traits evolving and made an animation showing that social behaviour can be affected by natural selection.

Other groups stuck to examples from the biology textbooks, showing (for instance) how giraffes got long necks. Overall, almost 90\% of the ENS animations in study 2 contained some humorous detail or imaginative details, often towards the end of the animation.

These examples of references to popular culture tell us something about the learners' conceptions of evolution. Their understanding clearly is not only influenced by science education but also by the various ideas and images of evolution that circulate in society. Thus, our findings provide indications that ideas (and incorrect versions) of ENS have pervaded society, but to my knowledge their effects on evolution education have not been previously explore and they require further attention.

In the chemistry animations examples of humour or flirting with cliché were observed, but they were less frequent. One example likened the presentation of the school experiment to a cook preparing a dish in advance in order to show the results in cookery show. Some of the evolution animations also seemed to parody nature shows on TV.

One of the arguments for introducing this kind of activity in the classroom was to show an aesthetic and creative side of science, but there must be a balance between just having fun and actually practicing science communication and developing understanding of the concepts.

\subsubsection{Animals}

Allowing students to pick what organism they wanted to work with led to a clear result. All groups in Study 2 chose a scenario with animals (or simplified models with animal behaviour). This is potentially interesting as it could be an expression of thinking that evolving organisms need agency, which passive plants lack. The finding may also be linked to the phenomenon of plant blindness (Wandersee \& Schussler, 1999), i.e., plants simply not being noticed. The implied neglect of the crucial ecological roles of organisms accounting for of $80 \%$ of the biomass on earth has raised calls to pay more attention to plants 
in biology education on all levels (Jose, Wu, \& Kamoun, 2019). Furthermore, this reinforces a need to expose learners to ENS in contexts of organisms other than animals (Pugh et al., 2014).

Accordingly, Study 1 showed that changing to a bacterial context, led students to incorporate the origin of variation and the micro-levels of organisation in their explanations. In $\mathrm{DC}_{5}$ we designed the task to focus on single-cell algae, primarily to simplifying the model-making, but it also provided a rare example of teaching ENS in a non-animal context. Our observation was that the participating students had little pre-knowledge or understanding of the life conditions of algae, which may have contributed to difficulties they showed in imagining scenarios without the algae mating and moving around, in several cases the algae in their animations even used eyesight to find food. This observation indicates that a requirement for agency in evolutionary change might be a deeply held conception and that evolution education should be enriched with more examples from other kingdoms beside animals (McLure et al., 2020). This could allow learners to practice transfer of the principle between contexts and maybe shift from an agent-driven to a mechanistic explanation of evolution (Grotzer et al., 2017). This would be interesting to explore further.

\subsection{Representational skills}

The literature about student-generated SMAs noted that digital literacy is highly important for students' ability to express their ideas in a SMA (e.g. Farrokhnia et al., 2020). Thus, students' lack of experience of generating animations may partly explain why participants in Studies 2 and 3 skipped planning stages. Few groups made real storyboards according to the $5 \mathrm{R}$ model (Hoban \& Nielsen, 2010), so most students missed an opportunity for reflection and did not make a representation that would probably have improved their understanding and facilitated work in subsequent stages. In Study 4 and data collection 5 in which the animation intervention was an integral part of the teaching learning sequence, we included a workshop for generating storyboards to prevent the students skipping this representation.

Elements of digital literacy include the representational skills needed to interpret and generate multimedia explanations. Important skills in the context of our studies were abilities to represent time and space in the multimedia mode of SMA. Some groups made great efforts to do this, indicating that there are foundations to build upon. Inclusion of discussion about different strategies for handling challenges related to representation of different levels of organization and time at the beginning of a project could help development of these skills. In addition, the teacher must be aware of representational challenges connected to the focal topic(s). For ENS the main difficulty lay in finding a way to show processes happening at different timescales, which could have been emphasized more in the instruction. In the case of chemical reactions, the need to connect the sub-microscopic and experiential levels was clear in the task and all groups strove to find ways to do so. 


\subsubsection{Representing organisational levels}

The chemistry task clearly required, and elicited, exploration and representation of phenomena at the invisible sub-microscopic level, which also should have received attention in the ENS animations. However, there was a striking neglect of the genetic level and molecular origin of variation in the ESN animations generated by students in both my studies and previous investigations using traditional methods (Kalinowski, Leonard, \& Taper, 2016). This problem is even more acute if only a historical Darwinian perspective of evolution is presented. In such cases an important part of the mechanism is lacking in the explanation. If there is no clear, non-directional, causal indication of the origin of variation, the field is open for more intuitive explanations based on intentionality and teleology. Although the students used the word mutation in their written and verbal communication only one animation in Study 2 portrayed mutation as a cause of new variation in a population. The far greater attention to connecting phenomena at sub-micro level with experiential observation may reflect difficulties the teacher students had in their animations of chemical reactions.

Connecting phenomena at these two levels was challenging, as shown in earlier research. However, our analysis of the process of generating the chemistry animations in Study 4 also showed that the sub-micro level may need further differentiation. When the students began making models that should have represented electron transfer it became clear that they did not understand the relations in size between electrons, atoms, and molecules. The models of the three levels of chemistry (Johnstone, 1991; Taber, 2013) would be even more useful for teachers if the sub-atomic (proton, neutron and electron) level was included. This also relates to biology education as many biological concepts concern levels of organisation ranging from macro to very sub-micro (Tsui \& Treagust, 2013). The example of ENS also highlights a problem with calling all things that are at least of visible size macro. Many phenomena representing high levels of organisation - including most populations, species, and ecosystems are too large to bring into the classroom and must be represented to be tangible for learners.

Most groups that generated ENS animations represented small populations. The negotiations about the minimum size of a population required to explain, for example how the giraffe's neck became so long could also be seen as a representational negotiation based on the students' representational competence. Sometimes an explanation is clearer if a few examples are shown instead of many. Accordingly, the teacher students representing chemical reactions close to show few examples. Although many student groups generated several models of atoms and ions, the reaction was often shown with two particles exchanging electrons. No group in the chemistry study attempted to generate a more realistic large multi-particle system with many reactions occurring simultaneously.

Another issue associated with population size and large numbers of particles, beside the laboriousness of making and moving numerous individuals, is that it 
is difficult for viewers to tell what is happening if there are numerous moving individuals (Paivio, 1991; Sweller, 2005). This effect became clear for the groups who slowly moved individuals in scenes they created in small steps, tracking what happened to each individual, because when they played the animation at normal speed, they were overwhelmed by all the movement on the screen. Even six or seven individuals moving around on the screen makes observation of important variations among the individuals impossible. The problems associated with many moving entities on the screen are also relevant when representing chemical reactions. With realistic molecular movements it would be impossible to observe the reactions, this is perhaps so obvious and therefore was never really discussed during the chemistry project. Every group represented a few particles and focused on those taking part in the reaction.

In a similar vein, that variation was represented in an either-or way instead of as continuous variation in most of the animations could be blamed on that students have read too much Mendelian genetics, which often focus dichotomous traits. However, it could also be a manifestation of representational competence: if it is a big difference between individuals, the difference is easier for a viewer to notice and keep track of. With this interpretation this becomes a feature and not a flaw.

\subsubsection{Representing time}

The disciplinary representations of chemical reactions and evolutionary change do not always give a clear understanding of the processes they are supposed to represent. What happens 'behind' the reaction arrow in a chemical equation is not obvious to a learner (Davidowitz et al., 2010; Taber, 2009). The lines in evolutionary cladograms pose similar challenges for learners (Gregory, 2008) and many college students reportedly interpret them as representing evolution as an either anagenic (rather than cladogenic) or teleological process (Catley et al., 2010). Our studies show that representing either ENS or chemical reactions is challenging and generating a dynamic multimedia explanation in the form of a SMA gives students an opportunity to tackle them in an alternative way.

Participants in the chemistry study slowed the fast processes and movements of electrons in chemical reactions effortlessly and without explicit reflection. This may have been simply because the students had little understanding of how rapidly atoms move (Akaygun, 2016)as such dynamic aspects of sub-micro level particles are not represented in the static representations in chemistry schoolbooks. Accelerating the passage of generations to provide enough time to portray the process of ENS was a more obvious challenge. The mentioned examples of a fast-forward arrow and supplementary text can be interpreted as signs that the students had a competence to represent a compression of time. Here too, the analysis of the students' work process indicates that dividing time into normal time and deep time (Catley \& Novick, 2009) is not enough to support students' understanding of the process of ENS. When working with the animations some student groups got stuck trying to think of ways to accelerate the process of growing up. 
Important aspects of time are the chronology and causality of events: what happens first and what does it lead to? Discerning these features of simple chemistry reactions is a straightforward matter of identifying reactants and products (although it may be far from straightforward if complex pathways with multiple interacting reactants and other variables are involved). In contrast, there are generally much less clear causal relations in ENS, although examples like increases in the cheetah's running speed may give that impression. Learners seem to have difficulty grasping that there is variation among individuals in all traits, regardless of their selective value, and tend to use an explanation (a favourable trait will arise if there is a need for it) that is close to a narrative format (Ware \& Gelman, 2014). However, our analysis of the SGSMAs indicates that in most cases variation was present in modelled populations before selection occurred, so more detailed studies of students' conceptualisation of causation in the process are needed.

The time-consuming methodology may have contributed to a pattern of declining level of explanation (from detailed initially to more schematic towards the end) observed in several of the ENS animations. For instance, an animation in which parts of a population were divided by a river began with a detailed description of the mechanism, but in later parts the evolution happened very rapidly. This may have been a clever way of speeding up the explanation: first establishing the mechanism then continuing the explanation in a simplified manner, assuming that the viewer keeps the mechanism in mind. If so, it would manifest a sort of representational competence of simplification. An alternative interpretation relate to the time constraint is that several groups may have been running out of time at the end.

\subsection{The process of generating stop-motion animations}

In the SMA literature there are claims that generating animations leads to increased conceptual understanding of the science subject matter represented in the animations (Hoban \& Nielsen, 2013; Keast et al., 2010; Macdonald \& Hoban, 2009). Van Meter, Aleksic, Schwartz, and Garner (2006) show that learner-generated representations (drawings) support higher order thinking rather than factual recollection and point out that this should be considered in assessment of such strategies.

In their written evaluations the students in our studies stated that it was fun to do something other than having lectures, but they had not learned much. Moreover, the teacher students thought that they learned more from the chemistry laboratory work than generating the animations. However, our analysis of the video-recorded work indicates the opposite, as there was little chemistry talk during the work in the laboratory and much more during the animation process (Study 4). A possible reason for the discrepancy is that this approach to teaching and learning seemed too unfamiliar to the students to be regarded as learning. This is one risk of educational innovation (Brown, 1992). The students may not have recognised the animation task as a learning situation in science education, which could perhaps tell us something about their idea of 
what learning science is and hence what science is. Approaches like studentgenerated SMA could potentially change such narrow views of science.

According to Hoban and Nielsen (2010), students develop understanding through re-representing their knowledge five times when generating a SMA. Clearly, each representation in the process poses new challenges to the students, requiring them to reconsider their prior conceptions and renegotiate them. During planning and storyboarding students often underestimate the complexity of evolution. As they engage in making models, they tend to focus on realism before usefulness, e.g., making fish look fishlike rather than thinking about how to show that the maximum swimming speed of the fish was a trait under selective pressure. When the students start moving the models, they realize that some things were taken for granted in previous stages.

Re-representing the processes of ENS and chemical reactions in new modes involves translation between modes (P. J. White et al., 2020) which develops thinking if the students do not get stuck on superficial details. Furthermore, our analysis of the process of generating SMAs show that it is not such a direct process of going through a series of four distinct phases as originally suggested (Hoban, 2007). We found that the students worked on the story while they generated physical models and when taking pictures. Depending on the representational possibilities and obstacles they encountered in the process their original ideas had to be reconsidered and modified, making them move between the phases in a non-linear way, as also described in studies on the process of generating SMAs (e.g., Hoban et al., 2009).

Our studies also confirm previous findings that important activities in a SMA approach that can improve learning outcomes include peer-feedback and adding narration (Farrokhnia et al., 2020).

\subsubsection{Feedback}

In efforts to avoid the known tendency of learners to make funny animations if they are given free rein (Kidman et al., 2012) we tried using peer feedback in our data collections rounds, but this was not productive. During $\mathrm{DC}_{3}$, students from different groups were brought together to discuss each other's storyboards, but there was little real discussion. Typically, one student presented an idea, there was very rarely a written storyboard for the others to see, and the other students asked very few questions, just valuing the ideas as fun or good. Similarly, during the presentations in DC2 some of the animations led to discussion about the process of evolutionary change and the mechanism behind it, but mostly the students were very polite and gave superficial feedback.

Giving productive feedback is a skill that students may need help with. One idea with proven utility is to provide learners with a rubric to support their evaluations (Kamp \& Deaton, 2013). However, the groups of teacher students (who probably had more practice in giving feedback) did challenge each other's ideas. It should also be noted that when working with young teenagers, social factors may inhibit individual students from speaking their mind in such a 
situation. This issue was addressed in DC 5 by letting the teacher (researcher) give written feedback on storyboards. In addition, task design was steered to a context with simple organisms (single-cell algae) enabling creation of larger numbers of individuals and generations, which increased the frequencies of representation of inheritance and timescales. Our comparison of the content of the student-generated animations showed that constraining the task to simple lifeforms enabled the generation of more models and with the supportive feedback on the storyboards, the students in the last study were able to represent several generations (Fig. 13).

Similarly, Kidman et al. (2012) note that students may proceed through the steps of their meaning-making, animation, editing, presentation, explanation, and reflection (MMAEPER) model in ways that promote mere surface learning or deep learning, depending on their engagement with the task of rerepresenting a concept. Kidman et al. (2012) and other authors also highlight the importance of the teachers' scaffolding in a representation construction approach generally and an SMA-based approach in particular (Farrokhnia et al., 2020; Tytler et al., 2018).

\subsubsection{Narration}

Narration was not only useful for viewers of the animations, but also helped the students relate to the scientific concepts (Study 4). This supports previous findings by e.g. Hoban and Nielsen (2013) that adding a narration can strongly enhance the stimulation of learning in the SMA approach. In a study of teacher students' production of animations of the lifecycle of a ladybug, they found that adding a narration induced student discussion about the concepts to be represented. In our study with teacher students generating SMAs of redox reactions, we found that adding narration was important for focusing the students' attention on the scientific vocabulary. While working with the first parts of the animation process, the students in our study used everyday language or substitute terms (e.g., "the green ones") or gestures to stand in for the scientific vocabulary. However, when they were adding the narration, the need for more precise scientific terms became clear.

\subsubsection{Choosing a reasonable task}

Earlier studies on the process of generating SM animations focused on topics involving directly causal processes including the lifecycle of ladybugs, phases of the moon, chemical interactions, and microscopic or cellular biological phenomena. These studies showed that the approach can engage students and provide learning gains. In my studies on student generated SMAs to explain ENS stand out in this respect, as the topic is huge compared to the lifecycle of a ladybug and the other previously covered topics.

Evolution and evolutionary change through natural selection are intimately connected to several kinds of content (e.g., genetics, molecular biology, physiology, anatomy, population dynamics and ecology) that a beginning learner in biology (secondary level) is unlikely to understand well. Thus, when 
asked to explain how a species can evolve s/he will be uncertain about many potentially relevant aspects, unlike a biology expert. So, any beginner will find explaining ENS in a SMA challenging, and that numerous aspects are difficult to represent.

From a review of the research on SMAs in science education Farrokhnia et al. (2020) concluded that the topic being animated needs to be restricted and not too difficult to represent for the approach to stimulate deep learning. Based on my studies I would like to add that a suitably constraining context of the task requires consideration. The apparent similarity of the stop motion technique and ENS did not lead to a conceptual transfer by itself, and the time-consuming nature of the technique suggests that it is more suitable for students generating animations about shorter processes like chemical reactions.

In the chemistry study, the task of generating an animation was given a context that constrained the students' work in a way that the evolution task had not. The ENS task was open, asking for an explanation or description of a general principle and the students could come up with any example they wanted to use in their animation. In this round the teacher students performed several laboratory exercises and chose one to present and explain in their animation. However, the choice was restricted to these examples, they could not invent any fantasy chemical reaction to illustrate. The task was further constrained by an explicit demand that they provide an explanation at the sub-microscopic level and relate it to perceptual level observations in the laboratory, thereby explicitly treating the threshold concept of scale, although not in terms of a threshold.

\subsubsection{Physical models}

One aspect of generating SMAs that has not been emphasised in earlier studies is how creating physical models may either help or hinder expression, depending on what concepts are supposed to be represented. In Study 4 we show how generating physical models can make abstract concepts concrete and help students communicate ideas before they have words for the concepts. However, generating the physical models from clay or other materials took too much time for attempts to explain ENS using SMAs, hindering the students from generating several generations of populations.

An alternative to SMAs for representing these aspects, with reportedly promising results, is to use some sort of simulation software. For example, Wilensky and Reisman (2006) found that the NetLogo programming environment helped a group of students to explore population dynamics in a productive way. The same program has been used by other researchers to facilitate students' exploration of the mechanism of natural selection (Ferguson \& Lynch, 2014). In a further example, in the Evolution readiness project Horwitz (2013) found that game-like simulations of evolution can be powerful tools for learning the complex process of ENS. However, we did find in Study 4 that the dynamics of chemical reactions became clear to the students in the animation workshop, not for calculating kinetic parameters of the reactions and the speed 
of particles in solutions, although that could be an interesting focus for the SMA approach in a different course. The attention of the teacher students in our study was directed to the movements and mechanics of chemical reactions, and a conclusion is that the models and animation format made the mechanisms of change/causal chains of events concrete.

\subsubsection{Engagement}

The students in our studies seemed engaged by the task of generating SMAs and according to the written evaluations did not think it was too difficult (Hoban, 2007; Kamp \& Deaton, 2013; Yaseen \& Aubusson, 2020). This is remarkable since almost all students crated their first SMA in our interventions. In the evaluations there were several remarks about this being different from and more fun than the usual science classes.

A sobering thought is that in all our data collections, the learners had not been previously asked to create an animation, which alone made the task more interesting, captivating and a break from the normal science classes. If all parts of the science curriculum for learners at this level were turned into animation projects, I imagine that most students would get fed up with stop-motion and find ways to get it done as fast as possible. So, I am not presenting the approach as a panacea, a one-fixes-all solution, but simply as a possible option for teachers who want to introduce more creative and alternative forms of tasks in their teaching and assessment. 


\section{Conclusions}

The focus of my thesis is on stop-motion and its use for displaying and probing understanding of ENS and chemical reactions and a number of conclusions can be drawn from the work.

Ideally, use of a single method of assessment should be avoided, and teachers should be able to collect and evaluate information about students' learning progression from diverse sources. No single assessment method provides a complete picture of students' understanding, so for a thorough assessment of students understanding different diagnostic approaches are required (R. White \& Gunstone, 1992). The findings in this thesis support the view that students' expression of different misconceptions is influenced by the context and representational form.

From my results I conclude that student-generated SMAs can be used to probe students' understanding as complementary tools together with other methods, both in schools and science education research and also support students reasoning and learning concepts covering multiple dimensions of organisational levels. Further conclusions are presented in the following list of benefits, issues to consider, and drawbacks:

\section{Benefits:}

- Generating a SMA increases this abstract world's tangibility and focuses attention on dynamic aspects of chemical reactions.

- A SMA task prompted students to discuss representational aspects concerning what a representation is for and various design choices associated with constructing representations of abstract phenomena. Showing that the task has potential to develop representational skills.

- Physical artefacts help students to explore how to talk about an unfamiliar phenomenon. Moving the physical models in the 'movie set' provoked questions about the locations in space of specific entities and their spatial relation to other parts.

- Re-representing concepts in a series of representations and putting them together in a finished animation make students think in multimedia ways to represent ideas.

- Although students bring different strategies for zooming in time and space, the SMA approach offer opportunities for eliciting and develop these.

- When students are given the opportunity to express their understanding in alternative media, it can reveal new insights about what knowledge they bring to the classroom.

To consider:

- When representing processes that are connected to different organisational levels (from atoms to the universe), it is important to 
clarify which levels must be illustrated and discuss possible ways to connect them.

- When representing processes that happen at time rates beyond our perceptual range it can be important to clarify if the processes need to be slowed or accelerated.

- Including narration stimulates students to use appropriate scientific terms in explanations of abstract phenomena.

- Plan for enough time for students to generate storyboards as this is an important part of translating from static to dynamic representations that need time.

Drawbacks:

- Practical constraints associated with generating complex physical models and sets increase the time it takes to generate an animation.

- Generating SMAs is time consuming but the approach offers students opportunities to profoundly engage with central concepts.

\subsection{Educational implications,}

As a teacher it is easy to be enticed by new flashy teaching approaches, but one needs to be wary of what content, educational goals, and contexts the approach is suitable for. My experience from working with the SMA approach and its implications are already treated in the results and discussion chapters ( 9 and 10) concerning the process of generating SMAs. However, in this section I want to highlight a couple of points from the point of view of the teaching practice.

The SMA approach is not just for telling stories or describing phenomena, it is a method with the potential of engaging learners in work on difficulties at the core of abstract invisible scientific processes. Thus, the implications from my work have wide application in science education, not only the two examples explored here (ENS and redox chemistry). However, the suitability of the stop-motion technique for generating animations of a specific process appears to depend on the nature of the process. A process with high complexity, like ENS, is unlikely to be captured in full by a 45 second animation, which is what is reasonable to expect a group of students to complete in a few hours, using this technique. One possible effect, as indicated in my studies, is that connections between evolutionary changes and a genetic basis for inheritance and origin of variation were not promoted by using the SMA technique, leaving these important connections excluded from the students' explanations. Thus, when working with complex process is advised to constrain the task and make explicit what aspects of the process the students are supposed to focus in their animation work.

Students need to have defined frames, and suitable feed-back when making stop motion animations. Students may need guidance to keep focus on the process they are expected to explore, rather than making good-looking or funny models. However, a balance between artistic freedom and conceptual fidelity must be 
struck. In this context it is worth to consider if the goal of representational pedagogy always should be generation of perfect representations. A alternative approach would be to instead embrace imperfections in student-generated representations, thereby illuminating both understandings and misconceptions (Yaseen \& Aubusson, 2020).

Finally, regarding teachers who feel burdened by constant increases in content that must be covered in a science courses, and that any educational innovation worth considering should enable topics to be taught more rapidly, I would like to end with this quotation from the last century:

"in-depth coverage of several science topics will benefit students far more than fleeting coverage of numerous science topics" (Eylon \& Linn, 1988, p. 251).

\subsection{The future}

Seeing a thesis as the starting point of a career as researcher, it should lead to new questions to explore in the future. In the case of my work, although rewarding, it has not exhausted my curiosity.

To generate SMAs to explain ENS in just a few hours is a challenge, unless students are directed to focus on certain aspects of the process, this open for further explorations of student-generated SMAs in evolution education. One question is in what ways will directing students to focus for example, connecting the molecular level of mutations and inheritance with population change, support their reasoning and learning? Moreover, I find it motivated to explore if restricting the animation task to include taxa other than animals and more examples than trait gains would foster a more flexible understanding of evolution I would like to work in closer cooperation with teachers and together develop more extensive interventions, exploring the ideas above. Such interventions, based on student-generated representations, including SMAs, in a modelling approach for learning ENS, would be an interesting next step in my research adventure.

One perspective I have touched upon but would like to study more in depth is that students tend not to recognise processes like for example ENS, as emergent (Chi et al., 2012; Grotzer et al., 2017). The potential to coordinate processes at different levels make it motivated to explore how using SMAs can help learners appropriate emergent explanations for such processes. 


\section{Appendix 1}

Photo of storyboard and the type of feedback the students got during data collection 5 .

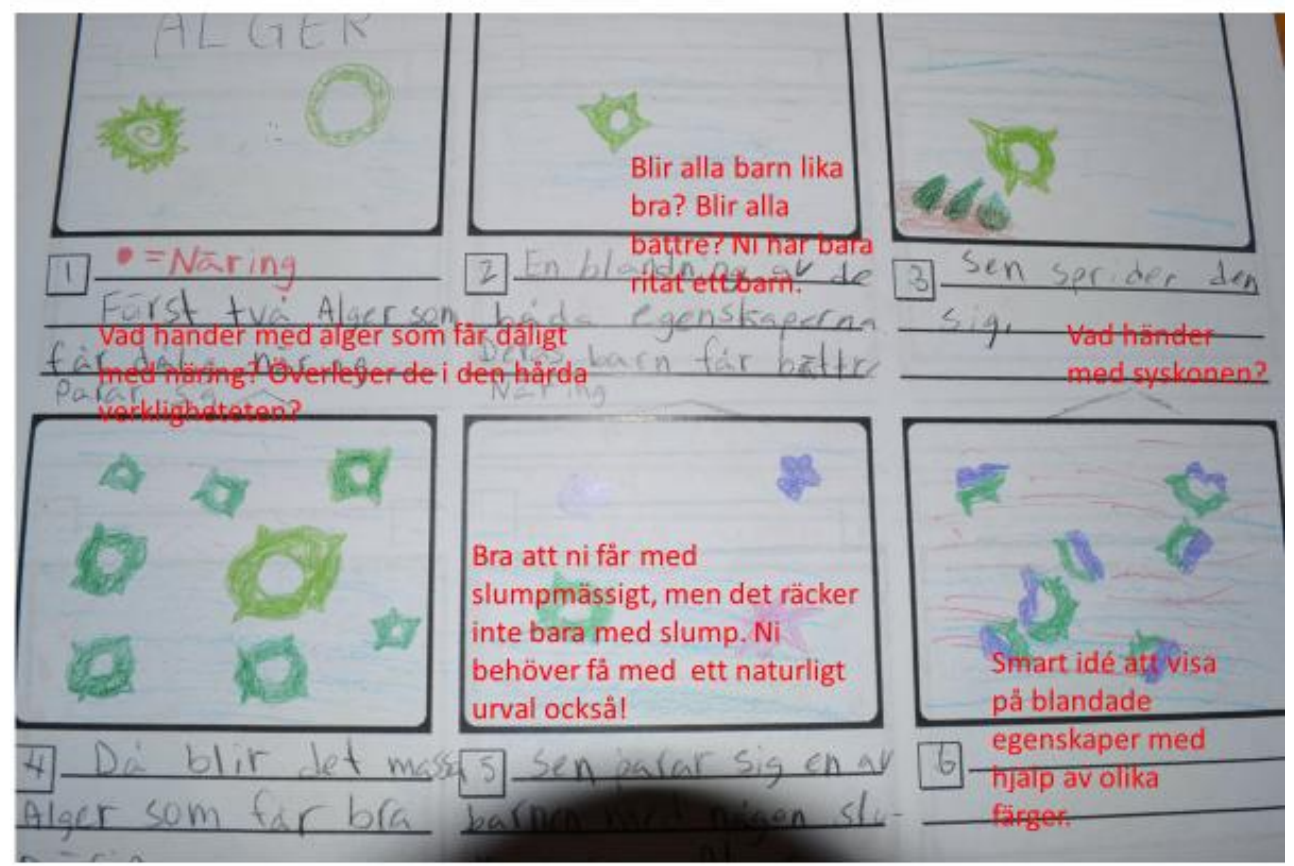

Translation: Student text $1:{ }^{*}=$ Nourishment. First two algae that get bad nourishment mate. 2: A mix of both traits, their children get better nourishment. 3: Then it spreads. 4: Then there are lots of algae that get good nutrients. 5: Then one of the children mates ... (out of picture) randomly. Feedback text: First: What happens to algae that don't get enough nutrients? Do they survive in the harsh reality? Second: Does all children get equally good? Does all get better? You have only drawn one child. Third: What happens to the siblings? Fourth: Great that you include randomness, but it is not enough with just randomness. You need to include natural selection as well! Fifth: A smart idea to represent mixt traits using different colors. 


\section{References}

Abrams, E., \& Southerland, S. (2001). The how's and why's of biological change: How learners neglect physical mechanisms in their search for meaning. International Journal of Science Education, 23(12), 1271-1281.

Ainsworth, S. (2006). DeFT: A conceptual framework for considering learning with multiple representations. Learning and instruction, 16(3), 183-198.

Ainsworth, S., Prain, V., \& Tytler, R. (2011). Drawing to learn in science. Science, 333(6046), 1096-1097. Retrieved from

https://lt.ltag.bibl.liu.se/login?url=http://search.ebscohost.com/login.aspx?direct=tr ue\&db=aph\&AN=65317656\&site $=$ ehost-live

Airey, J., \& Linder, C. (2009). A disciplinary discourse perspective on university science learning: Achieving fluency in a critical constellation of modes. Journal of Research in Science Teaching, 46(1), 27-49.

Akaygun, S. (2016). Is the oxygen atom static or dynamic? The effect of generating animations on students' mental models of atomic structure. Chemistry Education Research and Practice, 17(4), 788-807.

Akaygun, S., \& Jones, L. L. (2014). Words or pictures: A comparison of written and pictorial explanations of physical and chemical equilibria. International Journal of Science Education, 36(5), 783-807.

Al-Zahrani, A. (2008). Darwin's metaphors revisited: Conceptual metaphors, conceptual blends, and idealized cognitive models in the theory of evolution. Metaphor and Symbol, 23(1), 50-82.

Albert, J. L. (2012). Using Student-Generated Animations about Water Boiling to Impact Student Understanding of the Particulate Nature of Matter. North Carolina State University

Anderson, D. L., Fisher, K. M., \& Norman, G. J. (2002). Development and evaluation of the conceptual inventory of natural selection. Journal of Research in Science Teaching, 39(10), 952-978.

Andersson, B., \& Wallin, A. (2006). On Developing Content-oriented Theories Taking Biological Evolution as an Example. International Journal of Science Education, 28(6), 673-695.

Andersson, J., Löfgren, R., \& Tibell, L. A. (2020). What's in the body? Children's annotated drawings. Journal of Biological Education, 54(2), 176-190.

Andrews, T. M., Leonard, M. J., Colgrove, C. A., \& Kalinowski, S. T. (2011). Active learning not associated with student learning in a random sample of college biology courses. CBE-Life Sciences Education, 10(4), 394-405.

Archibald, J. D. (2014). Aristotele's ladder, Darwin's tree: the evolution of visual metaphors for biological order. New York: Colombia University Press.

Ausubel, D. P. (1968). Educational psychology: a cognitive view. Holt, Rinehart and Winston: New York.

Bailer-Jones, D. M. (2002). Models, metaphors and analogies. In P. Machamer \& M. Silberstein (Eds.), The Blackwell guide to the philosophy of science (pp. 108-127). Oxford, UK: Blackwell Publishers.

Barab, S., \& Squire, K. (2004). Design-based research: Putting a stake in the ground. The journal of the learning sciences, 13(1), 1-14.

Batzli, J. M., Knight, J. K., Hartley, L. M., Maskiewicz, A. C., \& Desy, E. A. (2016). Crossing the threshold: Bringing biological variation to the foreground. CBE-Life Sciences Education, 15(4), es9.

Ben-Zvi, R., Eylon, B.-S., \& Silberstein, J. (1986). Is an atom of copper malleable? Journal of Chemical Education, 63(1), 64.

Bishop, B. A., \& Anderson, C. W. (1990). Student conceptions of natural selection and its role in evolution. Journal of Research in Science Teaching, 27(5), 415-427. 
Bohlin, G., Göransson, A., Höst, G. E., \& Tibell, L. A. (2017). A conceptual characterization of online videos explaining natural selection. Science \& Education, 26(7-9), 975-999.

Bowler, P. J. (2009). Evolution: The History of an Idea (3 ed.). Berkeley: Univ of California Press.

Brown, A. L. (1992). Design experiments: Theoretical and methodological challenges in creating complex interventions in classroom settings. The journal of the learning sciences, 2(2), 141-178.

Bruna, C. (2013). Motivating active learning of biochemistry through artistic representation of scientific concepts. Journal of Biological Education, 47(1), 46-51.

Bruner, J. S. (1986). Actual Minds, Possible Worlds. Cambridge, Massachusetts and London, England: Harvard University Press.

Catley, K. (2006). Darwin's missing link - A novel paradigm for evolution education. Science Education, 9o(5), 767-783. doi:10.1002/sce.20152

Catley, K., \& Novick, L. (2008). Seeing the wood for the trees: An analysis of evolutionary diagrams in biology textbooks. BioScience, 58(10), 976-987.

Catley, K., \& Novick, L. (2009). Digging Deep: Exploring College Students' Knowledge of Macroevolutionary Time. Journal of Research in Science Teaching, 46(3), 311-332. doi:10.1002/tea.20273

Catley, K., Novick, L., \& Shade, C. (2010). Interpreting evolutionary diagrams: When topology and process conflict. Journal of Research in Science Teaching, 47(7), 861882.

Chang, H.-Y., Quintana, C., \& Krajcik, J. (2014). Using drawing technology to assess students' visualizations of chemical reaction processes. Journal of Science Education and Technology, 23(3), 355-369.

Chang, H.-Y., Quintana, C., \& Krajcik, J. S. (2010). The impact of designing and evaluating molecular animations on how well middle school students understand the particulate nature of matter. Science Education, 94(1), 73-94. doi:10.1002/sce.20352

Chi, M. T. (2005). Commonsense conceptions of emergent processes: Why some misconceptions are robust. The journal of the learning sciences, 14(2), 161-199.

Chi, M. T. (2008). Three types of conceptual change: Belief revision, mental model transformation, and categorical shift. In S. Vosniadou (Ed.), Handbook of research on conceptual change (pp. 61-82): Hillsdale, NJ: Erlbaum.

Chi, M. T., Roscoe, R. D., Slotta, J. D., Roy, M., \& Chase, C. C. (2012). Misconceived causal explanations for emergent processes. Cognitive Science, 36(1), 1-61.

Christensen-Dalsgaard, J., \& Kanneworff, M. (2009). Evolution in Lego®: a physical simulation of adaptation by natural selection. Evolution: Education and outreach, 2(3), 518-526.

Church, W., Gravel, B., \& Rogers, C. (2007). Teaching parabolic motion with stop-action animations. International Journal of Engineering Education, 23(5), 861.

Clark, C. A. (2001). Evolution for John Doe: Pictures, the public, and the Scopes trial debate. The Journal of American History, 87(4), 1275-1303.

Cobb, P., Confrey, J., diSessa, A., Lehrer, R., \& Schauble, L. (2003). Design experiments in educational research. Educational researcher, 32(1), 9-13.

Cokelez, A. (2012). Junior high school students' ideas about the shape and size of the atom. Research in Science Education, 42(4), 673-686.

Coley, J. D., \& Tanner, K. (2015). Relations between Intuitive Biological Thinking and Biological Misconceptions in Biology Majors and Nonmajors. CBE-Life Sciences Education, 14(1), 1-19. doi:10.1187/cbe.14-06-0094

Cooper, M. M., Stieff, M., \& DeSutter, D. (2017). Sketching the invisible to predict the visible: from drawing to modeling in chemistry. Topics in cognitive science, 9(4), 902-920.

Cooper, R. A. (2017). Natural selection as an emergent process: instructional implications. Journal of Biological Education, 51(3), 247-260.

Coyne, J. A. (2010). Why evolution is true: Oxford University Press.

Darwin, C. (1859) ). On The origin of species by Means of Natural Selection. In E. O. Wilson (Ed.) From so simple a beginning- The four great books of Charles Darwin. London: WW Norton \& Company. 
Davidowitz, B., Chittleborough, G., \& Murray, E. (2010). Student-generated submicro diagrams: a useful tool for teaching and learning chemical equations and stoichiometry. Chemistry Education Research and Practice, 11(3), 154-164.

Dawkins, R. (1996). The blind watchmaker: Why the evidence of evolution reveals a universe without design. London: WW Norton \& Company.

Dawkins, R. (1997). Climbing mount improbable: Penguin Books.

Deaton, C. C., Deaton, B. E., Ivankovic, D., \& Norris, F. A. (2013). Creating Stop-Motion Videos with iPads to Support Students' Understanding of Cell Processes: 'Because You Have to Know What You're Talking about to Be Able to Do It”. Journal of Digital Learning in Teacher Education, 30(2), 67-73.

Delisma, D., Wiji, \& Widhiyanti, T. (2020). Conception, threshold concept, and troublesome knowledge in redox reaction. Paper presented at the International Conference on Mathematics and Science Education 2019 (ICMScE 2019).

diSessa, A. (1993). Toward an epistemology of physics. Cognition and Instruction, 10(2-3), 105-225.

diSessa, A. (2004). Metarepresentation: Native competence and targets for instruction. Cognition and Instruction, 22(3), 293-331. Retrieved from http://www.jstor.org/stable/3233911

diSessa, A. (2009). A history of conceptual change research: Threads and fault lines. In K. Sawyer (Ed.), The cambridge handbook of the learning sciences (pp. 265-281): Cambridge university press. Cambridge, UK

Dobzhansky, T. (1973). Nothing in biology makes sense except in the light of evolution. American Biology Teacher, 35(3), 125-129.

Duit, R., \& Treagust, D. F. (2003). Conceptual change: A powerful framework for improving science teaching and learning. International Journal of Science Education, 25(6), 671-688.

Evans, E. M. (2008). Conceptual Change and Evolutionary Biology: A Developmental Analysis. In S. Vosniadou (Ed.), International handbook of research on conceptual change (pp. 263-294). New York and London: Routledge.

Evans, E. M., Spiegel, A. N., Gram, W., Frazier, B. N., Tare, M., Thompson, S., \& Diamond, J. (2009). A conceptual guide to natural history museum visitors' understanding of evolution. Journal of Research in Science Teaching, 47(3), 326-353

Eylon, B.-S., \& Linn, M. C. (1988). Learning and instruction: An examination of four research perspectives in science education. Review of educational research, 58(3), 251-301.

Farrokhnia, M., Meulenbroeks, R. F., \& van Joolingen, W. R. (2020). Student-Generated Stop-Motion Animation in Science Classes: a Systematic Literature Review. Journal of Science Education and Technology, 26(6), 797-812.

Ferguson, J. P., \& Lynch, S. C. (2014). Students' Collaborative Reasoning about Natural Selection as a Complex System Through the Use of NetLogo as a Digital Representation. Paper presented at the The Asian Conference on Technology in the Classroom 2014.

Ferry, B., Hoban, G., \& Macdonald, D. (2009). Improving Preservice Teachers' Science Knowledge by Creating, Reviewing and Publishing Slowmations to Teacher Tube. Paper presented at the Society for Information Technology \& Teacher Education International Conference 2009, Chesapeake.

Feynman, R. P., Leighton, R. B., \& Sands, M. (1963). The Feynman lectures on physics (Vol. 1): Addison-Wesley Publishing company, inc.

Fiedler, D., Sbeglia, G. C., Nehm, R. H., \& Harms, U. (2019). How strongly does statistical reasoning influence knowledge and acceptance of evolution? Journal of Research in Science Teaching, 56(9), 1183-1206.

Fiedler, D., Tröbst, S., \& Harms, U. (2017). University students' conceptual knowledge of randomness and probability in the contexts of evolution and mathematics. CBE-Life Sciences Education, 16(2), ar38.

Fitzgerald, A., Hackling, M., \& Dawson, V. (2013). Through the viewfinder: Reflecting on the collection and analysis of classroom video data. International Journal of Qualitative Methods, 12, 52-64. 
Fleer, M., \& Hoban, G. (2012). Using ‘Slowmation'for intentional teaching in early childhood centres: Possibilities and imaginings. Australasian Journal of Early Childhood, $37(3), 61-70$.

Foos, P. W., Mora, J. J., \& Tkacz, S. (1994). Student study techniques and the generation effect. Journal of Educational Psychology, 86(4), 567.

Garvin-Doxas, K., \& Klymkowsky, M. W. (2008). Understanding randomness and its impact on student learning: lessons learned from building the Biology Concept Inventory (BCI). CBE-Life Sciences Education, 7(2), 227-233.

Gee, J. P., \& Green, J. L. (1998). Discourse Analysis, Learning, and Social Practice: A Methodological Study. Review of Research in Education, 23, 119-169.

Gelman, S. A., \& Rhodes, M. (2012). " Two-Thousand Years of Stasis": How Psychological Essentialism Impedes Evolutionary Understa. In Evolution challenges: Integrating research and practice in teaching and learning about evolution, Oxford: Oxford University Press.

Gilbert, J. K. (2005). Visualization in science education. Dordrecht: Springer.

Gilbert, J. K. (2010). The role of visual representations in the learning and teaching of science: An introduction.

Gilbert, J. K., \& Treagust, D. F. (2009a). Introduction: Macro, submicro and symbolic representations and the relationship between them: Key models in chemical education. In J. K. Gilbert \& D. F. Treagust (Eds.) Multiple representations in chemical education (pp. 1-8) Dordrecht: Springer.

Gilbert, J. K., \& Treagust, D. F. (2009b). Multiple Representations in Chemical Education (Vol. 4) Dordrecht: Springer Science \& Business Media.

Godfrey-Smith, P. (2007). Conditions for evolution by natural selection. The Journal of Philosophy, 104(10), 489-516.

Gould, S. J., \& Lewontin, R. C. (1979). The spandrels of San Marco and the Panglossian paradigm: a critique of the adaptationist programme. Proceedings of the Royal Society of London B: Biological Sciences, 205(1161), 581-598.

Gouvea, J. S. (2018). Alternative Perspectives on Students' Reasoning about Emergent Processes. CBE-Life Sciences Education, 17(1), fe2.

Gouvea, J. S., \& Simon, M. R. (2018). Challenging Cognitive Construals: A Dynamic Alternative to Stable Misconceptions. CBE-Life Sciences Education, 17(2), ar34.

Graneheim, U. H., \& Lundman, B. (2004). Qualitative content analysis in nursing research: concepts, procedures and measures to achieve trustworthiness. Nurse Education Today, 24(2), 105-112.

Gregory, T. R. (2008). Understanding evolutionary trees. Evolution: Education and Outreach, 1(2), 121.

Gregory, T. R. (2009). Understanding natural selection: Essential concepts and common misconceptions. Evolution: Education and outreach, 2(2), 156-175.

Griffiths, A. K., \& Preston, K. R. (1992). Grade-12 students' misconceptions relating to fundamental characteristics of atoms and molecules. Journal of Research in Science Teaching, 29(6), 611-628.

Grotzer, T. A., Derbiszewska, K., \& Solis, S. L. (2017). Leveraging fourth and sixth graders' experiences to reveal understanding of the forms and features of distributed causality. Cognition and Instruction, 35(1), 55-87.

Göransson, A., Orraryd, D., Fiedler, D., \& Tibell, L. A. E. (2020). Conceptual Characterization of Threshold Concepts in Student Explanations of Evolution by Natural Selection and Effects of Item Context. CBE-Life Sciences Education, 19(1), ar1.

Ha, M., \& Nehm, R. H. (2014). Darwin's difficulties and students' struggles with trait loss: cognitive-historical parallelisms in evolutionary explanation. Science \& Education, 23(5), 1051-1074.

Haglund, J. (2013). Collaborative and self-generated analogies in science education. Studies in Science Education, 49(1), 35-68.

Hallström, J., \& Schönborn, K. J. (2019). Models and modelling for authentic STEM education: reinforcing the argument. International Journal of STEM Education, 6(1), 22. 
Harms, U., \& Reiss, M. J. (2019). The present status of evolution education. In Reiss, M. J. Harms U. (Eds.), Evolution Education Re-considered (pp. 1-19): Springer, Cham.

Harrison, A. G., \& Treagust, D. F. (2000a). Learning about atoms, molecules, and chemical bonds: A case study of multiple-model use in grade 11 chemistry. Science Education, 84(3), 352-381.

Harrison, A. G., \& Treagust, D. F. (200ob). A typology of school science models. International Journal of Science Education, 22(9), 1011-1026.

Harrison, A. G., \& Treagust, D. F. (2002). The particulate nature of matter: Challenges in understanding the submicroscopic world. In J. K. Gilbert, O. De Jong, R. Justi, D. F. Treagust, \& J. H. Van Driel (Eds.) Chemical education: Towards research-based practice (pp. 189-212): Springer.

Hoban, G. (2007). Using slowmation to engage presevice elementary teachers in understanding science content knowlege. Contemporary Issues in Technology and Teacher Education 7(2), 75-91.

Hoban, G. (2010). Data dumping, after the test you forget it all: seeking deep approaches to science learning with slowmation. Proceedings of the 16th UniServe Annual Conference (pp. 2-6), Sydney: University of Sydney.

Hoban, G., Loughran, J., \& Nielsen, W. (2011). Slowmation: Preservice elementary teachers representing science knowledge through creating multimodal digital animations. Journal of Research in Science Teaching, 48(9), 985-1009.

Hoban, G., \& Nielsen, W. (2010). The 5 Rs: A new teaching approach to encourage slowmations (studentgenerated animations) of science concepts. Teaching Science, 56(3), 33-38.

Hoban, G., \& Nielsen, W. (2011). Using "Slowmation" to enable preservice primary teachers to create multimodal representations of science concepts. Research in Science Education, 1-19.

Hoban, G., \& Nielsen, W. (2013). Learning Science through Creating a 'Slowmation': A case study of preservice primary teachers. International Journal of Science Education, 35(1), 119-146.

Hoban, G., Nielsen, W., Macdonald, D., \& Ferry, B. (2009). Validating the Slowmation learning design: comparing a learning design with students' experiences of learning. Proceedings of The Future of Learning Designs Conference (pp. 61-68). Wollongong, NSW: University of Wollongong

Hoban, G., Nielsen, W., \& McKnight, A. (2010). Linking Semiotics and Science Education: A Theoretical Framework for Slowmations (student-generated animations). Australian Association for Research in Education, Melbourne, Australia.

Horwitz, P. (2013). Evolution Is a Model, Why Not Teach It That Way? In D. F. Treagust \& C. Y. Tsui (Eds.) Multiple representations in biological education (pp. 129-145): Springer.

Hsieh, H.-F., \& Shannon, S. E. (2005). Three approaches to qualitative content analysis. Qualitative Health Research, 15(9), 1277-1288.

Hubscher-Younger, T., \& Narayanan, N. (2008). Turning the tables: Investigating characteristics and efficacy of student-authored animations and multimedia representations. In R. Lowe \& W. Schnotz (Eds.), Learning with animation: Research implications for design (pp. 235-262). Cambridge: Cambridge University Press

Höffler, T. N., \& Leutner, D. (2007). Instructional animation versus static pictures: A metaanalysis. Learning and instruction, $17(6), 722-738$.

Jakobson, B., \& Wickman, P. O. (2008). The roles of aesthetic experience in elementary school science. Research in Science Education, 38(1), 45-65.

Jiménez-Aleixandre, M. P. (1992). Thinking about theories or thinking with theories?: a classroom study with natural selection. International Journal of Science Education, 14(1), 51-61.

Johnson, C. N. (2015). Darwin's Dice: The Idea of Chance in the Thought of Charles Darwin: OUP Us. 
Johnstone, A. H. (1991). Why is science difficult to learn? Things are seldom what they seem. Journal of computer assisted learning, 7(2), 75-83.

Johnstone, A. H. (2010). You Can't Get There from Here Journal of Chemical Education, $87(1), 22-29$.

Jose, S. B., Wu, C. H., \& Kamoun, S. (2019). Overcoming plant blindness in science, education, and society. Plants, People, Planet, 1(3), 169-172.

Jördens, J., Asshoff, R., Kullmann, H., \& Hammann, M. (2016). Providing vertical coherence in explanations and promoting reasoning across levels of biological organization when teaching evolution. International Journal of Science Education, 38(6), 960-992.

Kalinowski, S. T., Leonard, M. J., \& Andrews, T. M. (2010). Nothing in evolution makes sense except in the light of DNA. CBE-Life Sciences Education, 9(2), 87-97.

Kalinowski, S. T., Leonard, M. J., \& Taper, M. L. (2016). Development and validation of the conceptual assessment of natural selection (CANS). CBE-Life Sciences Education, 15(4), ar64.

Kamp, B. L., \& Deaton, C. C. (2013). Move, stop, learn: illustrating mitosis through stopmotion animation. Science Activities, 5O(4), 146-153.

Kampourakis, K. (2007). Teleology in biology, chemistry and physics education: what primary teachers should know. Review of Science, Mathematics and ICT Education, 1(2), 81-96.

Kampourakis, K. (2020). Students' "teleological misconceptions" in evolution education: why the underlying design stance, not teleology per se, is the problem. Evolution: Education and outreach, 13(1), 1-12.

Kampourakis, K., \& Strasser, B. J. (2014). The Evolutionist, the Creationist, and the" unsure": picking-up the wrong fight? International Journal of Science Education, Part B: Communication and Public Engagement, 5(3), 271-275.

Kampourakis, K., \& Zogza, V. (2008a). Preliminary Evolutionary Explanations: A Basic Framework for Conceptual Change and Explanatory Coherence in Evolution. Science \& Education, 18(10), 1313-1340.

Kampourakis, K., \& Zogza, V. (2008b). Students' intuitive explanations of the causes of homologies and adaptations. Science \& Education, 17(1), 27-47.

Kampourakis, K., \& Zogza, V. (2009). Preliminary evolutionary explanations: A basic framework for conceptual change and explanatory coherence in evolution. Science \& Education, 18(10), 1313-1340.

Karakoyun, F., \& Yapici, Ü. (2018). Use of Slowmation in Biology Teaching. International Education Studies, 11(10), 16-27.

Keast, S., Cooper, R., Berry, A., Loughran, J., \& Hoban, G. (2010). Slowmation as a pedagogical scaffolding for improving science teaching and learning. Brunei International Journal of Science and Mathematics, 2(1), 1-15.

Kelemen, D. (2004). Are Children "Intuitive Theists"? Reasoning about Purpose and Design in Nature. Psychological Science, 15(5), 295-301. Retrieved from www.jstor.org/stable/40063977

Kereluik, K., Mishra, P., Fahnoe, C., \& Terry, L. (2013). What knowledge is of most worth: Teacher knowledge for 21st century learning. Journal of Digital Learning in Teacher Education, 29(4), 127-140.

Kidman, G., Keast, S., \& Cooper, R. (2012). Responding to the 5rs: An alternate perspective of slowmation. Teaching Science, 58(2), 24-30.

Kinchin, I. M. (2010). Solving Cordelia's dilemma: Threshold concepts within a punctuated model of learning. Journal of Biological Education, 44(2), 53-57.

Knoblauch, H., Schnettler, B., \& Raab, J. (2006). Video Analysis. Methodological Aspect of Interpretive Audiovisual Video-Analysis in Social Research. In H. Knoblauch, B. Schnettler, J. Raab, \& H.-G. Soeffner (Eds.)Video Analysis: Methodology and Methods, Oxford: Peter Lang.

Kottova, A. (2015). Filmmaking: a new pedagogical method to explore students' view of nature of science. Victoria: University of Victoria 
Kozma, R. (2003). The material features of multiple representations and their cognitive and social affordances for science understanding. Learning and instruction, 13(2), 205226.

Kozma, R., Chin, E., Russell, J., \& Marx, N. (2000). The roles of representations and tools in the chemistry laboratory and their implications for chemistry learning. The journal of the learning sciences, 9(2), 105-143.

Kozma, R., \& Russell, J. (1997). Multimedia and understanding: Expert and novice responses to different representations of chemical phenomena. Journal of Research in Science Teaching, 34(9), 949-968.

Kozma, R., \& Russell, J. (2005). Students becoming chemists: Developing representationl competence. In J. K. Gilbert (Eds.) Visualization in science education (pp. 121-145) Dordrecht: Springer.

Krippendorff, K. (2013). Content analysis : an introduction to its methodology (3rd ed. ed.): SAGE.

Kuschmierz, P., Meneganzin, A., Pinxten, R., Pievani, T., Cvetković, D., Mavrikaki, E., .. . Beniermann, A. (2020). Towards common ground in measuring acceptance of evolution and knowledge about evolution across Europe: a systematic review of the state of research. Evolution: Education and outreach, 13(1), 1-24.

Kutschera, U., \& Niklas, K. J. (2004). The modern theory of biological evolution: an expanded synthesis. Naturwissenschaften, 91(6), 255-276.

Land, R., \& Meyer, J. H. (2010). Threshold concepts and troublesome knowledge (5): Dynamics of assessment. In R. Land, J. H. Mayer, \& C. Baillie (Eds.)Threshold concepts and transformational learning (pp. 61-79): Brill Sense.

Land, R., Meyer, J. H., \& Baillie, C. (2010). Editors' preface: threshold concepts and transformational learning. In R. Land, J. H. Mayer, \& C. Baillie (Eds.), Threshold concepts and transformational learning. Sense; Brill.

Land, R., Meyer, J. H., \& Flanagan, M. T. (2016). Threshold concepts in practice: Springer.

Larkin, J. H., \& Simon, H. A. (1987). Why a diagram is (sometimes) worth ten thousand words. Cognitive Science, 11(1), 65-100.

Law, J., \& Lynch, M. (1990). Lists, field guides, and the descriptive organization of seeing: Birdwatching as an exemplary observational activity. In M. Lynch \& S. Woolgar (Eds.), Representation in Scientific Practice (pp. 267-299). Cambridge: The MIT Press.

Laverty, J. T., Underwood, S. M., Matz, R. L., Posey, L. A., Carmel, J. H., Caballero, M. D., . . . Cooper, M. M. (2016). Characterizing College Science Assessments: The ThreeDimensional Learning Assessment Protocol. PLOS ONE, 11(9).

Lawson, A. E., Alkhoury, S., Benford, R., Clark, B. R., \& Falconer, K. A. (2000). What kinds of scientific concepts exist? Concept construction and intellectual development in college biology. Journal of Research in Science Teaching: The Official Journal of the National Association for Research in Science Teaching, 37(9), 996-1018.

Lee, H. S., Liu, O. L., Price, C. A., \& Kendall, A. L. (2011). College students' temporalmagnitude recognition ability associated with durations of scientific changes. Journal of Research in Science Teaching, 48(3), 317-335.

Lee, S. W.-Y., \& Tsai, C.-C. (2013). Technology-supported learning in secondary and undergraduate biological education: observations from literature review. Journal of Science Education and Technology, 22(2), 226-233.

Leonard, M. J., Kalinowski, S. T., \& Andrews, T. C. (2014). Misconceptions yesterday, today, and tomorrow. CBE-Life Sciences Education, 13(2), 179-186.

López, V., \& Pintó, R. (2017). Identifying secondary-school students' difficulties when reading visual representations displayed in physics simulations. International Journal of Science Education, 39(10), 1353-1380.

Loughran, J., Mulhall, P., \& Berry, A. (2008). Exploring Pedagogical Content Knowledge in Science Teacher Education. International Journal of Science Education, 30(10), 1301-1320. 
Louw, S., Todd, R. W., \& Jimarkon, P. (2014). Picking the ripe cherry: Extract selection in qualitative research. Paper presented at the Proceedings of the International Conference: Research in Applied Linguistics, June.

Lowe, R. K. (1996). Background knowledge and the construction of a situational representation from a diagram. European Journal of Psychology of Education, 11(4), 377-397.

Lowe, R. K. (2000). Visual literacy in science and technology education. Connect, Unesco International Science, Technology and Environmental Education Newsletter, 25, 13 .

Lowe, R. K., Boucheix, J.-M., \& Fillisch, B. (2017). Demonstration Tasks for Assessment. In R. Lowe \& R. Ploetzner (Eds.), Learning from Dynamic Visualization: Innovations in Research and Application (pp. 177-201). Cham: Springer International Publishing.

Lowe, R. K., Schnotz, W., \& Rasch, T. (2011). Aligning Affordances of Graphics with Learning Task Requirements. Applied cognitive psychology, 25(3), 452-459.

Luckin, R., Bligh, B., Manches, A., Ainsworth, S., Crook, C., \& Noss, R. (2012). Decoding learning: the proof, promise and potential of digital education. Retrieved from https://apo.org.au/node/32254

Lynch, M. (1991). Science in the age of mechanical reproduction: Moral and epistemic relations between diagrams and photographs. Biology and Philosophy, 6(2), 205-226.

Lyons, T. (2006). Different countries, same science classes: Students' experiences of school science in their own words. International Journal of Science Education, 28(6), 591613 .

Macdonald, D., \& Hoban, G. (2009). Developing science content knowledge through the creation of slowmations. The International Journal of Learning, 16(6), 319-330.

MacLure, M. (2010). The offence of theory. Journal of education policy, 25(2), 277-286.

Marbach-Ad, G., Rotbain, Y., \& Stavy, R. (2008). Using computer animation and illustration activities to improve high school students' achievement in molecular genetics. Journal of Research in Science Teaching: The Official Journal of the National Association for Research in Science Teaching, 45(3), 273-292.

Maskiewicz, A. C., \& Lineback, J. E. (2013). Misconceptions are "so yesterday!". CBE-Life Sciences Education, 12(3), 352-356.

Mathewson, J. H. (2005). The visual core of science: Definition and applications to education. International Journal of Science Education, 27(5), 529-548.

Matuk, C., \& Uttal, D. (2012). Narrative spaces in the representation and understanding of evolution. In In K. S. Rosengren, S. K. Brem, E. M. Evans, \& G. M. Sinatra (Eds,) Evolution challenges: Integrating research and practice in teaching and learning about evolution (pp. 119-144). Oxford: Oxford University Press

Mayer, R. E. (2003). The promise of multimedia learning: using the same instructional design methods across different media. Learning and instruction, 13(2), 125-139.

Mayer, R. E. (2005). The Cambridge handbook of multimedia learning: Cambridge University Press.

Mayr, E. (1982). The growth of biological thought : diversity, evolution, and inheritance. Cambridge, Mass.: Belknap P. of Harvard U.P.

Mayr, E. (2004). What makes biology unique?: considerations on the autonomy of a scientific discipline: Cambridge University Press.

McKenney, S., \& Reeves, T. (2012). Conducting Educational Design Research. Routledge, Taylor \& Francis Group.

McLure, F., Won, M., \& Treagust, D. (2020). Students' understanding of the emergent processes of natural selection: the need for ontological conceptual change. International Journal of Science Education, 1-18.

Mead, L. S., \& Scott, E. C. (2010). Problem concepts in evolution part II: cause and chance. Evolution: Education and outreach, 3(2), 261-264.

Meyer, J., \& Land, R. (2003). Threshold concepts and troublesome knowledge: linkages to ways of thinking and practising within the disciplines: University of Edinburgh Edinburgh. 
Meyer, J., \& Land, R. (2005). Threshold concepts and troublesome knowledge (2): Epistemological considerations and a conceptual framework for teaching and learning. Higher education, 49(3), 373-388.

Mills, R., Tomas, L., \& Lewthwaite, B. (2019). The Impact of Student-Constructed Animation on Middle School Students' Learning about Plate Tectonics. Journal of Science Education and Technology, 28(2), 165-177.

Nehm, R., \& Ha, M. (2011). Item feature effects in evolution assessment. Journal of Research in Science Teaching, 48(3), 237-256.

Nehm, R., \& Reilly, L. (2007). Biology Majors' Knowledge and Misconceptions of Natural Selection. BioScience, 57(3), 263-272.

Nelson, C. E. (2012). Why don't undergraduates really "get" evolution? What can faculty do. In K. S. Rosengren, S. K. Brem, E. M. Evans, \& G. M. Sinatra (Eds.), Evolution challenges: Integrating research and practice in teaching and learning about evolution (pp. 311-347). New York: Oxford University Press.

Niebert, K., \& Gropengiesser, H. (2015). Understanding Starts in the Mesocosm: Conceptual metaphor as a framework for external representations in science teaching. International Journal of Science Education, 37(5-6), 903-933.

Nielsen, W., Georgiou, H., Jones, P., \& Turney, A. (2020). Digital explanation as assessment in university science. Research in Science Education, 50(6), 2391-2418.

Nielsen, W., \& Hoban, G. (2015). Designing a digital teaching resource to explain phases of the moon: a case study of preservice elementary teachers making a slowmation. Journal of Research in Science Teaching, 52(9), 1207-1233.

Nieswandt, M., \& Bellomo, K. (2009). Written extended-response questions as classroom assessment tools for meaningful understanding of evolutionary theory. Journal of Research in Science Teaching: 46(3), 333-356.

Norris, S. P., Guilbert, S. M., Smith, M. L., Hakimelahi, S., \& Phillips, L. M. (2005). A theoretical framework for narrative explanation in science. Science Education, 89(4), 535-563.

Ogborn, J., Kress, G., \& Martins, I. (1996). Explaining science in the classroom: McGraw-Hill Education (UK).

Paivio, A. (1991). Dual coding theory: Retrospect and current status. Canadian Journal of Psychology/Revue canadienne de psychologie, 45(3), 255.

Papert, S. (1994). Hur gör giraffen när den sover; skolan, datorn och kunskapsprocessen. Göteborg: Daidalos.

Papert, S., \& Harel, I. (1991). Situating constructionism. In I. Harel \& S. Papert (Eds.), Constructionism (pp. 1-11). Ablex Publishing.

Perkins, D. N., \& Grotzer, T. A. (2000). Models and Moves: Focusing on Dimensions of Causal Complexity To Achieve Deeper Scientific Understanding. American Educational Research Association Annual Conference, New Orleans

Phillips, L. M., Norris, S. P., \& Macnab, J. S. (2010). Visualization in mathematics, reading and science education. Dordrecht, Heidelberg, London, New York: Springer.

Pintó, R., \& Ametller, J. (2002). Students' difficulties in reading images. Comparing results from four national research groups. International Journal of Science Education, 24(3), 333-341.

Pinxten, R., Vandervieren, E., \& Janssenswillen, P. (2020). Does integrating natural selection throughout upper secondary biology education result in a better understanding? A cross-national comparison between Flanders, Belgium and the Netherlands. International Journal of Science Education, 42(10), 1609-1634.

Posner, G. J., Strike, K. A., Hewson, P. W., \& Gertzog, W. A. (1982). Accommodation of a scientific conception: Toward a theory of conceptual change. Science Education, 66(2), 211-227.

Prain, V. (2019). Future Research in Learning with, Through and from Scientific Representations. In V. Prain \& B. Hand (Eds.)Theorizing the Future of Science Education Research (pp. 151-168): Springer. 
Prain, V., \& Tytler, R. (2012). Learning through constructing representations in science: A framework of representational construction affordances. International Journal of Science Education, 34(17), 2751- 2773.

Pramling, N. (2009). The Role of Metaphor in Darwin and the Implications for Teaching Evolution. Science Education, 93(3), 535-547.

Prediger, S., Gravemeijer, K., \& Confrey, J. (2015). Design research with a focus on learning processes: an overview on achievements and challenges. ZDM, 47(6), 877-891.

Pugh, K. J., Koskey, K. L., \& Linnenbrink-Garcia, L. (2014). High school biology students' transfer of the concept of natural selection: a mixed-methods approach. Journal of Biological Education, 48(1), 23-33.

Rector, M., Nehm, R., \& Pearl, D. (2013). Learning the Language of Evolution: Lexical Ambiguity and Word Meaning in Student Explanations. Research in Science Education, 43(3), 1107-1133.

Reeves, T. C. (2011). Can educational research be both rigorous and relevant. Educational Designer, 1(4), 1-24.

Reiss, M. J., Tunnicliffe, S. D., Andersen, A. M., Bartoszeck, A., Carvalho, G. S., Chen, S. Y., . . . Marchenko, N. (2002). An international study ofyoung peoples' drawings of what is inside themselves. Journal of Biological Education, 36(2), 58-64.

Robson, C. (2011). Real World Reasearch (third ed.). Chichester: John Wiley \& Sons Ltd.

Robson, R. L., \& Burns, S. (2011). Gain in Student Understanding of the Role of Random Variation in Evolution Following Teaching Intervention Based on Luria-Delbruck Experiment. Journal of Microbiology \& Biology Education: JMBE, 12(1), 3.

Rosengren, K., \& Evans, E. (2012). Commentary on section 1: Constrained learning: Reframing the problem of evolution understanding and implications for science education. In K. S. Rosengren, S. K. Brem, E. M. Evans, \& G. M. Sinatra (Eds.), Evolution challenges: Integrating research and practice in teaching and learning about evolution (pp. 200-210). Oxford: Oxford University Press.

Ross, P. M., Taylor, C. E., Hughes, C., Whitaker, N., Lutze-Mann, L., Kofod, M., \& Tzioumis, V. (2010). Threshold concepts in learning biology and evolution. Biology International, 47, 47-54.

Roth, W.-M., \& Bowen, G. M. (1999). Of cannibals, missionaries, and converts: graphing competencies from grade 8 to professional science inside (classrooms) and outside (field/laboratory). Science, Technology, \& Human Values, 24(2), 179-212.

Roth, W.-M., \& Pozzer-Ardenghi, L. (2013). Pictures in biology education. In Multiple representations in biological education (pp. 39-53): Springer.

Rozenblit, L., \& Keil, F. (2002). The misunderstood limits of folk science: An illusion of explanatory depth. Cognitive Science, 26(5), 521-562.

Saldaña, J. (2016). The coding manual for qualitative researchers (3rd ed.). Los Angeles: SAGE.

Schnotz, W. (2002). Towards an Integrated View of Learning From Text and Visual Displays. Educational Psychology Review, 14(1), 101. doi:10.1023/A:1013136727916

Schönborn, K. J., \& Anderson, T. R. (2009). A model of factors determining students' ability to interpret external representations in biochemistry. International Journal of Science Education, 31(2), 193-232.

Shtulman, A. (2006). Qualitative differences between naive and scientific theories of evolution. Cognitive Psychology, 52(2), 170-194. doi:10.1016/j.cogpsych.2005.10.001

Shtulman, A., \& Schulz, L. (2008). The relation between essentialist beliefs and evolutionary reasoning. Cognitive Science, 32(6), 1049-1062.

Siegel, S., \& Castellan, N. J. (1988). Nonparametric statistics for the behavioral sciences. New York: McGraw-Hill.

Sinatra, G. M., Brem, S. K., \& Evans, E. M. (2008). Changing minds? Implications of conceptual change for teaching and learning about biological evolution. Evolution: Education and outreach, 1(2), 189.

Skolverket. (2013). Curriculum for the upper secondary school. Stockholm Retrieved from https://www.skolverket.se/download/18.4fc05a3f164131a7418104a/1535372296309/ Biology-swedish-school.pdf 
Smith, J. I., \& Tanner, K. (2010). The problem of revealing how students think: concept inventories and beyond. CBE-Life Sciences Education, 9(1), 1-5.

Smith, M. (2010a). Current status of research in teaching and learning evolution: I. Philosophical/epistemological issues. Science \& Education, 19(6-8), 523-538.

Smith, M. (2010b). Current status of research in teaching and learning evolution: II. Pedagogical issues. Science \& Education, 19(6-8), 539-571.

Smith, M., \& Siegel, H. (2004). Knowing, believing, and understanding: What goals for science education? Science \& Education, 13(6), 553-582.

Southerland, S. A., Abrams, E., Cummins, C. L., \& Anzelmo, J. (2001). Understanding students' explanations of biological phenomena: Conceptual frameworks or p-prims? Science Education, 85(4), 328-348.

Stenlund, J. I., Schönborn, K. J., \& Tibell, L. A. E. (2020). Zooming in Time-Exploring Students' Interpretations of a Dynamic Tree of Life. Journal of Science Education and Technology.

Sweller, J. (2005). Implications of Cognitive Load Theory for Multimedia Learning. In R. Mayer (Ed.), The Cambrige handbook of multimedia learning: Cambridge University Press.

Taber, K. S. (2009). Learning at the symbolic level. In Multiple representations in chemical education (pp. 75-105): Springer.

Taber, K. S. (2013). Revisiting the chemistry triplet: drawing upon the nature of chemical knowledge and the psychology of learning to inform chemistry education. Chemistry Education Research and Practice, 14(2), 156-168.

Talanquer, V. (2006). Commonsense chemistry: A model for understanding students' alternative conceptions. Journal of Chemical Education, 83(5), 811.

Talanquer, V. (2007). Explanations and teleology in chemistry education. International Journal of Science Education, 29(7), 853-870.

Talanquer, V. (2013). When atoms want. Journal of Chemical Education, 9o(11), 1419-1424.

Talanquer, V. (2015). Threshold concepts in chemistry: The critical role of implicit schemas. Journal of Chemical Education, 92(1), 3-9.

Talanquer, V. (2018). Progressions in reasoning about structure-property relationships. Chemistry Education Research and Practice, 19(4), 998-1009.

Tibell, L. A., \& Harms, U. (2017). Biological Principles and Threshold Concepts for Understanding Natural Selection. Science \& Education, 26(7-9), 953-973.

Treagust, D. F., \& Tsui, C.-Y. (2013). Multiple representations in biological education: Springer Science \& Business Media.

Tsui, C.-Y., \& Treagust, D. F. (2013). Introduction to multiple representations: Their importance in biology and biological education. In D. F. Treagust \& C. Y. Tsui (Eds.) Multiple representations in biological education (pp. 3-18): Springer.

Tversky, B., Morrison, J. B., \& Betrancourt, M. (2002). Animation: can it facilitate? International Journal of Human-Computer Studies, 57(4), 247-262.

Tytler, R., Prain, V., \& Hubber, P. (2018). Representation construction as a core science disciplinary literacy. In K. S. Tang \& K. Danielsson (Eds.) Global developments in literacy research for science education (pp. 301-317): Springer.

Wallin, A. (2004). Evolutionsteorin i klassrummet : på väg mot en ämnesdidaktisk teori för undervisning i biologisk evolution. Göteborg: Acta Universitatis Gothoburgensis.

Van Meter, P., Aleksic, M., Schwartz, A., \& Garner, J. (2006). Learner-generated drawing as a strategy for learning frorn content area text. Contemporary Educational Psychology, 31(2), 142-166.

Van Meter, P., \& Garner, J. (2005). The promise and practice of learner-generated drawing: Literature review and synthesis. Educational Psychology Review, 17(4), 285-325.

Wandersee, J. H., \& Schussler, E. E. (1999). Preventing Plant Blindness. The American Biology Teacher, 61(2), 82-86.

Ware, E. A., \& Gelman, S. A. (2014). You get what you need: An examination of purposebased inheritance reasoning in undergraduates, preschoolers, and biological experts. Cognitive Science, 38(2), 197-243. 
Vetenskapsrådet. (2017). God forskningssed. Stockholm Retrieved from https://www.vr.se/download/18.2412c5311624176023d25b05/1555332112063/Godforskningssed VR 2017.pdf

White, P. J., Tytler, R., \& Nielsen, W. (2020). Animation Construction as Cross-Modal Translation in Senior Biology. In Learning from Animations in Science Education (pp. 209-228): Springer.

White, R., \& Gunstone, R. (1992). Probing understanding. New York: RoutledgeFalmer.

Wickman, P.-O. (2006). Aesthetic experience in science education: Learning and meaningmaking as situated talk and action: Routledge.

Wilensky, U., \& Reisman, K. (2006). Thinking like a wolf, a sheep, or a firefly: Learning biology through constructing and testing computational theories - An embodied modeling approach. Cognition and Instruction, 24(2), 171-209. 1

Wishart, J. (2017). Exploring how creating stop-motion animations supports student teachers in learning to teach science. Journal of Research on Technology in Education, 49(1-2), 88-101.

Vosniadou, S. (1994). Capturing and modeling the process of conceptual change. Learning and instruction, 4(1), 45-69.

Wright, L. (1972). Explanation and teleology. Philosophy of Science, 39(2), 204-218.

Yaseen, Z. (2018). Using student-generated animations: the challenge of dynamic chemical models in states of matter and the invisibility of the particles. Chemistry Education Research and Practice, 19(4), 1166-1185.

Yaseen, Z., \& Aubusson, P. (2020). Exploring student-generated animations, combined with a representational pedagogy, as a tool for learning in chemistry. Research in Science Education, 5o(2), 529-548.

Zabel, J. (2015). Narrative and Metaphor as Conceptual Tools for Understanding Evolution Theory. Paper presented at the Innovazione nella didattica delle scienze nella scuola primaria e dell'infanzia: al crocevia fra discipline scientifiche e umanistiche, Modena

Zetterqvist, A. (2003). Ämnesdidaktisk kompetens i evolutionsbiologi : en intervjuundersökning med no/biologilärare. Göteborg: Acta Universitatis Gothoburgensis.

Zhang, Z. H., \& Linn, M. C. (2011). Can generating representations enhance learning with dynamic visualizations? Journal of Research in Science Teaching . 48(10), 1177-1198

Zohar, A., \& Ginossar, S. (1998). Lifting the taboo regarding teleology and anthropomorphism in biology education-Heretical suggestions. Science Education, 82(6), 679-697.

Özdemir, G., \& Clark, D. B. (2007). An Overview of Conceptual Change Theories. Eurasia Journal of Mathematics, Science \& Technology Education, 3(4).

Özmen, H. (2004). Some student misconceptions in chemistry: A literature review of chemical bonding. Journal of Science Education and Technology, 13(2), 147-159.

Özmen, H. (2013). A cross-national review of the studies on the particulate nature of matter and related concepts. Eurasian Journal of Physics and Chemistry Education, 5(2). 


\section{Studies}

The studies associated with this thesis have been removed for copyright reasons. For more details about these see:

http://urn.kb.se/resolve?urn=urn:nbn:se:liu:diva-173038 


\section{FACULTY OF EDUCATIONAL SCIENCES}

Linköping Studies in Science and Technology Education Dissertation No. 110, 2021

Department of Behavioural Sciences and Learning

Linköping University

SE-60174 Norrköping, Sweden

www.liu.se

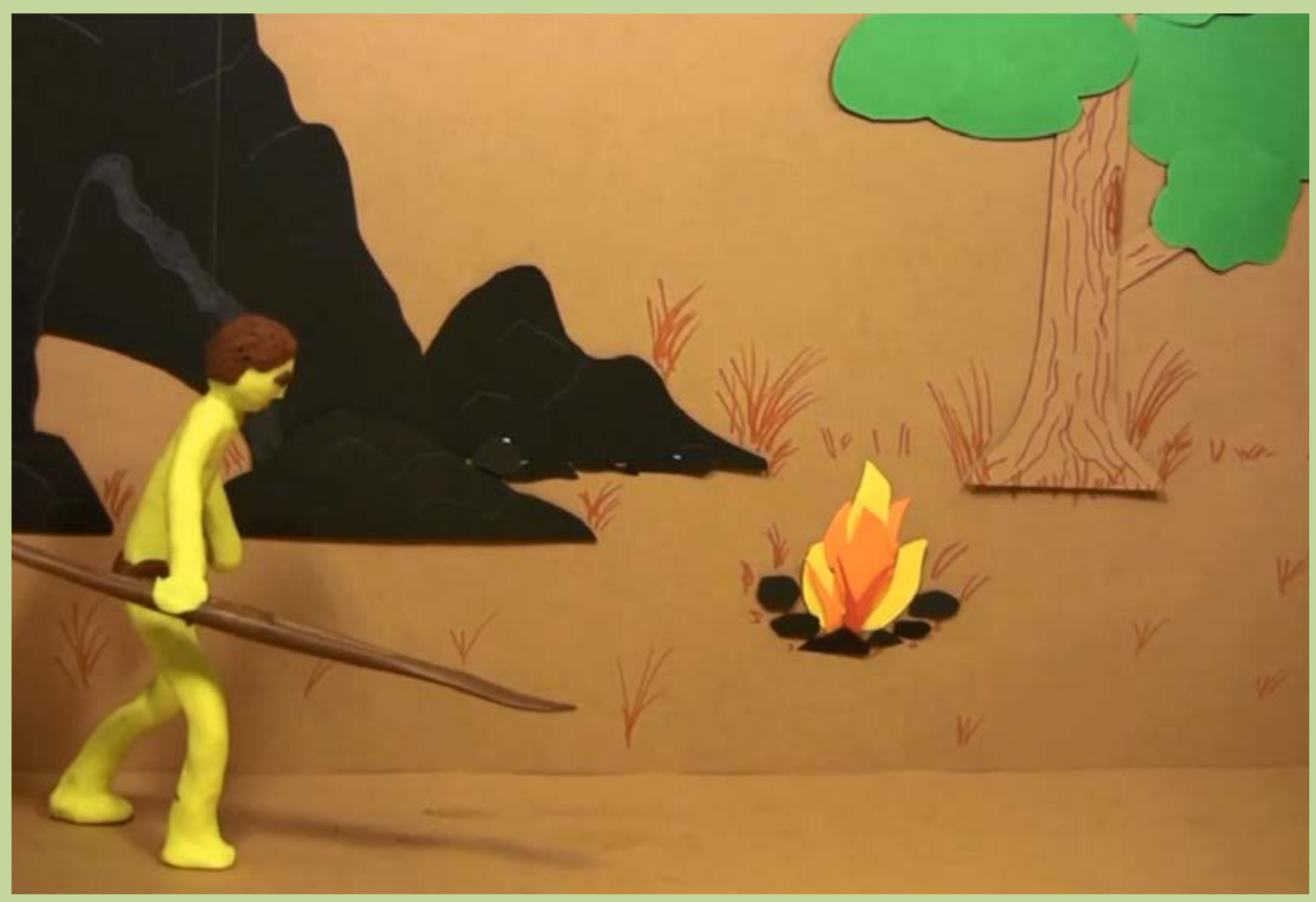

